\title{
The "Mailbox" Computer System for the
}

IAEA Verification Experiment on HEU Downblending at the

Portsmouth Gaseous Diffusion Plant

\author{
July 31, 2000
}

UNITED STATES MEMBER STATE SUPPORT PROGRAM TO IAEA SAFEGUARDS

DEPARTMENT OF ENERGY

DEPARTMENT OF STATE

NUCLEAR REGULATORY COMMISSION

DEPARTMENT OF DEFENSE

\section{Prepared by}

Arnold L. Aronson and David M. Gordon

Brookhaven National Laboratory

Upton, New York 11973 
BNL-52605

Formal Report

ISP0-411

\section{The "Mailbox" Computer System \\ for the}

IAEA Verification Experiment on HEU Downblending

at the

Portsmouth Gaseous Diffusion Plant

July 31, 2000

Prepared by

Arnold L. Aronson and David M. Gordon

Brookhaven National Laboratory

Upton, New York 11973

This work was performed under the auspices of the U.S. Department of Energy under Contract No. DE-ACO2-98CH10886. 


\section{Disclaimer}

This report was prepared as an account of work sponsored by an agency of the United States Government. Neither the United States Government nor any agency thereof, nor any of their employees, nor any of their contractors, subcontractors, or their employees, makes any warranty, express or implied, or assumes any legal liability or responsibility for the accuracy, completeness, or usefulness of any information, apparatus, product, or process disclosed, or represents that its use would not infringe privately owned rights. Reference herein to any specific commercial product, process, or service by trade name, trademark, manufacturer, or otherwise, does not necessarily constitute or imply its endorsement, recommendation, or favoring by the United States Government or any agency, contractor, or subcontractor thereof. The views and opinions of authors expressed herein do not necessarily state or reflect those of the United States Government or any agency, contractor or subcontractor thereof. 


\begin{abstract}
In April 1996, the United States (US) added the Portsmouth Gaseous Diffusion Plant to the list of facilities eligible for the application of International Atomic Energy Agency (LAEA) safeguards. At that time, the US proposed that the IAEA carry out a "Verification Experiment" at the plant with respect to the downblending of about 13 metric tons of highly enriched uranium (HEU) in the form of uranium hexafluoride $\left(\mathrm{UF}_{6}\right)$. During the period December 1997 through July 1998, the IAEA carried out the requested Verification Experiment. The verification approach used for this experiment included, among other measures, the entry of process-operational data by the facility operator on a near-real-time basis into a "Mailbox" computer located within a tamper-indicating enclosure sealed by the IAEA. These data included information on the weights and the connection/disconnection times for the cylinders containing the HEU UF 6 being downblended. The facility operator had also agreed to keep the cylinders connected to the feed stations for agreed lengths of time (the declared "residence times") which depended on cylinder size and contained mass of $\mathrm{UF}_{6}$. The IAEA inspectors then performed short-notice random inspections at the plant to verify the data entered by the facility operator. This report describes the hardware and software for the "Mailbox" computer system and the role that the "Mailbox" system plays in short-notice random inspections. In addition, it provides a listing of the software developed for this application.
\end{abstract}


(THIS PAGE INTENTIONALLY LEFT BLANK) 


\section{Table of Contents}

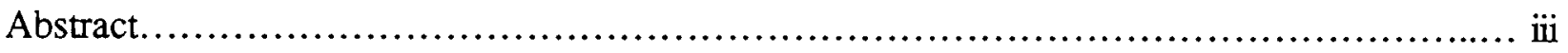

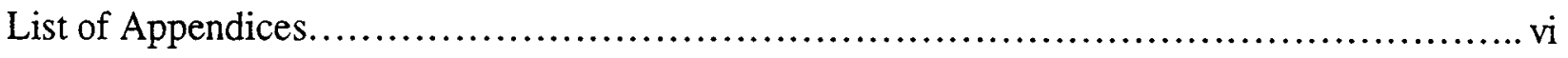

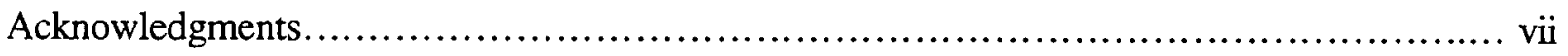

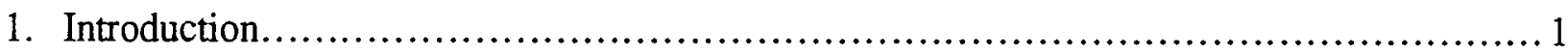

2. Description of the HEU Downblending Process.............................................. 1

3. Verification Approach for the Verification Experiment.................................. 2

3.1 Design Information Verification and Re-verification..................................... 3

3.2 Operator Declarations of Cylinder Feed Operations via Computerized "Mailbox"................................................................. 3

3.3 Load-Cell-Based Weighing System for HEU Feed Cylinders.................................. 3

3.4 Video Surveillance of the HEU Feed Stations........................................... 4

3.5 Verification of HEU Feed Cylinder Weights....................................... 4

3.6 Non-Destructive Assay (NDA) Measurements for HEU Feed Cylinders..................4

3.7 Application of Seals to Process Valves and Flanges..................................... 5

3.8 NDA Measurements for HEU and LEU Piping.......................................

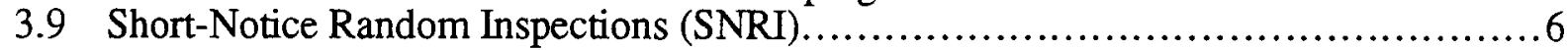

3.10 Role of the "Mailbox" Computer System in the Verification Experiment...................6

4. "Mailbox" Computer System Design Requirements.................................... 7

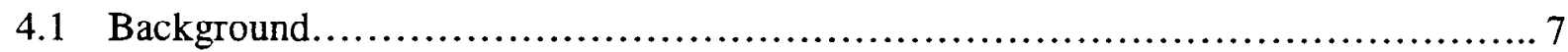

Design Requirements for the "Mailbox" System for the
Verification Experiment....................................................................

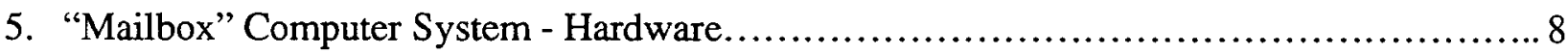

5.1 Operator's Data-Preparation Computer.............................................. 8

5.2 The "Mailbox" Computer........................................................... 9

5.3 IAEA Inspector's Data-Analysis Computer..................................... 9

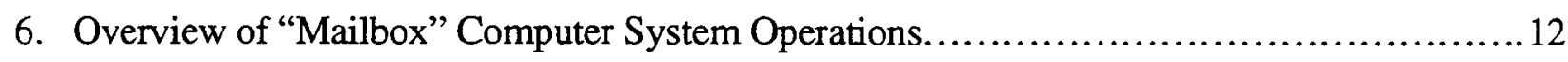

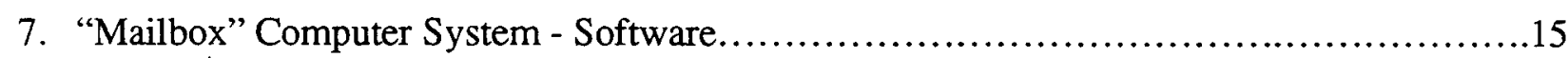

7.1 Overview of the Software........................................................... 15

7.2 Plant Operator's Data-Preparation Computer................................................ 17

7.3 The "Mailbox" Computer..................................................................... 20

7.3.1 Software Used for Data Entry...................................................... 20

7.3.2 Software Used for Data Downloading............................................2

7.4 The IAEA's Data-Analysis Laptop Computer..................................... 21

7.4.1 The Pre-processing Software .............................................. 21

7.4.2 The Report Generation Software ........................................ 24

8. Experience with the "Mailbox" Computer System.......................................25

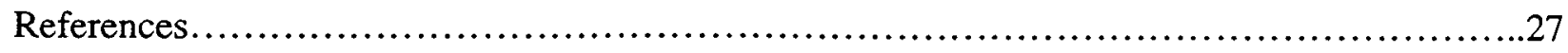




\section{List of Appendices}

A. The IAEA SP-1 Support Programme Task Proposal.................................. A-1

B. The Task Statement for the "Mailbox" Computer System................................. B-1

E. First Line Manager's Instructions for the Plant Data-Preparation Computer .................

E. First Line Manager's Instructions for the "Mailbox" Computer......................... D-1

E. LAEA Inspector's Instructions for the "Mailbox" Computer............................ E-1

E. Inspector's Instructions for Generating Reports Using the Data-Analysis Laptop Computer........................................................

E. The Plant Operator (First Line Manager) Data-Entry Program.......................... G-1

E. The FLM Supervisor's Password Program.............................................

E. FLM Supervisor's Instructions for the Password Program.............................. I-1

E. The AUTOEXEC.BAT File for the "Mailbox" Computer.............................. J-1

E. "Mailbox" Software to Collect the Plant Operator's Declaration..........................

E. Batch File to Download the Plant Operator's Declaration from the "Mailbox" Computer to the IAEA Representative's Floppy Diskette....................................

E. The RESET Program to Reset the "Mailbox"......................................... M-1

E. Programs to Incorporate the Plant Operator's Declarations of Purity (Uranium Weight Percent) and Assay (U-235 Weight Percent) ....................... N-1

E. Programs to Incorporate the Plant Operator's Declarations of Minimum Residence Times for $\mathrm{UF}_{6}$ Cylinders Attached at Feed Stations............................ 1

E. The Pre-processor Programs..........................................................

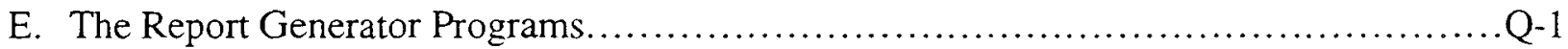

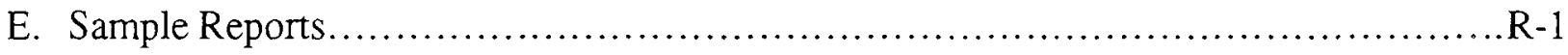




\section{Acknowledgments}

Many persons and organizations contributed to the successful completion of the IAEA Verification Experiment on HEU Downblending at the Portsmouth GDP. However, particular thanks and appreciation go to the following people:

- O. Lynn Calvert, Thomas N. Bonner, and Jeff Castle at the Portsmouth Gaseous Diffusion Plant, whose dedication, help and strong personal support made the "Mailbox" computer system, the short-notice random inspections, and the Verification Experiment a success;

- David A. Shisler, whose organization prepared the nuclear material accountability data, and Karl Shucker, who was extremely helpful in providing data that resolved discrepancies in data entry for the "Mailbox";

- Neville Whiting, Prachaks Jinamornphongs, Tamas Biro, and Eugene Chilkine of the IAEA inspection team, whose hard work and patience were essential to the success of the Verification Experiment;

- Willi Theis (Section Head, IAEA Division of Safeguards Concepts and Planning), who was instrumental in planning and gaining approval for undertaking the Verification Experiment;

- Mano Subudhi of Brookhaven National Laboratory, who was extremely helpful in reviewing the "Mailbox" data, resolving data-entry discrepancies, and assisting with the Experiment; and

- Amy B. Whitworth and Ronald C. Cherry of the Department of Energy International Safeguards Division, who provided overall guidance and support for the project. 
(THIS PAGE INTENTIONALLY LEFT BLANK) 


\section{Introduction}

In April 1996, the United States (US) added the Portsmouth Gaseous Diffusion Plant (GDP) to the list of facilities eligible for the application of International Atomic Energy Agency (IAEA) safeguards. At that time, in the event that the LAEA chose not to select the plant for the application of traditional safeguards, the US proposed that the IAEA carry out a "Verification Experiment" at the plant with respect to the downblending of 13.2 metric tons of highly enriched uranium (HEU, with enrichment $\geq 20 \% \mathrm{U}-235$ ) in the form of uranium hexafluoride $\left(\mathrm{UF}_{6}\right)$. This material is part of the 226 metric tons of fissile material that President Clinton has declared to be excess to US national-security needs and which will be permanently withdrawn from the US nuclear stockpile. However, because of the nature of the downblending process and equipment, it was not feasible to perform a nuclear-material balance around the blending point where the HEU and the low-enriched uranium (LEU, with enrichment $<20 \% \mathrm{U}-235$ ) are mixed to produce an LEU product with slightly greater enrichment than the LEU blendstock. Thus, the focus of the Verification Experiment was on technical measures to verify the HEU downblending operation.

The US and the IAEA met during April, August, and September of 1997 for technical exchanges; on the US side, the participants included US Government personnel (Department of Energy, Department of State, Nuclear Regulatory Commission, and Arms Control and Disarmament Agency), staff from several of the Department of Energy's national laboratories, the United States Enrichment Corporation (USEC, the operator of the Portsmouth GDP), and Lockheed Martin Utility Services, Inc. (LMUS, the operating contractor for the plant). Following these meetings, the IAEA committed to performing the Verification Experiment based on the agreed verification measures and procedures. The Verification Experiment began on December 1, 1997, and the IAEA carried out its design information verification activities during December 1-17, 1997. At the commencement of the Verification Experiment, about 3.7 metric tons of the original 13.2 metric tons remained available for verification. The HEU downblending activity was completed on July 17, 1998, and the IAEA performed a close-out inspection during October 5-14, 1998.

\section{Description of the HEU Downblending Process}

Highly enriched uranium in the form of $\mathrm{UF}_{6}$ was blended down to LEU in the uraniumenrichment gaseous-diffusion cascade at the Portsmouth GDP. This material had a variety of enrichments ranging from about $20-98 \%$ U-235 (with an average enrichment of about 70\% U-235 for uranium subject to the Verification Experiment) and was contained in 5-, 8-, and 12inch-diameter cylinders. The $\mathrm{HEU} \mathrm{UF}_{6}$ was fed at nine cylinder stations located in a room on the first floor of Process Bldg. X-326; each station included a process-control load-cell-based weighing system (LCBWS) for real-time measurement of cylinder weights as the contents of the cylinders were being transferred to the cascade blending point. The solid HEU UF 6 in the cylinders was converted to gaseous $\mathrm{UF}_{6}$ by sublimation at temperatures slightly elevated above room temperature. In principle, the $\mathrm{HEU} \mathrm{UF}_{6}$ gas could be transported by either of two piping headers to any of several cells of operating gaseous-diffusion equipment located on the second 
floor of this process building. In actual practice, the same header was used to carry the gas to the same cell during the entire course of the Verification Experiment. The length of this piping header was about $240 \mathrm{~m}$. Almost all of the HEU feed piping from the cylinder feed stations to the blending point was contained within heated enclosures typically maintained at temperatures of about $70-85^{\circ} \mathrm{C}$; the remainder was heat-traced and surrounded with insulating jackets. While some of the piping was readily visible, that portion contained within heated enclosures was not visible; as such, it was not traceable without removing the enclosure panels.

For his own security purposes, the plant operator prevented the flow of $\mathrm{HEU} \mathrm{UF}_{6}$ to any other location by closing, locking, and sealing all valves for piping that branched off from the selected header and which could provide a flow path to other locations. The closed, locked, and sealed valves along the piping headers from the feed stations to the selected blending point which defined and limited the HEU UF $_{6}$ flow to one and only one destination -- the selected blending point -- were called "boundary" valves. "In-line" valves along the piping were open valves that permitted the flow of $\mathrm{HEU} \mathrm{UF}_{6}$ to the selected blending point.

The blending of the $\mathrm{HEU} \mathrm{UF} \mathrm{UF}_{6}$ feed stock with the LEU UF 6 blend stock took place within the gaseous-diffusion equipment comprising the LEU enrichment cascade. Specifically, the blending point (or blending " $T$ ") was the juncture of the 3-inch-diameter pipe (carrying the HEU $\mathrm{UF}_{6}$ ) with the 20 -inch-diameter pipe between the Stage 12 diffuser and the Stage 12 compressor of Cell 3 within Unit 25-7, which is in the upper portion of the cascade. The HEU mass-flow rate in the 3-inch pipe was in the range from about 1 to $80 \mathrm{~kg} \mathrm{U}$ per day, while the LEU mass-flow rate in the 20 -inch pipe was typically about $39000 \mathrm{~kg}$ U per day. The LEU mass-flow rates were calculated quantities; there is no instrumentation available which can directly measure the flow of the LEU UF 6 either upstream or downstream of the blending point. Thus, a small amount of HEU $\mathrm{UF}_{6}$ carried in a small pipe was mixed with a very large amount of LEU UF 6 carried in a very large pipe; the U-235 enrichment of the LEU stream was increased by only about $1 \%$ (relative). After leaving the compressor, the blended LEU UF 6 entered an 8-inch-diameter pipe, and after passing through a cooler, the blended LEU entered the first stage of the next higher on-stream cell in the cascade.

\section{Verification Approach for the Verification Experiment}

The purpose of the IAEA's verification measures was to verify the quantity of $\mathrm{HEU} \mathrm{UF}_{6}$ that was fed to the cascade and blended down to $\mathrm{LEU} \mathrm{UF}_{6}$. In order to accomplish this, the IAEA needed to verify (1) the amount of $\mathrm{HEU} \mathrm{UF}_{6}$ removed from the feed cylinders, and (2) the fact that the $\mathrm{HEU} \mathrm{UF}_{6}$ removed from the cylinders entered the blending point and was blended down to LEU $\mathrm{UF}_{6}$. It was recognized that the verification purpose and the associated verification measures did not constitute a material balance for the operation. The verification measures to accomplish this purpose are outlined below. Of these, the measures in Sections 3.2 - 3.6 were intended primarily to verify the amount of $\mathrm{HEU} \mathrm{UF}_{6}$ removed from the feed cylinders, while the measures in Sections $3.1,3.7$, and 3.8 were intended primarily to verify that $\mathrm{HEU} \mathrm{UF}_{6}$ removed from cylinders entered 
the blending point and was blended down to LEU UF 6 . The verification measure in Section 3.9, the short-notice random inspections (SNRIs), served both purposes.

\subsection{Design Information Verification and Re-verification}

In November 1997, the Portsmouth GDP provided the IAEA with comprehensive design information concerning the HEU downblending equipment and process. The design information verification and re-verification measures that could be performed by the IAEA inspectors included: visual checking of the HEU feed piping at five randomly selected locations during each inspection for comparison with the declared piping drawings and for detection of undeclared piping; performing a pressure check and a vacuum check to confirm that all "boundary" valves had been placed in the closed position; performing a flow check to confirm the existence of a flow path from the feed stations through the blending point; and performing a volume measurement for comparison with the engineering calculated volume of the entire HEU feed piping system.

\subsection{Operator Declarations of Cylinder Feed Operations via Computerized "Mailbox"}

The facility operator entered process-operation data on a near-real-time basis into a "Mailbox" computer, which was located within a tamper-indicating enclosure sealed by the IAEA. The data to be entered included the HEU feed cylinder identification number, HEU feed station number, type of event (cylinder connection, cylinder disconnection, or error correction), date and time of the event, cylinder adjusted gross weight, cylinder adjusted tare weight, and concise note for explanations. The facility operator also provided accountability data for each feed cylinder subject to the Verification Experiment, including accountability gross weight, accountability tare weight, $\mathrm{UF}_{6}$ purity (grams of uranium per gram of $\mathrm{UF}_{6}$ ), and U-235 enrichment (grams of U-235 per gram of uranium). The facility operator also agreed to keep the cylinders connected to the feed stations for agreed lengths of time (the declared "residence times") which depended on cylinder size and contained mass of $\mathrm{UF}_{6}$.

\subsection{Load-Cell-Based Weighing System for HEU Feed Cylinders}

HEU UF 6 cylinders could be fed at any of nine feed stations. Each of these stations included an operator-installed load-cell-based platform scale for process control. The electrical outputs from these nine platform scales were connected by cable to nine corresponding computer-compatible readout units, each of which contained additional electronics for data storage and data authentication; these readout units had tamper-indicating enclosures sealed by the IAEA. The nine readout units were connected by cable to an LAEA computer contained within a tamper-indicating enclosure sealed by the IAEA. The IAEA computer collected weight data every ten seconds and stored weight data every 30 minutes from each of the nine readout units. Events such as rapid changes in scale readings were logged and also used to trigger the video-surveillance cameras 
viewing the nine feed stations. Stored data could be downloaded and printed out, plotted, or manipulated with standard data-base programs. The LCBWS permitted the IAEA to correlate realtime weight data, obtained as the HEU UF 6 feed cylinders were emptied, with the "Mailbox" declarations and video-surveillance system results.

\subsection{Video Surveillance of the HEU Feed Stations}

The nine HEU feed stations were under continuous observation by two separate videosurveillance cameras equipped with wide-angle lenses; each camera viewed all nine feed stations, with diminished resolution for those cylinders farthest from the camera location. The videosurveillance system was used to detect attempts to falsify the weight values recorded by the LCBWS and to detect removal of $\mathrm{HEU} \mathrm{UF}_{6}$ from feed cylinders through piping attached to the second cylinder valve. Each of the video cameras, along with additional electronics for data storage and data authentication, was contained within its own tamper-indicating enclosure sealed by the IAEA. The cameras were connected by cable to an IAEA computer contained within a tamper-indicating enclosure sealed by the IAEA. The video cameras were triggered to record images in any of three ways: motion detection based on detection of scene changes within the field of view; rapid changes in the weight observed by any of the nine load-cell-based weighing systems; or elapsed time interval. The video surveillance system and the load-cell-based weighing systems provided a mutually supporting set of data for confirming the operator's "Mailbox" declarations.

\subsection{Verification of HEU Feed Cylinder Weights}

Whenever the LAEA inspectors arrived for an inspection, they could request that the facility operator weigh any cylinder in the feed area on the facility's confirmatory scale. Any four of the nine cylinders attached at the feed stations could be selected. The IAEA could authenticate this confirmatory scale using its own standard weights. These verified cylinder weights could be used to check the functioning and accuracy of the LCBWS scales.

\subsection{Non-Destructive Assay (NDA) Measurements for HEU Feed Cylinders}

Whenever the IAEA inspectors arrived for an inspection, they could perform gamma-ray NDA measurements of U-235 enrichment for the $\mathrm{UF}_{6}$ in all cylinders in the feed area. The purpose of these measurements was to verify the operator's "Mailbox" enrichment declarations. These measurements were made using a portable high-resolution gamma-ray detector and were based on the standard enrichment-meter principle, with corrections for the attenuation of the 186$\mathrm{keV}$ gamma rays by the intervening materials. In general, these measurements were made in situ through the cylinder-supporting sleeve of the transport dolly, with the cylinder remaining attached at the feed station. However, the IAEA could request that up to four of the nine cylinders be 
detached from their feed stations and removed from their dollies for measurements made directly through the cylinder wall.

\subsection{Application of Seals to Process Valves and Flanges}

The IAEA installed seals on all 30 closed "boundary" valves along the piping from the HEU feed stations to all the potential blending points; these valves defined and limited the HEU UF 6 flow path to one and only one destination - the declared blending-point. In addition, the IAEA sealed a number of valve bodies and piping flanges, which might otherwise have been used to divert the flow of $\mathrm{HEU} \mathrm{UF} \mathrm{UF}_{6}$ to locations other than the blending point. Each of the "boundary" valves was sealed with two seals - an AIMS Fiber-Optic Seal (AFOS) and a standard IAEA E-type metal seal and seal wire. The AFOS seals were part of a radio-frequency-based remote-monitoring Authenticated Item Monitoring System (AIMS) which included the fiber-optic seals and redundant data-collection systems (repeaters, receivers, and Receiver Processing Units) to collect, store, and read out the seal events. Each Receiver Processing Unit monitored the seal-activity data for all the installed seals; these data could be downloaded to a computer for detailed analysis.

\subsection{NDA Measurements for HEU and LEU Piping}

Whenever the IAEA inspectors arrived for an inspection, they were in principle able to perform NDA measurements of the enrichment for the $\mathrm{UF}_{6}$ in the 3-inch-diameter piping carrying $\mathrm{HEU} \mathrm{UF}_{6}$ to the blending point and the 8-inch-diameter piping carrying blended LEU UF 6 from the blending point. The purpose of these measurements was to confirm that HEU UF 6 was actually arriving at the blending point and that $\mathrm{LEU} \mathrm{UF}_{6}$ was actually available for blending with the HEU UF 6 . The NDA method used in both cases was the Cascade Header Enrichment Monitor (CHEM) technique used by the LAEA at other enrichment facilities. The measurements were performed on an intermittent basis (i.e., during SNRIs), not on a continuous unattended basis. Between inspections, the equipment was stored in tamper-indicating enclosures sealed by the IAEA.

However, these NDA measurements met with only limited success, since the high-purity germanium detector used for the measurements was not able to withstand the high temperature environment $\left(85^{\circ} \mathrm{C}\right)$ when clamped onto the hot piping for extended periods. As an alternative measure, the IAEA was able to obtain samples of $\mathrm{UF}_{6}$ from the LEU piping near the blending point. These samples were shipped to IAEA Headquarters in Vienna, Austria, where they were measured using a mass spectrometer to determine their U-235 enrichment. These measurements confirmed the operator's declarations concerning the enrichment of the LEU UF 6 at the blending point. 


\subsection{Short-Notice Random Inspections (SNRI)}

The IAEA performed short-notice random inspections to confirm the facility operator's "Mailbox" declarations (including confirming the actual presence of HEU cylinders that had been declared to be present, performing NDA measurements of enrichment for HEU feed cylinders, and confirming cylinder weights); to re-verify the design information; to confirm the status of the applied seals; to perform gamma-ray NDA measurements of the enrichment of $\mathrm{UF}_{6}$ in $\mathrm{HEU}$ and LEU piping near the blending point; to review and correlate the LCBWS data, the videosurveillance data, and the "Mailbox" data; and to review operating records and accounting ledgers maintained by the facility operator. The IAEA inspectors coming for SNRIs were given access to the plant at any time including holidays, weekends, and off-normal working-day hours as well as normal working hours. It was anticipated that inspector access would take about one hour during normal working hours (7:30 AM to 4 PM local time. Monday through Friday) and up to about three hours during non-working hours.

\subsection{Role of the "Mailbox" Computer System in the Verification Experiment}

A major feature of the Verification Experiment was the implementation of a Short-Notice Random Inspection (SNRI) approach. Three conditions must be met for this approach to applicable: (i) all items in the population of $\mathrm{HEU} \mathrm{UF}_{6}$ cylinders must be available for selection for verification; (ii) the plant operator must declare to the IAEA values for the nuclear-material content of $\mathrm{HEU} \mathrm{UF}_{6}$ cylinders before knowing which ones will be verified; and (iii) the operator must not be able to alter item identity or content after learning that an item has been chosen for verification and before the verification actually occurs. The "Mailbox" was a dedicated computer in a tamperindicating enclosure with keyboard access only by LAEA inspectors; the "Mailbox" computer system was used to fulfill condition (ii). The "Mailbox" declarations were unalterable operator statements of accountancy values and operational data against which IAEA inspectors could compare the results of verification measurements. Rapid access to the cylinders during shortnotice random inspections, coupled with the load-cell-based weighing systems and video surveillance of the cylinders attached at the feed stations, were used to fulfill condition (iii).

Each month, the facility operator (through the US Government) made official declarations, on a cylinder-by-cylinder basis, of the amounts of highly enriched uranium and U-235 that had been downblended during the previous month. The IAEA verified these official facility/US declarations by comparing them to the near-real-time declarations deposited in the "Mailbox" computer and the results of the verification measurements performed on the cylinders that were present at the time of the short-notice random inspections. These measurements included NDA measurements of the enrichment for the $U_{6}$ contained in the cylinders and confirmatory weighings of individual cylinders. In addition, the IAEA could confirm the amount of $\mathrm{UF}_{6}$ removed from each of the cylinders by examining the data from the load-cell-based weighing systems, which provided a time-stamped and real-time record of the cylinder-plus-dolly weight as a function of time. Finally, the IAEA could confirm the connection and disconnection times of the 
cylinders by reviewing the time-stamped images from the video surveillance system that viewed the cylinders at the feed stations. The "Mailbox", the load-cell-based weighing system, and the video surveillance system provided a powerful and mutually supporting set of data from which to draw verification conclusions concerning the amounts of $\mathrm{HEU} \mathrm{UF}_{6}$ removed from the cylinders.

\section{4. "Mailbox" Computer System Design Requirements}

\subsection{Background}

Short-notice random inspections for verification of inventory changes were first analyzed theoretically by Gordon and Sanborn (Ref. 1) based on a suggestion by Brenner (Ref. 2). Their analysis was directed toward IAEA verification of inventory changes for feed, product, and tails at gas centrifuge enrichment plants as part of the Hexapartite Safeguards Project (Ref. 3). According to this approach, the plant operator declares the contents of nuclear material items before knowing if an inspection will occur to verify them. Additionally, items about which declarations are made should remain available for verification for an agreed-upon length of time (the "residence time"). If these conditions are met, then a statistical inference can be made from the verification results for items verified during SNRIs to the entire population, even if inspectors were not present when the items were received or processed.

During 1993, the IAEA conducted a six-month field test of the feasibility of such SNRIs at the Westinghouse Electric Corporation Commercial Nuclear Fuel Division LEU fuel-fabrication plant located at Columbia, South Carolina, USA (Fishbone, et al., Ref. 4). Westinghouse personnel made daily declarations about both feed and product items (uranium hexafluoride cylinders and finished fuel assemblies), using a custom-designed computer "Mailbox". LAEA safeguards inspectors conducted eight SNRIs to verify these declarations; the inspectors arrived unannounced at the plant, usually after travel from the LAEA regional office in Canada. The field test demonstrated the feasibility and practicality of key elements of the SNRI approach for a large LEU fuel fabrication plant, particularly the "Mailbox" computer system and the SNRIs themselves.

\subsection{Design Requirements for the "Mailbox" System for the Verification Experiment}

During the course of the technical exchanges in August and September of 1997, the IAEA specified the main design requirements for the "Mailbox" computer system to be used for the Verification Experiment on HEU Downblending at Portsmouth. These were:

- the "Mailbox" computer system hardware and software should be as similar as possible to that used for the Westinghouse field test. The software should use as much of the existing Westinghouse "Mailbox" software as possible, with changes only as needed to take account of the differences in the items being declared. This requirement was necessary because of the need to begin the Verification Experiment as soon as possible in order to be able to verify the maximum possible amount of the remaining HEU. 
- the plant operator would enter the cylinder operations data into the "Mailbox" computer on a near-real-time basis, rather than on a once-per-day basis. That is, the data for a cylinder connection or disconnection should be entered as soon as feasible after that connection or disconnection actually took place. This was necessary so that the data in the "Mailbox" would be current regardless of when the LAEA inspectors arrived for a short-notice random inspection. Since cylinder-handling operations took place on a 24-hour per day, 7-day per week basis, this meant that the data would have to be entered by Production Operations personnel rather than by Nuclear Material Control and Accountability personnel. Thus, additional data-preparation software and procedures had to be developed and written for use by the Operations personnel. In addition, a data-preparation computer was provided to the plant.

- some data would be declared by the plant operator before the start of the Verification Experiment. This would eliminate the need for the Production Operations staff to enter these data, as well as eliminate data-entry errors for these quantities. These data included the agreed cylinder residence times (which depended on the cylinder size and contained mass of $\mathrm{UF}_{6}$ ) and accountability data for each feed cylinder subject to the Verification Experiment (including the U-235 enrichment and $\mathrm{UF}_{6}$ purity). Software had to be written to incorporate these data into the database files so that the quantities of uranium and U-235 for each cylinder could be calculated by the computer from the declared weights.

- the IAEA specified the type of reports that it desired to generate from the "Mailbox" data. Four types of reports were requested; these are described in Section 7.4.2.

In order to obtain "Mailbox" computer hardware and software that would meet the needs of the Verification Experiment, the IAEA requested the US Government to provide them through the US Program of Technical Assistance to LAEA Safeguards. The IAEA SP-1 Support Programme Task Proposal is provided as Appendix A, while the Brookhaven National Laboratory task statement to meet this SP-1 Proposal is provided as Appendix B.

\section{5. "Mailbox" Computer System - Hardware}

The "Mailbox" computer system consisted of three computers - the operator's datapreparation computer, the "Mailbox" computer itself, and the IAEA inspector's data-analysis computer. These are described in turn below.

\subsection{Operator's Data-Preparation Computer}

The operator's data-preparation computer was a Gateway E Series E3000-1166 desktop computer. This computer had an Intel 166- MHz Pentium processor with $16 \mathrm{MB}$ of RAM, a 1.6GB hard drive, two 3.5-inch 1.44-MB floppy diskette drives, a standard 104-key keyboard, and a 
15-inch monitor. Since the operating system was MS-DOS, no mouse was used.

\section{2 "Mailbox" Computer}

The "Mailbox" computer was a Gateway E Series E3000-1166 desktop computer. This computer had an Intel 166-MHz Pentium processor with $16 \mathrm{MB}$ of RAM, a 1.6-GB hard drive, two 3.5-inch 1.44-MB floppy diskette drives and a 15-inch monitor. Since the operating system was MS-DOS, no mouse was used. The keyboard was stored near the computer until needed by the IAEA inspectors to take control of the "Mailbox" computer and download the data stored within it.

The "Mailbox" computer was contained within a tamper-indicating enclosure (TIE) designed and built by Sandia National Laboratories - Albuquerque (SNLA). SNLA staff had removed the computer's external case in order to obtain a closer and better fit between the computer and the TIE. The enclosure was constructed of three pieces of anodized aluminum. Two of these pieces surrounded the computer and were sealed together with a standard IAEA E-type metal seal and seal wire. The third piece covered the port for the keyboard; this third piece was sealed to the other two pieces with a standard IAEA E-type metal seal and seal wire. When the computer was sealed within the TIE, only the "B" floppy-diskette drive was accessible; the "A" drive was located behind the TIE. The power cable for both the "Mailbox" computer and its monitor were connected to a single, switched power strip with surge protection. "To initiate the operation of the "Mailbox" computer, the facility operator or the IAEA inspectors needed only to turn on the power switch.

During the Verification Experiment, the operator's data-preparation computer and the "Mailbox" computer were located side-by-side on a table in a plant Area Control Room near the location where the $\mathrm{HEU} \mathrm{UF}_{6}$ cylinders were being fed to the cascade. Figure 5.2.1 shows the data-preparation computer and the "Mailbox" computer installed in the Area Control Room. The "Mailbox" computer, located on the right in the photograph, was enclosed within its tamperindicating enclosure. Figure 5.2.2 shows a side view of the "Mailbox" computer within its tamper-indicating enclosure.

\subsection{IAEA Inspector's Data-Analysis Computer}

The IAEA inspector's data-analysis computer was a Toshiba Satellite 430 CDS Satellite Pro laptop computer with a $120-\mathrm{MHz}$ Pentium processor, $32 \mathrm{MB}$ of RAM, a 1.3-GB hard drive, a 10X CD-ROM drive, and a 3.5-inch 1.44-MB floppy diskette drive. The installed operating system was Microsoft Windows 95 but the analysis programs were run from the MS-DOS operating system. 
Figure 5.2.1

The data-preparation computer (on the floor, left) and the "Mailbox" computer in its gold-colored tamper-indicating enclosure (on the desk, right) installed in the area control room

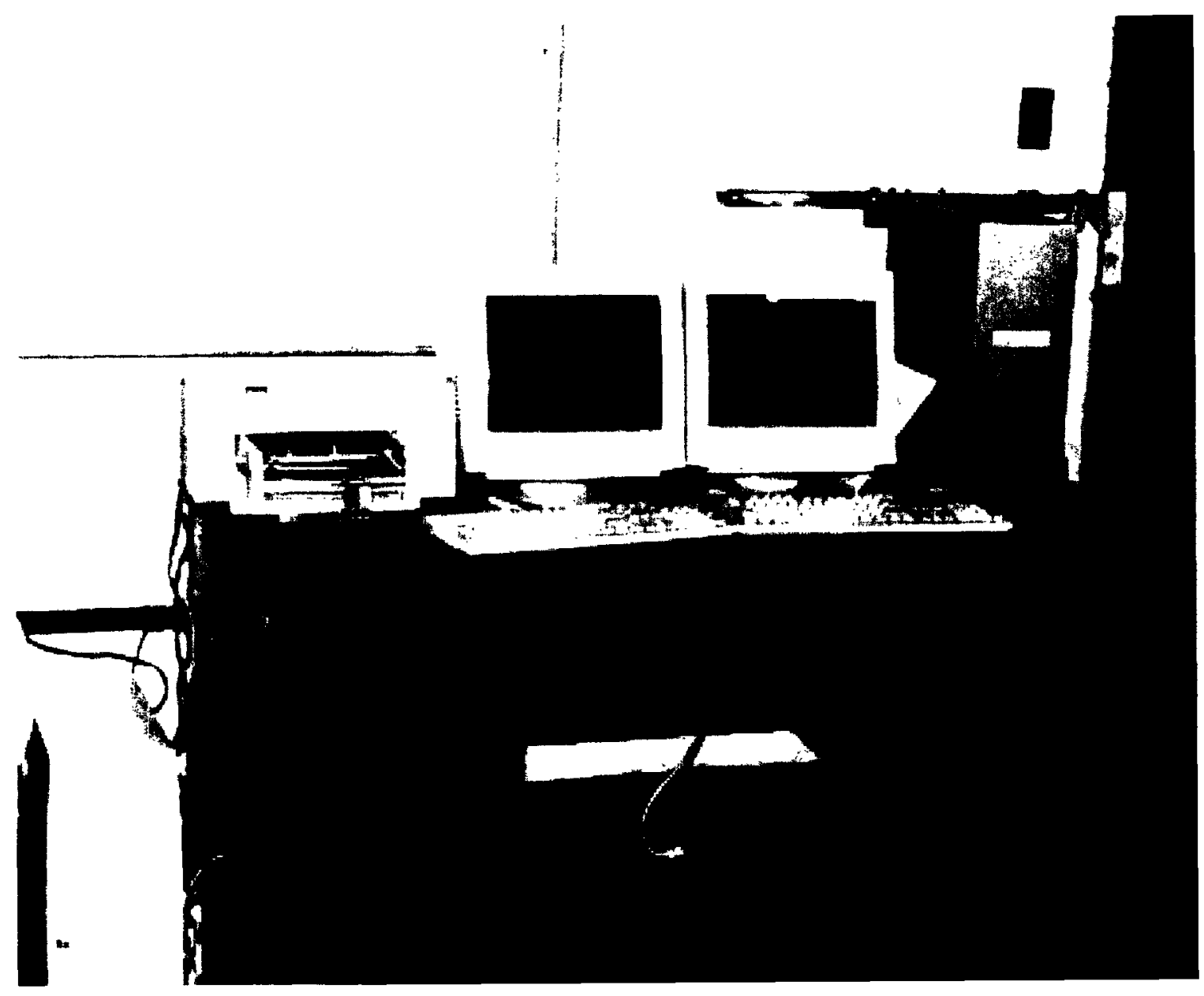


Figure 5.2.2

Side view of the "Mailbox" computer in its gold-colored tamper-indicating enclosure, showing the installed IAEA E-type seals and seal wires

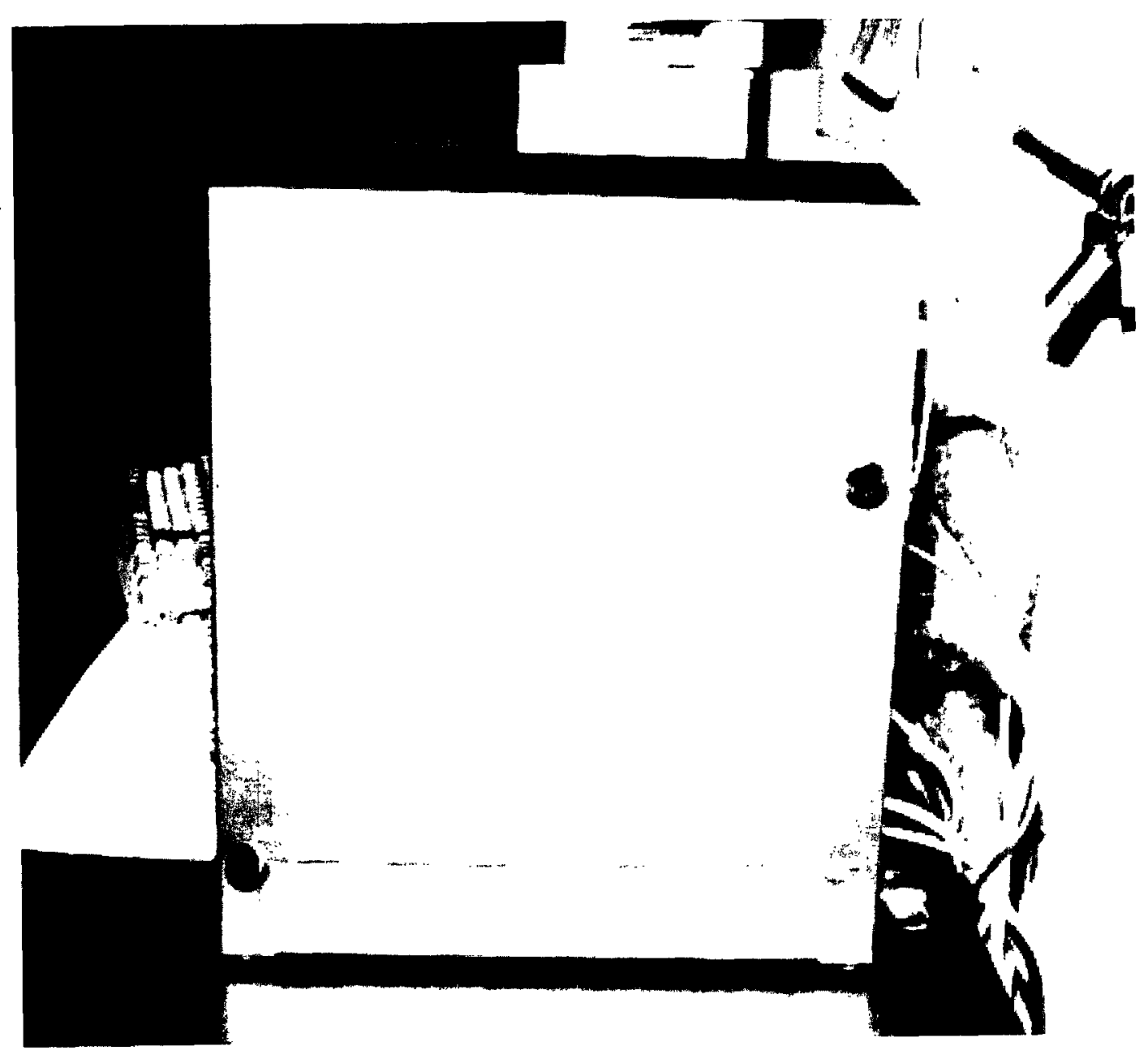




\section{Overview of "Mailbox" Computer System Operations}

The data for the "Mailbox" computer system used in connection with the IAEA Short-Notice Random Inspections at the Portsmouth Gaseous Diffusion Plant started with data declarations made by the facility operator. The Portsmouth GDP operating staff connected, emptied, and disconnected the $\mathrm{HEU} \mathrm{JF}_{6}$ cylinders whose contents were to be downblended according to the need for production of $\mathrm{LEU} \mathrm{UF}_{6}$ and the cascade operating conditions. Each time that a Portsmouth GDP Operations staff member connected or disconnected an HEU UF6 cylinder at one of the nine feed stations, he or she filled out a data sheet that provided the cylinder identification number, its gross and tare weights, the time and date of its connection or disconnection, and the feed station ("Position") at which the connection or disconnection took place. An example of this data sheet is provided as Figure 6.1. After filling out the form, the staff member sent it by facsimile machine to the local Area Control Room, where it was received by a member of the Production Operations supervisory staff known as the First Line Manager (FLM). The FLM then prepared the declaration for this cylinder, or set of cylinders, using a dedicated computer and a special-purpose data-input program; the computer used for this purpose was the data-preparation computer described in Section 5.1 above. The instructions for this data-entry procedure are provided in Appendix C. The FLM preparing the declaration turned on the computer (which started the program), supplied a password to allow execution, and then entered his name and badge number. The FLM was then prompted to enter the following information:

- cylinder identification number (a 6-character string)

- HEU feed station number (a 2-character string)

- type of event ( $c$ = connection, $d=$ disconnection, $e=$ error correction)

- event date (a 6-character string, in the format mmddyy)

- event time (a 4-character string in the format of a 24-hour clock)

- cylinder adjusted gross weight (in grams)

- cylinder adjusted tare weight (in grams)

- a concise note, if appropriate (up to four 80-character lines)

If the event type was "e" (that is, a correction for a previous incorrect entry), then the FLM was prompted to enter the date and time of the event being corrected, since that was the only way to identify an event uniquely (i.e., two events could not take place at exactly the same time). If the data entry that was being corrected was the type of event (e.g., "c" or "d"), then the FLM entered the corrected event type.

After the data for an event were entered, the FLM saw them displayed on the screen and had an opportunity to revise them. The revised entries were then displayed until the FLM indicated by an appropriate response to the prompts that no further revisions needed to be made. At that time, the information was entered into a database file in the computer. The FLM was prompted for any additional events to be entered during the current session at the computer. When the FLM indicated that there were no additional events to be entered, the database file was copied from the computer to a 3.5-inch floppy diskette, and the database file on the computer was erased. 
IAEA Mailbox Data

DATE $\quad 5.4 .98$

\begin{tabular}{|c|c|c|c|c|c|c|}
\hline Position & Cylinder & Time & Disconnect & Connect & Ops Adj Gross Wgt & Ops Adj Tare Wgt \\
\hline \multicolumn{7}{|l|}{1} \\
\hline \multicolumn{7}{|l|}{2} \\
\hline \multicolumn{7}{|l|}{3} \\
\hline \multicolumn{7}{|l|}{5} \\
\hline \multicolumn{7}{|l|}{6} \\
\hline 7 & 05.0293 & 0912 & $\checkmark$ & & 28560 & 27971 \\
\hline \multicolumn{7}{|l|}{8} \\
\hline \multicolumn{7}{|l|}{9} \\
\hline 10 & 08.0466 & 0916 & $\checkmark$ & & 52617 & 51033 \\
\hline
\end{tabular}


The FLM then entered the declaration data on the floppy diskette into the "Mailbox" computer; this was the computer described in Section 5.2 above. The instructions for this procedure are provided in Appendix D. According to this procedure, the FLM turned on the "Mailbox" computer and was asked by the computer "Are you an inspector?" Since the keyboard was disconnected and the keyboard port was covered by the tamper-indicating enclosure, the FLM was unable to answer this query. In the absence of an affirmative response after a short period of time, the computer recognized that the plant operator wished to enter declaration data. The FLM inserted the floppy diskette into the diskette drive of the "Mailbox" computer (the " $B$ " drive, which was the only drive accessible from outside the tamper-indicating enclosure). The "Mailbox" computer read the data, stored it in the appropriate files, and then instructed the FLM to turn off the "Mailbox" computer. The "Mailbox" computer accumulated the data declarations entered by the plant staff.

When the LAEA inspectors arrived at the plant for a short-notice random inspection, they were able to download the set of data declarations made by the plant operating staff. The instructions for this procedure are provided in Appendix E. The IAEA inspectors checked their seals on the tamper-indicating enclosure surrounding the "Mailbox" computer, and then removed the small section of the TIE which covered the keyboard port. They connected the keyboard to the port and then turned on the "Mailbox" computer, using the switch on the electrical power strip. The computer asked, "Are you an inspector?" and the inspectors responded by typing a "Y" (for "Yes") on the keyboard. The inspectors now had control of the computer and could download the data from it, as well as perform other operations. The inspectors inserted a floppy diskette into the diskette drive of the "Mailbox" computer (again, the " $\mathrm{B}$ " drive) and downloaded the operator's data declarations. After downloading these declarations onto the diskette, the inspectors removed the diskette from the "Mailbox" computer and then inserted the diskette with the operator's declarations into their data-analysis laptop computer (described in Section 5.3 above). The inspectors ran an analysis program to determine which HEU feed cylinders should be present and at which feed stations they should be located, based on the operator's declarations of cylinder connections and disconnections and upon the agreed cylinder residence times. The instructions for running this program and generating the relevant report (Report Type I) are provided in Appendix F. After determining this information, the inspectors then "reset" the "Mailbox" computer, disconnected the keyboard, reinstalled the tamper-indicating enclosure over the keyboard port, and reinstalled the IAEA seal and seal wire.

When the inspectors returned to their work area in the Administration Building, they could generate any of four types of reports based on the operator's declaration data. The instructions for generating these reports are provided in Appendix F. These reports include the following:

- Report Type I - provided a listing of cylinders that should be present at the feed stations either because their residence time had not been exceeded or because there had been no disconnection event recorded for them 
- Report Type II - provided detailed reports of the accumulated amount of material removed from the feed cylinders over a specified period

- Report Type III - provided a compact printed table of the amount of material removed from all cylinders over a specified time period

- Report type IV - provided a report of actual residence times for cylinders compared with their declared residence times

7. "Mailbox" Computer System - Software

\subsection{Overview of the Software}

As noted in Section 6, the First Line Manager (FLM) used the data-preparation computer and a special purpose data-input program to prepare the declarations regarding cylinder connection and disconnection operations. After the FLM completed the data entry for a cylinder connection or disconnection, these data were entered into the database file named INVENTOR.DBF, located in directory c: $S S N R N D B F$ within the data-preparation computer. When the FLM indicated that there were no additional events to be entered, the INVENTOR.DBF file was copied from the directory on the data-preparation computer to a floppy diskette, and the file on the computer was erased (initialized, or "zapped"). The FLM then inserted the floppy diskette into the "Mailbox" computer.

The software to accept the plant operator's declaration diskette into the "Mailbox" computer and allow the IAEA inspectors to download the declarations and reset the "Mailbox" computer to receive future declarations was adapted with only a few changes from software written by the IAEA for short-notice random inspections at the Westinghouse Electric Corporation Nuclear Fuel Division fuel-fabrication plant (Ref. 4).

The "Mailbox" computer also contained a file named INVENTOR.DBF, located in directory c:LSNRNDBF. In the "Mailbox" computer, this file was initialized ("zapped") at the beginning of the Verification Experiment, and was re-initialized whenever the "Mailbox" was "reset" by the IAEA inspectors during an inspection. Between resets, the several floppy diskette entries were accumulated in the INVENTOR.DBF file within the "Mailbox". When the IAEA inspector downloaded the data from the "Mailbox", the current INVENTOR.DBF file was copied to the inspector's floppy diskette, but was not altered. When the inspector was satisfied with the data and then reset the "Mailbox" computer, the current INVENTOR.DBF file was copied to a dated backup file in directory c: Ssnribackup, and the INVENTOR.DBF file was initialized (zapped). These backup files are dated by having file names assigned as "YYMMDD.DBF", the date of the reset. The backup files could be copied to floppy diskettes by inserting a floppy diskette in the "B" drive and typing

$$
\text { copy c:Isnribackup }{ }^{*} \text {.*b: } \backslash
$$

The IAEA inspectors then inserted the floppy diskette with the downloaded operational data into the laptop computer and ran the pre-processor program (named PREPRO). The pre-processor 
program was run once per inspection. The downloaded declaration data on the floppy diskette was read into the computer and stored in file named c: $S$ NRNDBF. The pre-processor program then performed a number of operations on this file:

- it eliminated duplicate records that would be present if the FLM had typed a record more than once, or had entered the same floppy diskette into the "Mailbox" computer more than once;

- it filled in the accountability data (weight \% uranium and weight \% U-235) for each relevant cylinder from a database file previously prepared from declarations provided by the facility operator;

- it computed the cylinder net weight by subtracting the cylinder adjusted tare weight from the cylinder adjusted gross weight;

- it assigned a minimum declared residence time from a database file prepared from a table of residence times as a function of cylinder size and net weight:

- it then added the completed INVENTOR.DBF file, minus error-correction records, to a database file named HISTORY.DBF in directory c: ISNRNHISTORY. This file was initialized at the beginning of the Verification Experiment, and was incremented by each entry of a diskette with an INVENTOR.DBF file read by the pre-processor program.

The pre-processor program then checked for and eliminated duplicate records in case a diskette downloaded from the "Mailbox" had been read into the IAEA computer more than once, or in case a "download" had been performed more than once during an inspection. The pre-processor then made the error corrections on the HISTORY.DBF file called for by the " $e$ "-type records on the INVENTOR.DBF file. The HISTORY.DBF file was the one used to generate the various reports that could be displayed on the screen and/or printed.

After the pre-processor finished the operations described above, the IAEA inspector could request the reports mentioned in Section 6 above; these reports could cover any desired period or periods during the entire previous history of the Verification Experiment. The report generation program was run as many times as desired.

All the programs used in connection with this activity were run under the DOS 6 operating system. The program to collect the declaration was written in $\mathrm{C}$, and that part was not recompiled from the program used at the Westinghouse plant. The remainder of the coding was written in CLIPPER5 (Ref. 5). Most of the CLIPPER compilations were done using the CLIPPER RMAKE utility, but some were done using a DOS batch file. Loading of compiled code was done using BLINKER2 (Ref. 6), and used additional subprograms from the LAEA, Department of Safeguards, Division of Safeguards Information Treatment (SGIT) library (Ref. 7). 


\subsection{Plant Operator's Data-Preparation Computer}

The facility First Line Managers (FLMs) prepared declarations of cylinder connections and disconnections using the plant operator's data-preparation computer and a program written specifically for that purpose. The software was written in CLIPPER5 and prompted the FLM entering the data to provide the required information. After each declaration, the FLM preparing the declaration could review and change what had been entered. After the preparer had indicated that no further review was desired, a printed copy of the declaration was generated. As many declarations as desired could be made during each session at the computer. When no further declarations were to be made in the current session, a floppy diskette was generated from the data in the structure of the database file INVENTOR.DBF.

The fields in the database file INVENTOR.DBF and their meaning are given in Table I. Not all of the fields were supplied through the plant operator's data-preparation computer. The fields supplied by the FLM are indicated on the second page of Table I. The remaining fields were filled in from other sources, and are discussed in later sections of this report.

The source code for the plant operator's data-preparation program, input instructions for the CLIPPER RMAKE utility, input for the BLINKER2 loader, and the batch file to execute the data entry program are all listed in Appendix G. Instructions for the plant First Line Managers, who prepare the declarations, are given in Appendix C.

The data-entry program had a password requirement to prevent unauthorized persons from making entries into the "Mailbox" computer. The Supervisor for the First Line Managers could change the password. The program to change the password was supplied to the Supervisor on a floppy diskette. When the Supervisor executed the batch file to change the password, the diskette was read from the "A" drive on the data-preparation computer. The Supervisor was prompted on how to change the password. After the program was finished, the program was deleted from the hard disk. The password was contained in the database file PASS.DBF that remained on the hard disk. The source code for the password program, input for the CLIPPER5 RMAKE utility, input for the BLINKER2 loader, the batch file to execute the password program, and the database file PASS.DBF are all listed in Appendix H. Instructions for the use of the Supervisor's password program are given in Appendix I. 


\section{Table I}

Structure of the Database File INVENTOR.DBF

\begin{tabular}{cllcl}
$\begin{array}{c}\text { Field } \\
\text { Number }\end{array}$ & \multicolumn{1}{c}{$\begin{array}{c}\text { Field } \\
\text { Name }\end{array}$} & $\begin{array}{c}\text { Type } \\
\text { Width }\end{array}$ & \multicolumn{1}{c}{ Description } \\
2 & TTEMTD & Character & 6 & Cylinder Number \\
2 & TRANS_TYPE & Character & 1 & $\begin{array}{l}\text { Type of event (connection, disconnection, or error } \\
\text { correction) }\end{array}$ \\
3 & PURITY & Numeric & 7 & Uranium weight percent \\
4 & ASSAY & Numeric & 7 & Enrichment weight percent \\
5 & LOCATION & Character & 2 & Feed station number \\
6 & GROSSWT & Numeric & 15 & Cylinder adjusted gross weight (grams) \\
7 & TAREWT & Numeric & 15 & Cylinder adjusted tare weight (grams) \\
8 & NETWT & Numeric & 15 & Cylinder adjusted net weight (grams) \\
9 & CDATE & Date & 8 & Date of event being corrected, if error correction \\
10 & CTIME & Character & 8 & Time of event being corrected, if error correction \\
11 & EDATE & Date & 8 & Event date \\
12 & ETLME & Character & 8 & Event time \\
13 & SLZE & Character & 2 & Cylinder size (diameter in inches) \\
14 & CYCLE & Numeric & 2 & Ordinal number of cylinder connection \\
15 & RESID & Numeric & 3 & Declared minimum residence time (hours) \\
16 & NOTES1 & Character & 80 & Concise note line 1 \\
17 & NOTES2 & Character & 80 & Concise note line 2 \\
18 & NOTES3 & Character & 80 & Concise note line 3 \\
19 & NOTES4 & Character & 80 & Concise note line 4 \\
20 & CORR_TYPE & Character & 1 & Corrected type of event being corrected, if changed \\
21 & CLOCK_DATE & Date & 8 & "Mailbox" input date \\
22 & CLOCK_TIME & Character & 8 & "Mailbox" input time
\end{tabular}




\section{Table I (continued)}

\section{Structure of the Database File INVENTOR.DBF}

\begin{tabular}{cll}
$\begin{array}{c}\text { Field } \\
\text { Number }\end{array}$ & \multicolumn{1}{c}{ Field } & \multicolumn{1}{c}{ Source of Data } \\
\cline { 1 - 3 } 1 & ITEMID & Entered by First Line Manager \\
2 & TRANS_TYPE & Entered by First Line Manager \\
3 & PURITY & Supplied during preprocessing from plant operator's prior declaration \\
4 & ASSAY & Supplied during preprocessing from plant operator's prior declaration \\
5 & LOCATION & Entered by First Line Manager \\
6 & GROSSWT & Entered by First Line Manager \\
7 & TAREWT & Entered by First Line Manager \\
8 & NETWT & Computed during preprocessing \\
9 & CDATE & Entered by First Line Manager \\
10 & CTIME & Entered by First Line Manager \\
11 & EDATE & Entered by First Line Manager \\
12 & ETIME & Entered by First Line Manager \\
13 & SIZE & Taken from cylinder identification during preprocessing \\
14 & CYCLE & Computed during preprocessing \\
15 & RESID & Supplied during preprocessing based on cylinder size and gross weight, according \\
& & to plant operator's prior declaration \\
16 & NOTES1 & Entered by First Line Manager \\
17 & NOTES2 & Entered by First Line Manager \\
18 & NOTES3 & Entered by First Line Manager \\
19 & NOTES4 & Entered by First Line Manager \\
20 & CORR_TYPE & Entered by First Line: Manager \\
21 & CLOCK_DATE & Automatically entered by “Mailbox" computer \\
22 & CLOCK_TIME & Automatically entered by “Mailbox" computer
\end{tabular}




\subsection{The "Mailbox" Computer}

\subsubsection{Software Used for Data Entry}

The "Mailbox" computer was a dedicated computer in a tamper-indicating enclosure. It had a special-purpose AUTOEXEC.BAT file that started when the computer was turned on. When the computer booted up, the screen prompts asked the question: "Are you an inspector?" When the IAEA inspectors were not present, the "Mailbox" computer did not have a keyboard attached. If a " $y$ " (for yes) was not entered within 5 seconds, the default was " $n$ " (for no) and the plant operator was instructed to enter the data diskette prepared on the data-preparation computer (see Section 7.1 ) into the " $\mathrm{B}$ " floppy diskette drive of the "Mailbox" computer. The diskette was read and the operator was instructed to remove the diskette and turn off the "Mailbox" computer. The AUTOEXEC.BAT file that resided on the "Mailbox" computer is listed in Appendix J, and the plant operator's (FLM's) instructions for entering data into the "Mailbox" computer are given in Appendix D.

The "Mailbox" computer software to collect the plant operator's declaration from the floppy diskette is listed in Appendix K. It includes five " $\mathrm{C}$ "-language programs that were not changed from those used during the field test of short-notice random inspections at the Westinghouse fuel fabrication plant (Reference 4) and were not re-compiled. In addition, there are the following files:

- a CLIPPER5 program (named APPEND.PRG) to append the data from the current floppy diskette to the database file accumulated since the last visit by the IAEA inspectors

- a header file used by APPEND.PRG and some of the C-language programs

- instructions to compile APPEND.PRG

- input to the BLINKER2 loader for APPEND.PRG.

The APPEND.PRG was changed slightly from the one used at the Westinghouse plant, and was re-compiled. It is called from the "C" language routine COLLECT.C.

In the "Mailbox" computer, the file INVENTOR.DBF was in directory c..dbf. The executable program collect.exe was in directory c:.exe. The executable program append.exe was in directory c:.exe.

\subsubsection{Software Used for Data Downloading}

On arrival at the facility, the IAEA inspectors opened the tamper-indicating enclosure and connected the keyboard to the "Mailbox" computer. They then started the computer. In response to the question "Are you an inspector?" they responded by entering the letter " $y$ ". Then they inserted a blank floppy diskette into the " $\mathrm{B}$ " drive of the "Mailbox" computer and typed 
"download". The declarations accumulated in the "Mailbox" computer in the database file INVENTOR.DBF since the last inspection were copied to the floppy diskette for processing in the IAEA inspector's data-analysis laptop computer. The batch file to download the plant operator's declaration from the "Mailbox" computer to the IAEA inspector's floppy diskette is listed in Appendix L. In the "Mailbox", it was loaded at c:download. The instructions for the IAEA inspectors to download the contents of the database file INVENTOR.DBF are given in Appendix E.

The IAEA inspectors entered the floppy diskette into their laptop computer and performed the pre-processing of the data. Then they generated a screen report of the cylinders that should be present at the feed stations. If there did not appear to be any problem, they reset the "Mailbox" computer to receive new declarations, disconnected the keyboard, and closed and sealed the tamper-indicating enclosure.

The source code for the program to reset the "Mailbox" computer (named RESET.PRG), instructions to compile RESET.PRG, and instructions to load the program and generate the executable file RESET.EXE are given in Appendix M. The executable code was loaded at c: reset.exe. The instructions for the IAEA inspectors to reset the "Mailbox" computer are given in Appendix E.

\subsection{The IAEA's Data-Analysis Laptop Computer}

\subsubsection{The Pre-processing Software}

When the IAEA inspectors entered the floppy diskette with the data that had been downloaded from the "Mailbox" computer into their laptop computer, the first procedure to be executed was the pre-processor. This was invoked by typing "prepro". Prompts told the LAEA inspector to insert the diskette, and to remove it when the pre-processing was finished. During the pre-processing, any indication of an abnormal condition in the data appeared on the screen. The pre-processing step was executed once per inspection, and merged the current declaration with information that the plant operator had previously supplied, in order to fill in some of the required information. Other information was generated from the information already present (e.g., the net weight was the gross weight minus the tare weight). Error-correction-type declarations were implemented. The completed current declaration was then added to the previous declarations accumulated in the file HISTORY.DBF. This file had the same structure as the INVENTOR.DBF file.

Data for two fields of the file INVENTOR.DBF were taken from declarations supplied by the plant operator in a different form. At the beginning of the Verification Experiment, the plant operator provided a floppy diskette that contained the plant's declaration of the cylinder identification number, the purity (uranium weight percent) and the assay (U-235 weight percent) for the $\mathrm{UF}_{6}$ contained in each cylinder to be included in the Verification Experiment. A CLIPPER5 
program was written to read this diskette and convert the information into a database file that would be read by the pre-processor program. The source code for this program (named

DECLARE1.PRG), the instructions to the CLIPPER RMAKE utility to compile it, the instructions to the BLINKER2 loader to load it and create an executable module (named DECL1MN.EXE), and the batch file to execute that module (named ACCOUNT.BAT) are all listed in Appendix N. An intermediate database file used in the processing (named ACCOUNT.DBF), and the final database file read by the pre-processor (named DECLARE.DBF) are also listed in Appendix N.

The plant operator's declaration of agreed minimum residence time is given in Table II. For each of the three sizes of cylinders involved in the Verification Experiment, the agreed minimum residence time was a function of the cylinder adjusted net weight ("UF 6 "). This minimum residence time was the minimum time that the cylinder would remain connected at a feed station. Exceptions for unusual conditions (e.g., a plugged cylinder valve that caused a cylinder to be removed from the feed station before expiration of the agreed minimum residence time) were explained by the operator in the concise notes.

A program (named RES.PRG) was written to create three database files, one for each cylinder size, to contain the information in Table II. These database files (named N5RES.DBF, N8RES.DBF and N12RES.DBF) were then read by the pre-processor and the minimum residence time for each cylinder, based on its size and net weight, was inserted in the INVENTOR.DBF file. The source code listing for RES.PRG, instructions to the CLIPPER RMAKE utility to compile it, instructions to the BLINKER2 loader to load it and create an executable module (named RESMAIN.EXE), and the batch file to execute that module are all listed in Appendix $O$, along with the (identical) structures of N5RES.DBF, N8RES.DBF, and N12RES.DBF.

These database files were created before the start of the Verification Experiment. The preprocessor module had a main program (named PREPRO.PRG) that controlled the flow of information, and seven sub-programs for specific functions. These programs are listed in Appendix P. Program COPYINV.PRG copied the database file from the floppy diskette downloaded from the file INVENTOR.DBF on the "Mailbox" computer into a database file with the same name and file structure on the inspector's laptop computer. Program ELIMDUPS.PRG examined INVENTOR.DBF and deleted duplicate records (identical except for the "Mailbox" input date and time). Program FILLUP.PRG added the purity and assay from file DECLARE.DBF. It computed the cylinder adjusted net weight by subtracting the cylinder adjusted tare weight from the cylinder adjusted gross weight and extracted the cylinder size from the cylinder identification number, since two of the characters in the identification number indicated the cylinder size. It then read the minimum residence time from file N5RES.DBF, N8RES.DBF or N12RES.DBF. Program PHYINV.PRG added INVENTOR.DBF to HISTORY.DBF. 


\section{Table II}

Agreed Minimum Residence Times for Cylinders To Be Connected at Feed Stations

Five-inch-diameter $\mathrm{UF}_{\underline{6}}$ Cylinders

If $\mathrm{UF}_{6}$ is

$>7.5 \mathrm{~kg}$, then residence time $=66$ hours

If $\mathrm{UF}_{6}$ is

$\leq 7.5 \mathrm{~kg}$

and

$>3 \mathrm{~kg}$, then residence time $=$

42 hours

If $\mathrm{UF}_{6}$ is

$\leq \quad 3 \mathrm{~kg}$

and $>0 \mathrm{~kg}$,

then residence time $=18$ hours

Eight-inch-diameter $\mathrm{UF}_{6}$ Cylinders

If $\mathrm{UF}_{6}$ is

If $\mathrm{UF}_{6}$ is $\leq 62 \mathrm{~kg}$

If $\mathrm{UF}_{6}$ is $\leq 33 \mathrm{~kg}$

If $\mathrm{UF}_{6}$ is $\leq 18 \mathrm{~kg}$

If $\mathrm{UF}_{6}$ is $\quad \leq 9 \mathrm{~kg}$

If $\mathrm{UF}_{6}$ is $\leq 3 \mathrm{~kg}$
$>62 \mathrm{~kg}$, then residence time $=138$ hours

and $>33 \mathrm{~kg}$, then residence time $=114$ hours

and $>18 \mathrm{~kg}$, then residence time $=90$ hours

and $>9 \mathrm{~kg}$, then residence time $=66$ hours

and $>3 \mathrm{~kg}$, then residence time $=42$ hours

and $>0 \mathrm{~kg}, \quad$ then residence time $=18$ hours

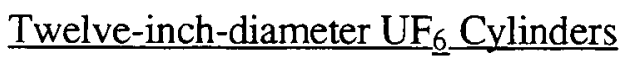

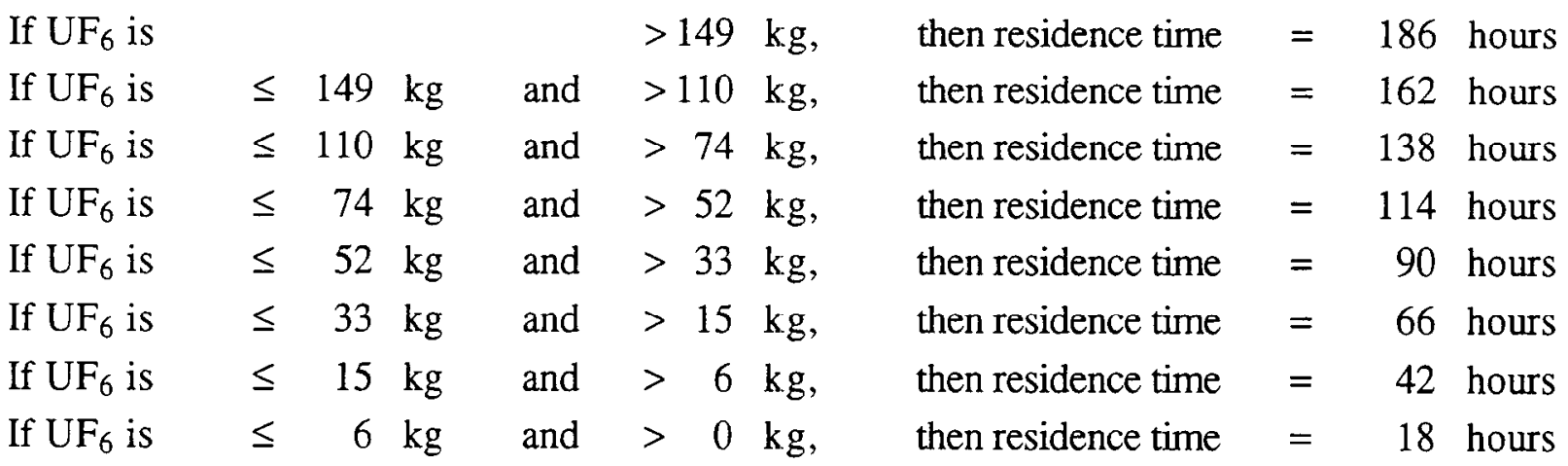

Note: the symbol $\mathrm{UF}_{6}$ means the net weight of the $\mathrm{UF}_{6}$ cylinder 


\subsubsection{The Report Generation Software}

There were several reports that could be generated from the HISTORY.DBF file on the LAEA data-analysis laptop computer. This program, or any portion of it, could be run as many times as desired during an inspection. The instructions for generating reports on the data-analysis laptop computer are provided in Appendix F. The listings of the programs are provided in Appendix Q. Examples of the reports that are available are provided in Appendix R.

\subsubsection{Report on Cylinders Attached at Feed Stations}

At the time of an inspection, the LAEA inspector could generate a report which identified the cylinders that should be attached at the feed stations because their minimum residence time had not expired, or because no disconnect event had been recorded for them. In order to generate this report, the IAEA inspector entered the date and time for the start of the current inspection. The program then looked at the HISTORY.DBF file and examined each entry of a cylinder connection. Based on the date and time of the cylinder connection, and the declared minimum residence time for that cylinder, the program calculated the expiration date and time of the minimum residence time and compared this date and time with the date and time for the start of the current inspection. If the minimum residence time had not expired, the program displayed the information about the cylinder on the screen. An example report of this type is provided in Appendix R, item (2).

The program then searched the HISTORY.DBF file to seek a disconnect event for all cylinders for which a connect event had been recorded. The program then displayed on the screen the identification number of all cylinders for which a connect event had been recorded without a corresponding disconnect event prior to the start of the current inspection date and time. If any cylinder had been connected and disconnected one or more times, and finally connected but not disconnected before the date the current inspection began, the program generated a report for that cylinder based on the last connection. An example report of this type is provided in Appendix R, item (3).

If a printer was attached to the portable computer at the time that the report was generated, then reports for all such cylinders could be printed, as well as displayed on the screen.

\subsubsection{Report on Amounts of Uranium and U-235 Removed During a Specified Interval}

The computer could generate detailed reports of the accumulated amount of uranium and U-235 removed from cylinders over a specified time period. The LAEA inspector entered the starting date and time, and the ending date and time, for the period of interest. This period could be from the start of the Verification Experiment to the start of the current inspection, or any interval in between. The program then examined the HISTORY.DBF file for connect/disconnect pairs for each cylinder. Where such pairs were found, the difference between the cylinder adjusted gross 
weight at the time of connection, and the cylinder adjusted gross weight at the time of disconnection was the amount of material removed. The computer could display this report on the screen, and could also print it. An example report of this type is provided in Appendix R, item (4).

\subsubsection{Summary Report on Amounts of Uranium and U-235 Removed}

The computer could generate reports, in the form of a compact table, of the amount of uranium and U-235 removed from all cylinders over a specified period. This report was only available as a printed report, and not on the screen. It contained a summary of the information from the reports described in Section 7.3.2.2. An example report of this type is provided in Appendix R, item (5).

\subsubsection{Report on Actual Residence Times of Cylinders}

The computer could generate reports of the actual residence time of a cylinder compared with its declared minimum residence time for normal feed operations. This type of report showed, for each time that a cylinder was connected and disconnected, the actual residence time (in hours) between the connect and the disconnect. It also showed the declared minimum residence time inferred from the cylinder size and adjusted net weight. The program then subtracted the declared minimum residence time from the actual residence time, and displayed this time difference. A negative residence time difference meant that the cylinder had been connected for less than the minimum declared residence time. The report also showed the difference between the time when the event was reported as having taken place, and the time when the declaration was entered into the "Mailbox" computer. A negative number implied that the declaration had been entered into the "Mailbox" before the event actually took place. Any such occurrence would need to be resolved by the IAEA inspectors in consultation with the plant operator. An example report of this type is provided in Appendix R, item (6).

\section{Experience with the "Mailbox" Computer System}

The "Mailbox" computer system operated successfully during the course of the Verification Experiment, which took place from December 1, 1997 through July 17, 1998. During this time, the IAEA conducted a design information verification visit followed by two scheduled inspections and five short-notice random inspections. In addition, the IAEA performed a final "close-out" inspection during the first two weeks of October 1998. There were no computer equipment failures until the very end of the experiment, when the failure of the operator's data-entry computer prevented the operator from declaring the connections and disconnections for the last two cylinders involved in the experiment. The "Mailbox" data supported the official declarations of HEU downblending reported by the plant operator and the US Government, and the "Mailbox" data were corroborated by the load-cell-based weighing system and video-surveillance data. 
However, there were numerous data-entry errors that required resolution. Since the IAEA inspectors could arrive at any time on a short-notice random basis, and since cylinder feed operations take place around the clock, the data for cylinder operations (e.g., cylinder identification number, connection/disconnection date and time, and weights) had to be entered on a near-realtime, 24-hour-per-day basis. This requirement meant that Production Operations staff, rather than the nuclear-materials-accountability staff, entered the data. These data-entry errors would probably have been avoided if the data had been entered by the accountability staff, but then the data entry could not have been done on a near-real-time basis and hence would not have met the timeliness requirement set by the LAEA.

The operator maintained an extensive set of operating records and logs that facilitated the resolution of the data-entry errors. Except for one cylinder, all data-entry errors and discrepancies were resolved by the IAEA and the plant operator.

Based on the verification approach and the results of the verification activities, including the "Mailbox" declarations, the IAEA was able to conclude, with a high degree of confidence, that 3.7 metric tons of HEU had been blended down to LEU during the course of the Verification Experiment. This confirmed the US Government's declaration for the quantity of HEU downblended during this time. 
References

1. D.M. Gordon and J.B. Sanborn, "An Approach to IAEA Material-Balance Verification with Intermittent Inspections at the Portsmouth Gas Centrifuge Enrichment Plant", Brookhaven National Laboratory Report BNL 51782, Brookhaven National Laboratory, Upton, New York USA, 1984.

2. L.M. Brenner, 1983 private communication, op.cit. Gordon and Sanborn 1984.

3. The Hexapartite Safeguards Project (HSP), "Safeguards Approach for Gas Centrifuge Enrichment Plants," Nuclear Materials Management, Vol. XII, No. 4, p. 30, 1983.

4. L.G. Fishbone, G. Moussalli, G. Naegele, P. Ikonomou, M. Hosoya, P. Scott, J. Fager, C. Sanders, D. Colwell, R. Ervin and C. J. Joyner, "Field Test of Short-Notice Random Inspections for Inventory-Change Verification at a Low-Enriched-Uranium Fuel-Fabrication Plant", IAEA Document STR-302/ISPO-371, Vols. 1, 2, and 3, International Atomic Energy Agency, Vienna, Austria, April 1995.

5. CLIPPER 5.01, The Nantucket Corporation, 1990.

6. BLINKER2, Assembler Software Manufacturers, Inc. ("Blincinc"), 1992.

5. SGIT PC Systems Development Handbook, R. Ellifritt, G. Hood, and K. Javorszky, International Atomic Energy Agency, Vienna, Austria, 1990. 
(THIS PAGE INTENTIONALLY LEFT BLANK) 
Appendix A

The IAEA Form SP-1 for the "Mailbox" Task 


\title{
SP-1 \\ TASK PROPOSAL PART
}

\author{
1. Task Proposal ID: 97/PST-001 Date received in SPA: 97-07-28 \\ 2. Task Title: \\ Revision of "Mailbox" Software for Use During Verification Experiment at \\ Portsmouth GDP
}

3. Task Category:

$\mathrm{D}$

\author{
R\&D/IS Need and its Priority: \\ D4.1 New IAEA Verification Missions
}

Important

4. Safeguards Problem Identification:

4.1 What is needed, why and when:

As part of its effort to reduce its nuclear-weapon-material stockpile, the U.S. is currently blending down 13 MTU of HEU UF6 to LEU UF6 in the cascade equipment at the Portsmouth Gaseous Diffusion Plant (GDP). This material is part of the 200 MT of fissile material that President Clinton has declared to be excess to U.S. national-security needs and which will be permanently withdrawn from the U.S. nuclear stockpile. In the blending process, a relatively small flow of HEU UF6 is blended with the relatively large flow of LEU UF6 in a cascade stage to form a blended LEU UF6 product with slightly increased enrichment.

The U.S. has proposed that the IAEA engage in a "verification experiment" with this material to assess the extent to which the IAEA can verify the U.S. declared quantities of HEU being blended down to LEU. A major feature of this verification experiment is the implementation of a Short Notice Random Inspection (SNRI) approach. Three conditions must be met for this approach to be applicable: (1) all items in the population must be available for selection for verification; (2) the plant operator must declare to the IAEA values for the nuclear-material content of items before knowing which items will be verified; and (3) the operator must not alter item identity or content after learning that an item is chosen for verification and before the verification actually occurs. The "Mailbox " concept is used to fulfill condition (2). "Mailbox" declarations are unalterable operator statements of accountancy values and operational data against which IAEA inspectors can compare the results of verification measurements. In a field test of the SNRI approach at the Westinghouse Electric Corporation Commercial Nuclear Fuel Division Fabrication Facility located in Columbia. South Carolina, USA. these operator declarations were made using a tamper-proof IAEA computer at the plant site to which the plant operator directly inserted information.

Software for the computer "Mailbox" was developed by the IAEA for use during the field test of SNRIs at the Westinghouse fuel fabrication facility. This field test was successfully completed in 1993. The software developed for that purpose must be revised for use during the HEU Downblending Verification Experiment at Portsmouth for two reasons: (1) the nuclear material strata and operating arrangements for the HEU downblending operations at Portsmouth are different from those at the Westinghouse fuel-fabrication facility; (2) several of the improvements suggested in the final report (STR-302/1SPO-371) for the Westinghouse field test should be incorporated in updated software.

The U.S. continues to blend down HEU UF6 at the Portsmouth GDP, and anticipates that blending operations there will be completed in August 1998. Accordingly, it is important that the Verification Experiment commence as soon as possible so that the IAEA can gain its desired experience in application of SNRIs (including "Mailbox" declarations by the plant operator) and design re-verification at selected locations on a short-notice random basis. This task needs to begin immediately so that the "Mailbox" software will be available by the time the other Verification-Experiment preparations have been completed and the Design Information Verification for the HEU downblending equipment at the Portsmouth GDP has been performed.

\subsection{How will the task results be used and by whom?}


Within the IAEA, the results of this task will be used by the Division of Operations B (SGOB1) and the Division of Concepts and Planning (SGCP) as a key verification measure during the course of the Verification Experiment for HEU Downblending at the Portsmouth Gaseous Diffusion Plant. More generally, the results of this task will be used by the IAEA to provide assurance, with a defined level of confidence, to the international community of NPT States that the U.S. has, in fact, complied with its commitment to reduce its stockpile of weapons-grade HEU by the declared quantity.

\section{2 Consequences if task is not performed:}

The use of a "Mailbox" for the operator declarations is essential to the SNRI approach. If a "Mailbox" is not available, then the SNRIs cannot be performed and as a consequence the HEU Downblending Verification Experiment cannot be performed. If this happens, the IAEA will miss an important opportunity to strengthen its public acceptance as a credible independent verification authority for arms-control agreements.

\section{IAEA Proposed Work Outline}

\subsection{Major task stages with timing:}

1. Establish the functional requirements for the revised software $\quad 8 / 30 / 97$

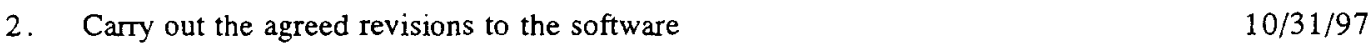

3. Test the revised software

$11 / 15 / 97$

4. Provide the revised software to the IAEA

5. Document the revised software in a report

\subsection{Estimated task completion date: 1997/11}

\subsection{Estimated duration in months: 3}

\section{Estimated Costs:}

6.1 To the IAEA to conduct the task:

$$
\begin{array}{llll}
\text { Person-months: } & 0 & \text { Person-trips: } & 0 \\
\text { Other costs in US }: & \$ 0.00 & \text { Total costs in US } \$: & \$ 0.00
\end{array}
$$

6.2 To the Support Programme (SP) to conduct the task:

$\begin{array}{llll}\text { Person-months: } & 3 & \text { Person-trips: } & 2 \\ \text { Other costs in US\$: } & \$ 5,000.00 & \text { Total costs in US\$: } & \$ 65,000.00\end{array}$

Remarks: The cost estimate is only to indicate the expected order of magnitude.

\section{Divisions Involved:}

\subsection{Requestor Division / Section / Person: SGCP / PST / Theis

$\begin{array}{lll}\text { 7.2 End User Division(s) / Section(s): } & \text { SGCP / PSS,PST } \\ \text { SGOB } / \text { OB } 1\end{array}$

8. Related SP Tasks:

SP(s) to which the task is proposed: USA

Is this a joint task for the SPs? No 
(THIS PAGE INTENTIONALLY LEFT BLANK)

A-4 


\section{Appendix B}

The Task Statement for the "Mailbox" Computer System

B-1 
TASR AREA D - Information Processing and Evaluation

$97 /$ PST-001

Subtask: Revision of "Mailbox" Software for Use during the IAEA

Verification Experiment at Portsmouth GDP

Contractor: BNL/SSN

Problem: The IAEA Verffication Experiment on downblending of HEU at the Portsmouth GDP w11l make use of the short Notice Random Inspection (SNRI) approach. The use of a "Maflbox" computer is essential to the SNRI approach, since the data Involved is classifled by the USA as confldential National security Information and cannot be transmitted offsite by facsimlle. However, the current "Mallbox" software is not usable in 1 ts current form and must be revised to make it compatible with portsmouth GDP nuclear material strata and operating arrangements and procedures.

Obfective: Revise the "Mallbox" software to make 1t compatible with the nuclear material strata and operating arrangements for the HeU downblending operations at the Portsmouth Gaseous Diffusion Plant, and Incorporate several of the software improvements suggested in the final report (STR-302/ISPO-371) from the SNRI field test at the Westinghouse fuel fabrication facility.

Act1vities:

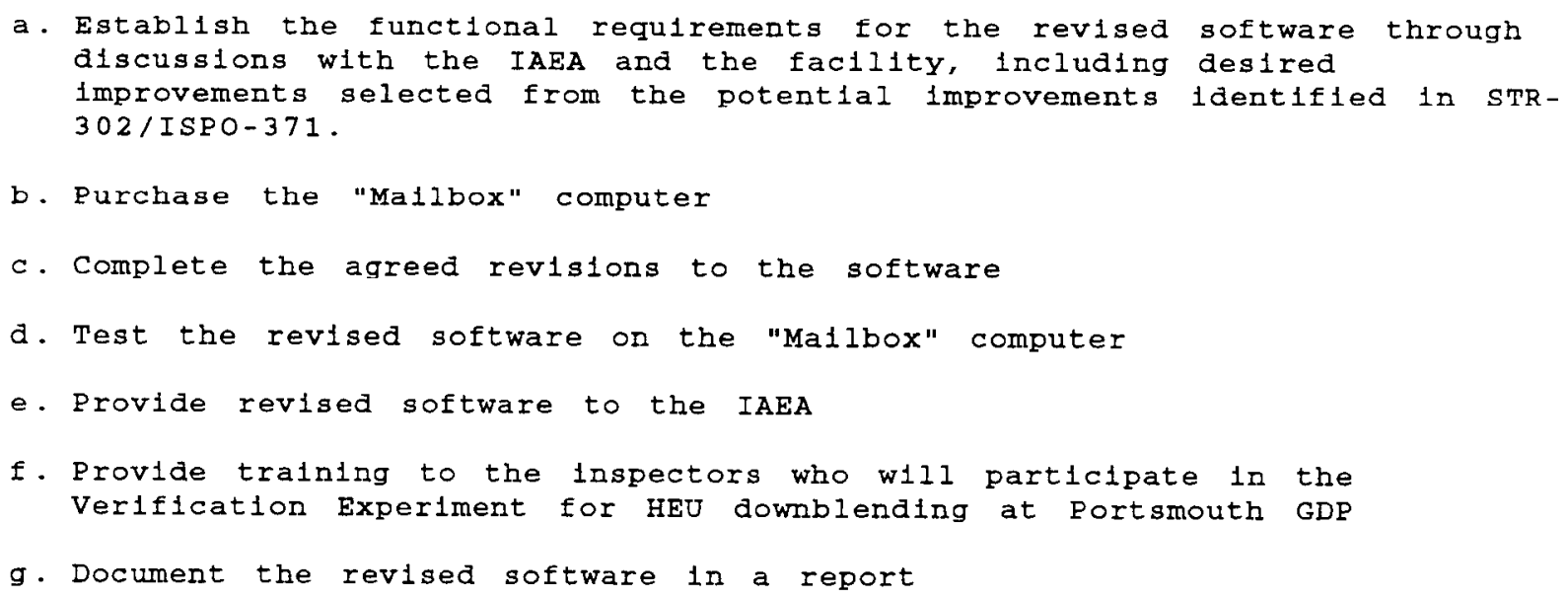
Schedule and M1lestones:

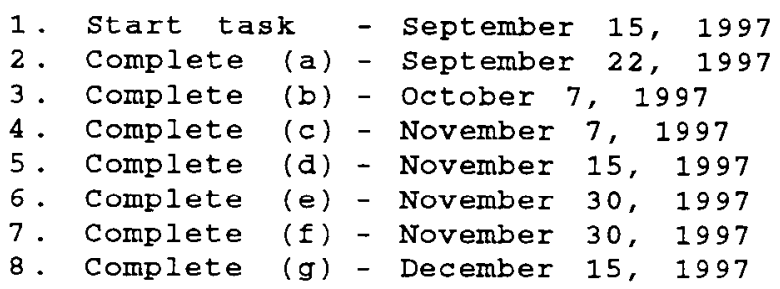

Funding:

1997

$\$ 65,000$ 


\begin{abstract}
Appendix C
First Line Manager's Instructions For the Plant Data-Preparation Computer
\end{abstract}

1. At the DOS prompt $(\mathrm{C}: \downarrow)$, type in the word "plant" and then press [ENTER]. If you enter an incorrect password, start over.

2. Follow the instructions on the screen.

3. Please enter event times uniquely; that is, no two events should take place at exactly the same time!

Example: Cylinder at feed position No. 1 connected at time 1405

Cylinder at feed position No. 2 connected at time 1406

4. Save the printed record of the data entry!

5. Then follow the instructions for the "Mailbox" computer

NOTE: Cylinder identification and event type should be entered in lower case. If they are not, the program will change upper case to lower case! 
(THIS PAGE INTENTIONALLY LEFT BLANK)

C-2 


\section{Appendix D}

\section{First Line Manager's Instructions for "Mailbox" Computer}

The "Mailbox" computer is contained in a tamper-indicating enclosure. Plant access to the computer is limited to the power cable and the "B" drive. When the machine is turned "ON," the system will start up automatically.

All system functions are automated. When the system prompts "Turn OFF the machine," the computer must be turned OFF to restart the data-collection procedure.

Operating Instructions:

1. Turn "ON" the computer (Switch on the power strip)

2. Do not wait for a screen prompt to insert the data diskette (insert it at the question, "Are you an inspector?")

3. The system will verify the data file name and structure

If correct, data will be appended to an existing file

If incorrect, note the error message, correct the problem, and if necessary, repeat the procedure

4. Wait for the message, "Turn this machine off."

5. Remove diskette

6. Turn "OFF" the computer

When there is an error:

The error-message prompt will be followed by a pause. After three prompts, the message "Turn the machine OFF" will be displayed. The machine must be turned OFF. Correct the data diskette and try again later.

Possible file-handling-function error messages:

Error: drive not ready reading drive B:

Diskette is not in drive $B$ :

Error: file not found on drive B:

The DBF file name on the diskette does not match the target DBF file name.

Put in the correct diskette.

Error: B: DBF contains extra fields

DBF file structure does not match the target file.

Put in the correct diskette. 
(THIS PAGE INTENTIONALLY LEFT BLANK)

D-2 


\section{Appendix E}

IAEA Inspector's Instructions for the "Mailbox" Computer

STEP 1: Download the Inventory Change Transactions from the "Mailbox" Computer

Overview:

Open the tamper-indicating enclosure and connect the keyboard allowing for full control of the computer. When the computer is turned on, the program for collection of operator's data begins automatically. You can prevent the continuation of this program by responding to the question, "Are you an Inspector?" Respond by typing "Y" to gain control of the system. If you fail to answer before the time elapses, the data-collection program will continue. To gain control of the system, you must restart the computer.

Two procedures must be completed on the "Mailbox" computer. At the beginning of the inspection, download the inventory change transactions for processing. Then reset and re-secure the "Mailbox" computer within its tamper-indicating enclosure.

Operating Instructions:

1. Open the tamper-indicating enclosure permitting access to the computer, and connect the keyboard.

2. Turn the machine "ON."

3. When the question, "Are you an Inspector?" is displayed, type "Y" within 10 seconds. Enter new date/time or press [ENTER] to accept the current date/time.

Note:

If you fail to respond with a "Y" within ten seconds, the plant's data collection program will execute. Wait until the system prompts "Turn this machine off." Turn the machine off, and begin again.

4. Insert a formatted diskette in Drive B: (the lower drive).

5. At the DOS prompt, (i.e., when you see "C: $>$ "), type "DOWNLOAD" and press [ENTER]. The screen should look as follows:

Wed 11-18 15:00 c:DOWNLOAD

Insert a diskette into drive $\mathrm{B}$ :

Press any key to continue...

Any files on this diskette will be overwritten.

Copying C: USNRNDBFINVENTOR.DBF to B:

1 file(s) copied

Wed. 11-18 15:00 C: $\backslash$

5. When the DOS prompt is displayed, remove the diskette from drive B by pushing the button just below the slot. Label it with the date of the inspection. The diskette is the input for the Short-Notice Random Inspection (SNRI) pre-processor and will also serve for archive purposes.

5. Turn the machine "OFF". Do not disconnect the keyboard and do not secure the computer inside the tamper-indicating enclosure at this time. 
STEP 2: Identify Cylinders That Should be Present at Feed Stations in Bldg. X-326

1. Turn "ON" the portable computer. Go into DOS.

2. At the DOS prompt "C: $\$ ", type "prepro". This is a pre-processing procedure which is performed only once per inspection.

3. At the screen prompt, insert the diskette that has just been removed from the "B" drive of the "Mailbox" computer into the floppy disk drive of the portable computer. Press [ENTER].

4. At the next screen prompt, remove the diskette from the floppy disk drive. Follow the agreedupon procedure for handling of the diskette.

5. At the DOS prompt "C: $\checkmark$ ", type "reports". This will start the report generation program. Several reports are available, with output to the screen and/or printer. Respond to the prompts.

6. At the appropriate prompt, type " $y$ " to ask for reports of cylinders which should be connected because their declared residence time has not been exceeded, or because no disconnect has been recorded. Do NOT ask for a printed copy at this time because no printer is attached. By hand, note the identification of the cylinders that should be attached, and any other information that is required immediately. Press [ENTER] to advance from screen to screen.

7. Do not ask for other reports at this time. [See STEP 4 for the other reports.]

8. If there is no problem with pre-processing of the diskette or obtaining the reports, turn "OFF" the portable computer.

9. Proceed to the instructions for resetting the "Mailbox" computer.

10. If there are problems with pre-processing of the diskette or the report generation, try downloading the inventory-change transaction data from the "Mailbox" computer using a different diskette.

STEP 3: Reset the "Mailbox" Computer

This procedure should not be executed until after the inventory-change data has been successfully read into the inspector's portable computer. This procedure copies the plant data to a dated backup file and erases the original inventory-change transaction data. The dated backup files are in the "Mailbox" computer in directory c: snribackup. To copy these files to a floppy disk, insert the formatted disk into the B drive at the DOS prompt following completion of item 2 on this page, and type

"copy c: \snribackup ${ }^{*}$ * b: :".

Operating Instructions:

1. Turn the machine "ON."

2. When the question, "Are you an Inspector?" is displayed, type "Y" within 10 seconds.

Note: If you fail to respond with a "Y" within the ten seconds, the plant's data collection program will execute. Wait until the system prompt, "Turn this machine off", is displayed before restarting the computer. 
3. At the DOS prompt C:৬, type "RESET" and press [ENTER].

The screen should look as follows:

C: \RESET

WARNING: All data in the collected inventory database will be removed.

Are you sure you know what you are doing?

At this point you should re-confirm that the inventory change data has been successfully read into the inspector's portable computer. If you are sure that this is the case, continue.

4. Type "Y" and press [ENTER].

The following messages will be displayed:

num, Records copied to BACKUP.DBF

INVENTOR.DBF Zapped

Turn this machine "OFF," disconnect the keyboard, and secure the computer inside the tamperindicating enclosure.

5. Turn the machine "OFF." Disconnect the keyboard. Secure the computer inside the tamperindicating enclosure, and seal the enclosure.

Possible Error Messages:

If the data set has already been backed up and zapped, you will overwrite your backup with an empty file. If you get one of the following messages, STOP and make certain you know what you are doing.

WARNING: The collected inventory change transaction database contains no data. Are you sure you know what you are doing?

This message tells you that you have already completed this action and you should not repeat it. If you do repeat it, you will overwrite the file with blank data.

WARNING: A dated backup file already exists for the date and will be overwritten. Are you sure you know what you are doing?

This message tells you that you have already completed this action and you should not repeat it. If you do repeat it, you will overwrite the file with blank data. 
(THIS PAGE INTENTIONALLY LEFT BLANK) 


\section{Appendix F}

Inspector's Instructions for Generating Reports Using the Data-Analysis Laptop Computer

\section{Step 4:}

(Note: Steps 1-3 are provided in Appendix E)

1. Turn "ON" the portable computer. Go into DOS.

2. At the DOS prompt "C:\", type "reports".

3. Follow instructions on the screen for the various types of reports that can be generated, either on the screen or on the printer.

4. Turn "OFF" the portable computer.

5. Report generation may be repeated as many times per inspection as desired.

Note: Four types of reports are available. The screen prompts for each of the types is given below.

\section{Report Type I}

1. The computer will ask 'Do you want to have reports for cylinders that should be attached to feed stations because their residence time has not been exceeded and reports for cylinders that should be attached to feed stations because there is no disconnect recorded? $(\mathrm{y} / \mathrm{n})^{\prime}$

If the answer to this question is yes, type " $y$ " and if the answer to this question is no, then type "n"

2. The computer will ask 'Date on which this inspection started (format is ddmmyy)'

Enter the date on which this inspection started in the format ddmmyy, where dd is the two-digit day, $\mathrm{mm}$ is the two-digit month, and yy is the two-digit year

3. The computer will ask 'Time at which this inspection started (format is military time $=\mathrm{xxxx})^{\prime}$

Enter the time at which this inspection started in the format $\operatorname{xxxx}$, where the time is given in military time according to the 24-hour clock

4. The computer will ask 'Do you want printed reports in addition to the screen reports? $(\mathrm{y} / \mathrm{n})^{\prime}$

If the answer to this question is yes, type " $y$ " and if the answer to this question is no, then type " $n$ " 


\section{$\underline{\text { Report Type II }}$}

1. The computer will ask 'Do you want to have detailed reports of the accumulated amount of material removed from cylinders over a specified period? $(\mathrm{y} / \mathrm{n})^{\prime}$

If the answer to this question is yes, type " $y$ " and if the answer to this question is no, then type "n"

2. The computer will ask 'Starting date of period (format is ddmmyy), (000000 means Dec. 17, 1997)'

Enter the starting date of the desired period in the format ddmmyy, where dd is the two-digit day, $\mathrm{mm}$ is the two-digit month, and yy is the two-digit year

3. The computer will ask 'Starting time of period (format is military time $=\mathrm{xxxx})^{\prime}$

Enter the starting time of the desired period in the format $\mathrm{xxxx}$, where the time is given in military time according to the 24-hour clock

4. The computer will ask 'ending date of period (format is ddmmyy)'

Enter the ending date of the desired period in the format ddmmyy, where dd is the two-digit day, $\mathrm{mm}$ is the two-digit month, and yy is the two-digit year

5. The computer will ask 'ending time of period (format is military time $=\mathrm{xxxx})^{\prime}$

Enter the ending time of the desired period in the format $\mathrm{xxxx}$, where the time is given in military time according to the 24-hour clock

6. The computer will ask 'Do you want printed reports in addition to the screen reports? $(\mathrm{y} / \mathrm{n})^{\prime}$

If the answer to this question is yes, type " $y$ " and if the answer to this question is no, then type "n"

\section{Report Type III}

1. The computer will ask 'Do you want to have a compact printed table of the material removed from all cylinders over a specified time period? $(\mathrm{y} / \mathrm{n})^{\prime}$

If the answer to this question is yes, type " $y$ " and if the answer to this question is no, then type "n"

2. The computer will ask 'Starting date of period (format is ddmmyy), (000000 means Dec. 17 , 1997)'

Enter the starting date of the desired period in the format ddmmyy, where dd is the two-digit day, $\mathrm{mm}$ is the two-digit month, and yy is the two-digit year

3. The computer will ask 'Starting time of period (format is military time $=\mathrm{xxxx}$ )'

Enter the starting time of the desired period in the format $\mathrm{xxxx}$, where the time is given in military time according to the 24-hour clock 
4. The computer will ask 'Ending date of period (format is ddmmyy)'

Enter the ending date of the desired period in the format ddmmyy, where dd is the two-digit day, $\mathrm{mm}$ is the two-digit month, and yy is the two-digit year

5. The computer will ask 'Ending time of period (format is military time $=x \times x x)^{\prime}$

Enter the ending time of the desired period in the format $\mathrm{xxxx}$, where the time is given in military time according to the 24-hour clock

\section{Report Type IV}

1. The computer will ask 'Do you want to have reports of actual residence time of cylinders compared with declared residence time for normal refeed? $(y / n)^{\prime}$

If the answer to this question is yes, type " $y$ " and if the answer to this question is no, then type "n"

2. The computer will ask 'Do you want printed reports in addition to the screen reports? $(\mathrm{y} / \mathrm{n})^{\prime}$

If the answer to this question is yes, type " $y$ " and if the answer to this question is no, then type "n"

If the reported connection declaration time difference is a negative number, this means that the actual time of data entry (as determined by the computer internal clock) precedes the declared time for that event. This discrepancy should be resolved with the plant operator. If the residence time difference is a negative number, this means that the actual residence time was less than the agreed, declared residence time. This discrepancy should be resolved with the plant operator. 
(THIS PAGE INTENTIONALLY LEFT BLANK) 


\section{Appendix G}

The Plant Operator's (First Line Manager's) Data-Entry Program

1) CLIPPER5 source code for the PLANT program:

file c: Isnrilsrcloperator \lant.prg

2) Listing of input data to the CLIPPER RMAKE Utility:

file c: Snnrisrcloperator \plant.rmk

3) Listing of input to the BLINKER2 loader:

file c: Snritsrcloperator plant.lnk

4) Batch file to execute the PLANT program:

file c: plant.bat 


\section{Appendix G}

\section{(1) CLIPPER5 source code for the PLANT program} file c: Isnrilsrchoperator plant.prg

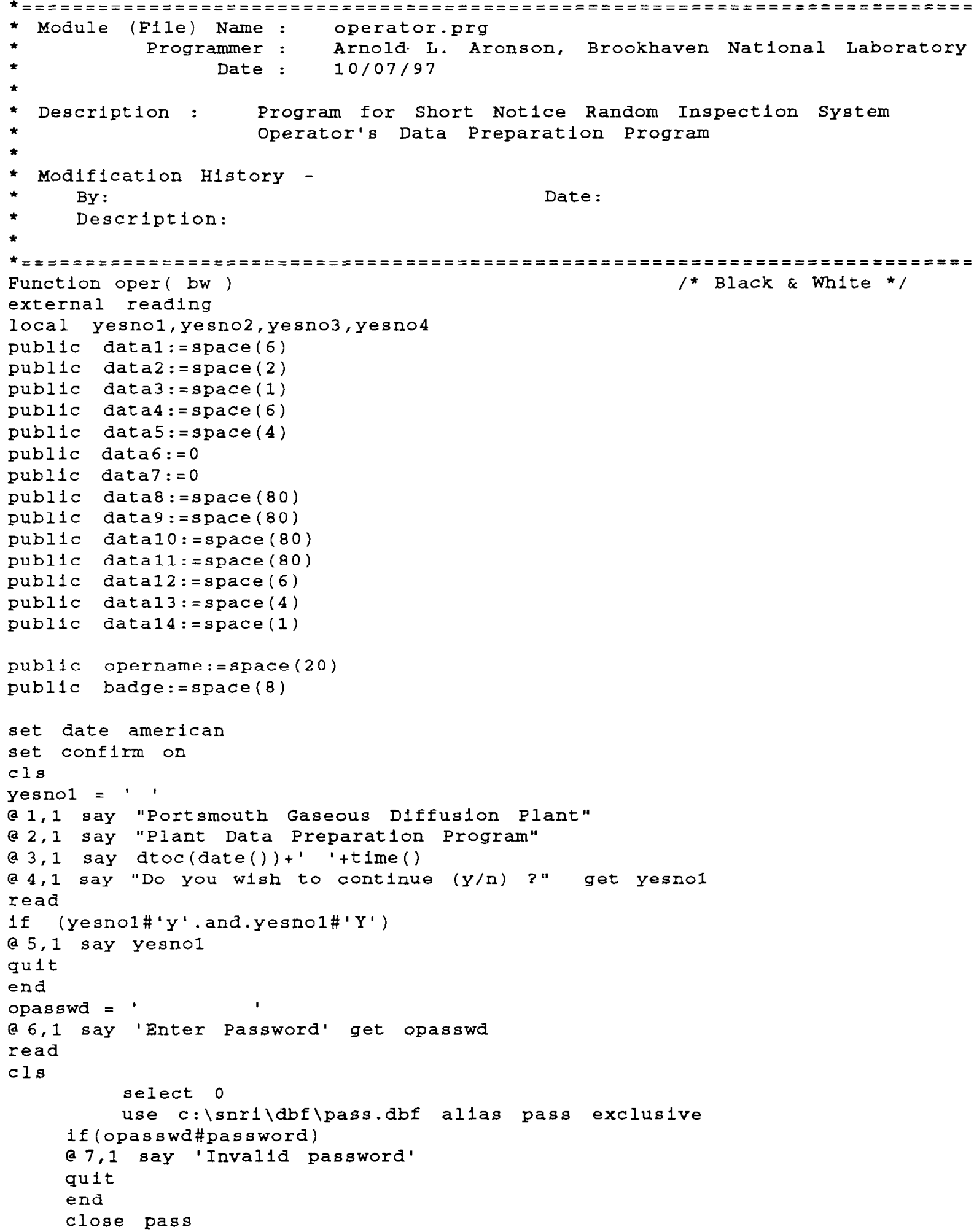




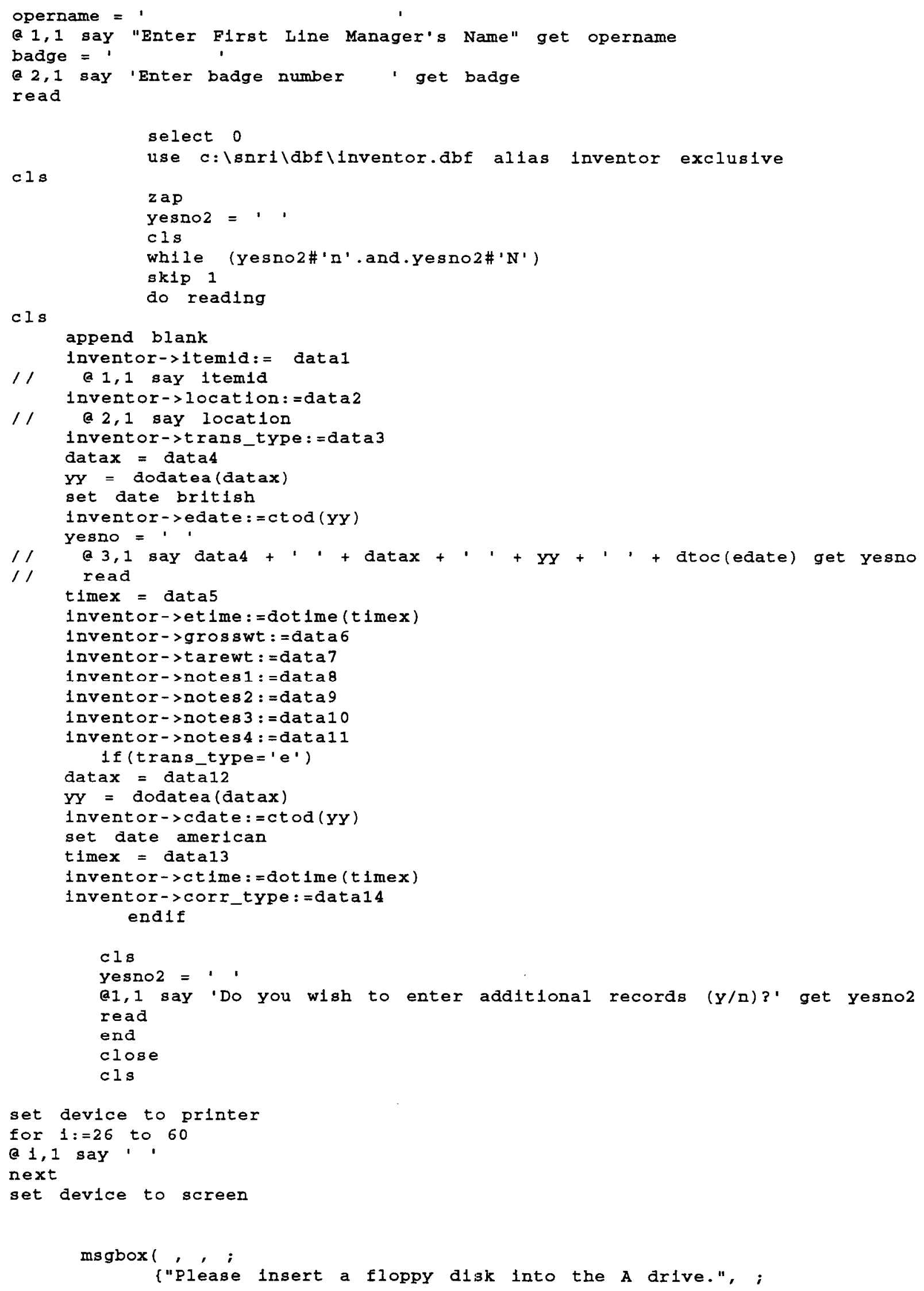




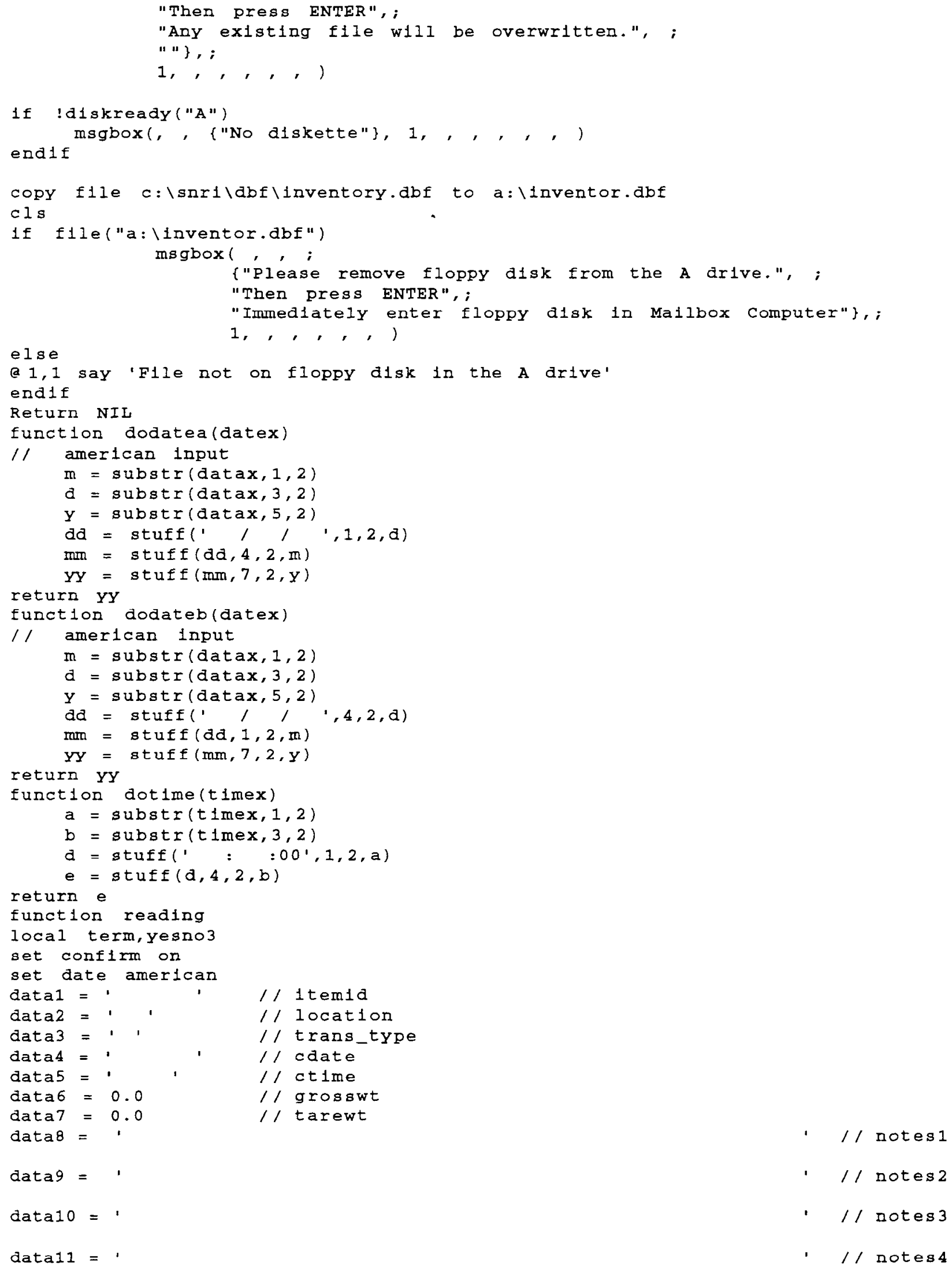




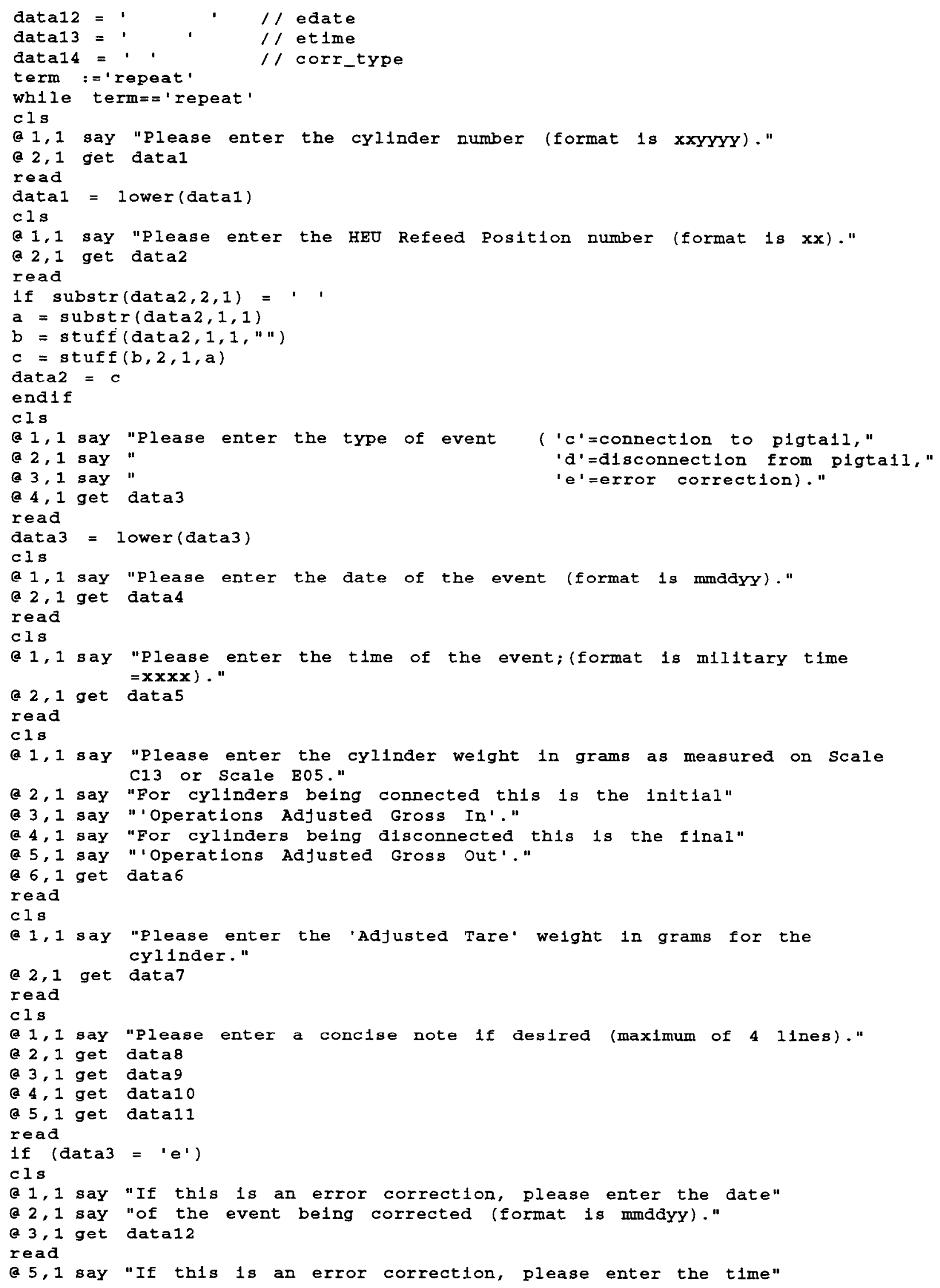




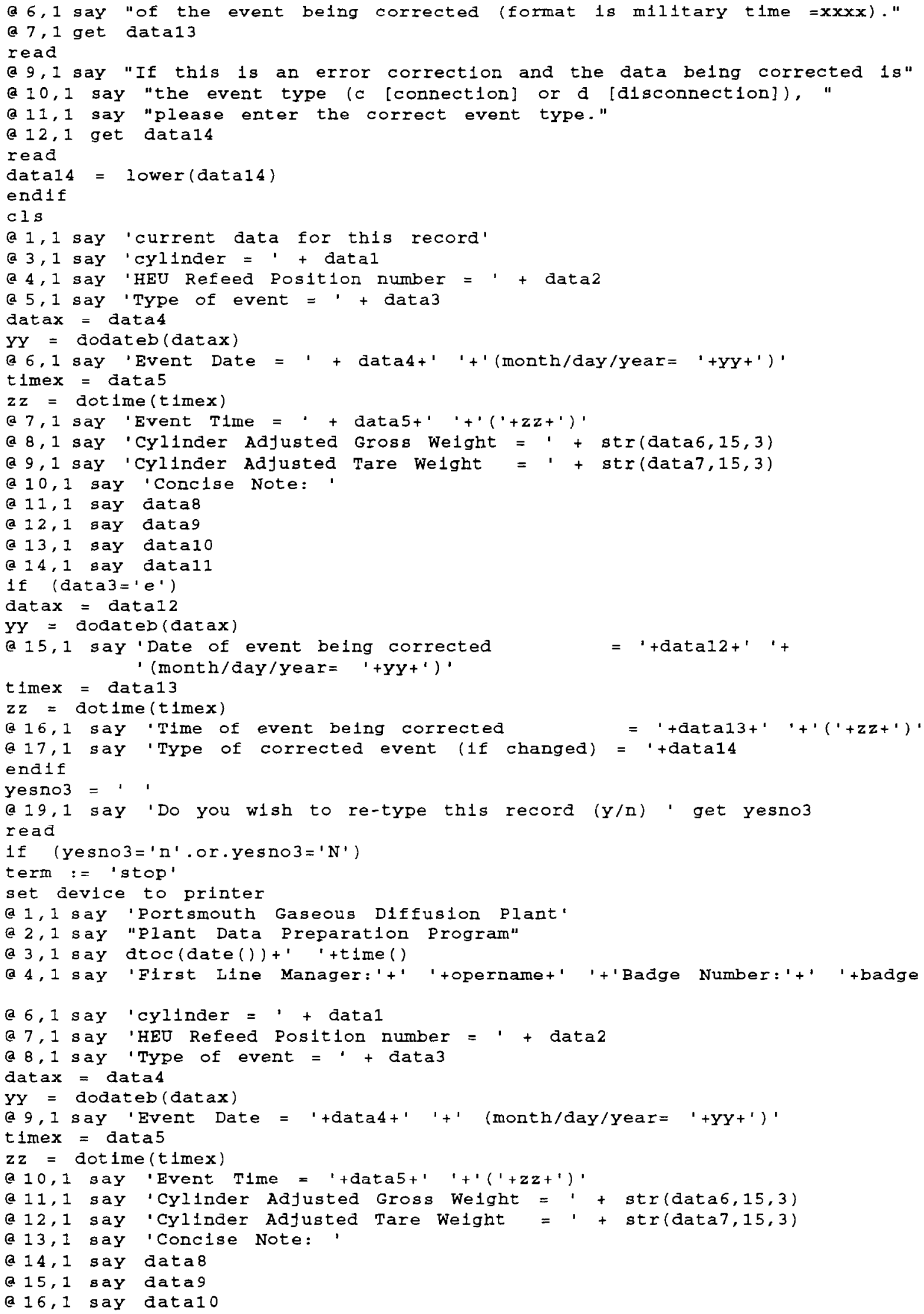




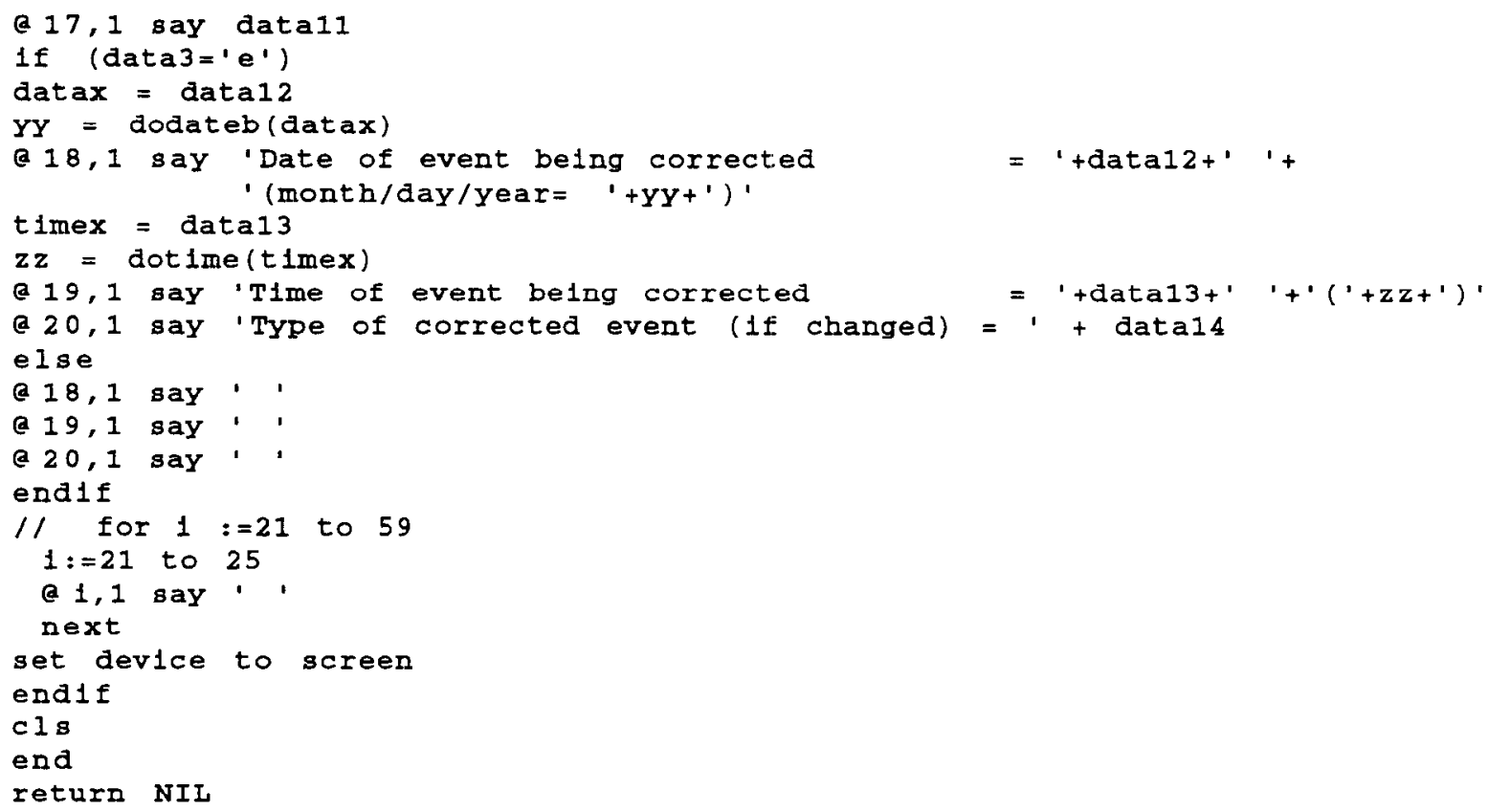




\section{Appendix G}

2) Listing of input data to the CLIPPER RMAKE Utility: file c: snrilsrcloperator plant.rmk

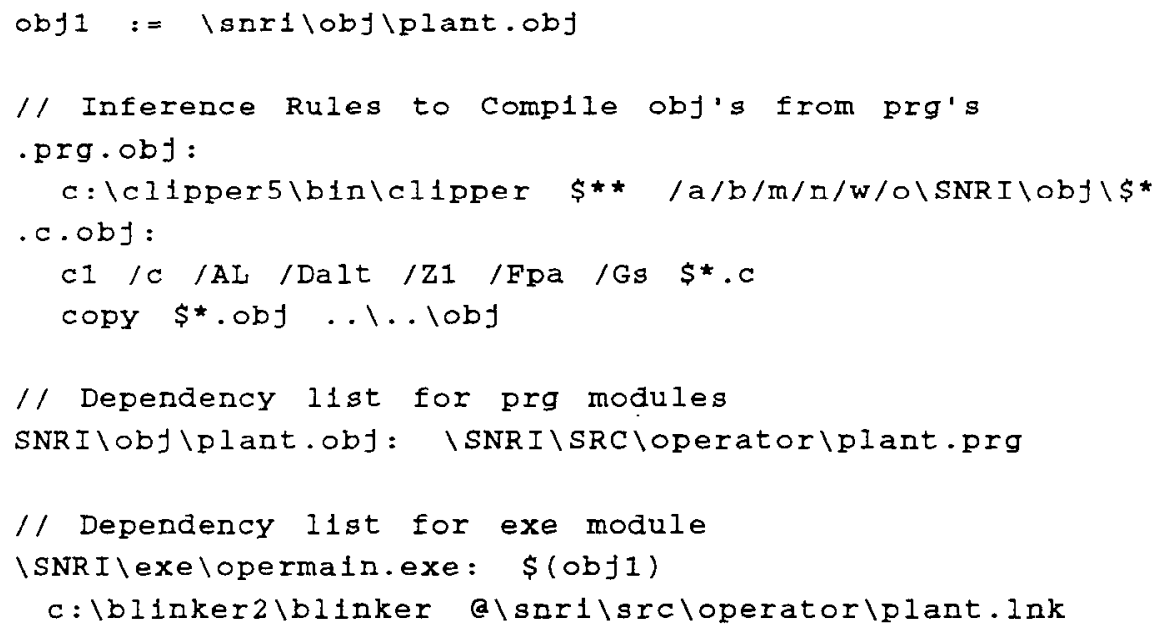

3) Listing of input to the BLINKER2 loader: file c: Isnrilsrchoperator plant.lnk

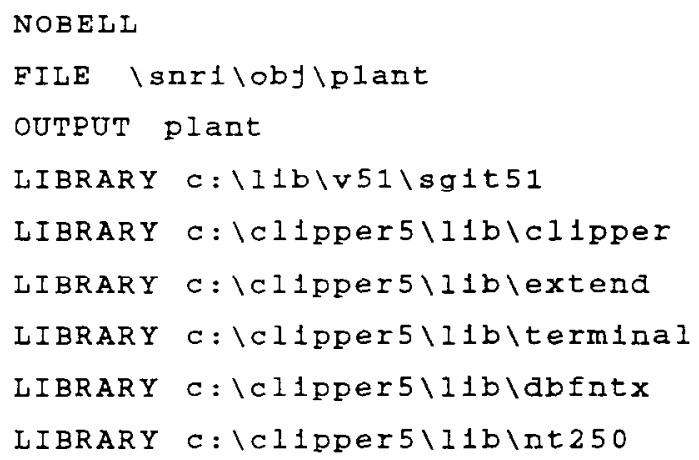

4) Batch file to execute the PLANT program:

file c: plant.bat 


\section{Appendix $\mathrm{H}$}

The FLM Supervisor's Password Program

1) CLIPPER5 source code for the PASSWORD program: file c: tsnritsrchoperatorypass.prg

2) Listing of input data to the CLIPPER RMAKE utility: file c: isnrilsrchoperator $p a s s . r m k$

3) Listing of input to the BLINKER2 loader:

file c: Isnrilsrchoperator'pass.lnk

4) Batch file to execute the PASSWORD program:

file c:pass.bat

5) Structure of the database file PASS.DBF:

file c: ssnrildbfyass.dbf 


\section{Appendix $\mathrm{H}$}

1) CLIPPER5 source code for the PASSWORD program:

file c:tsnritsrchoperator $p a s s . p r g$

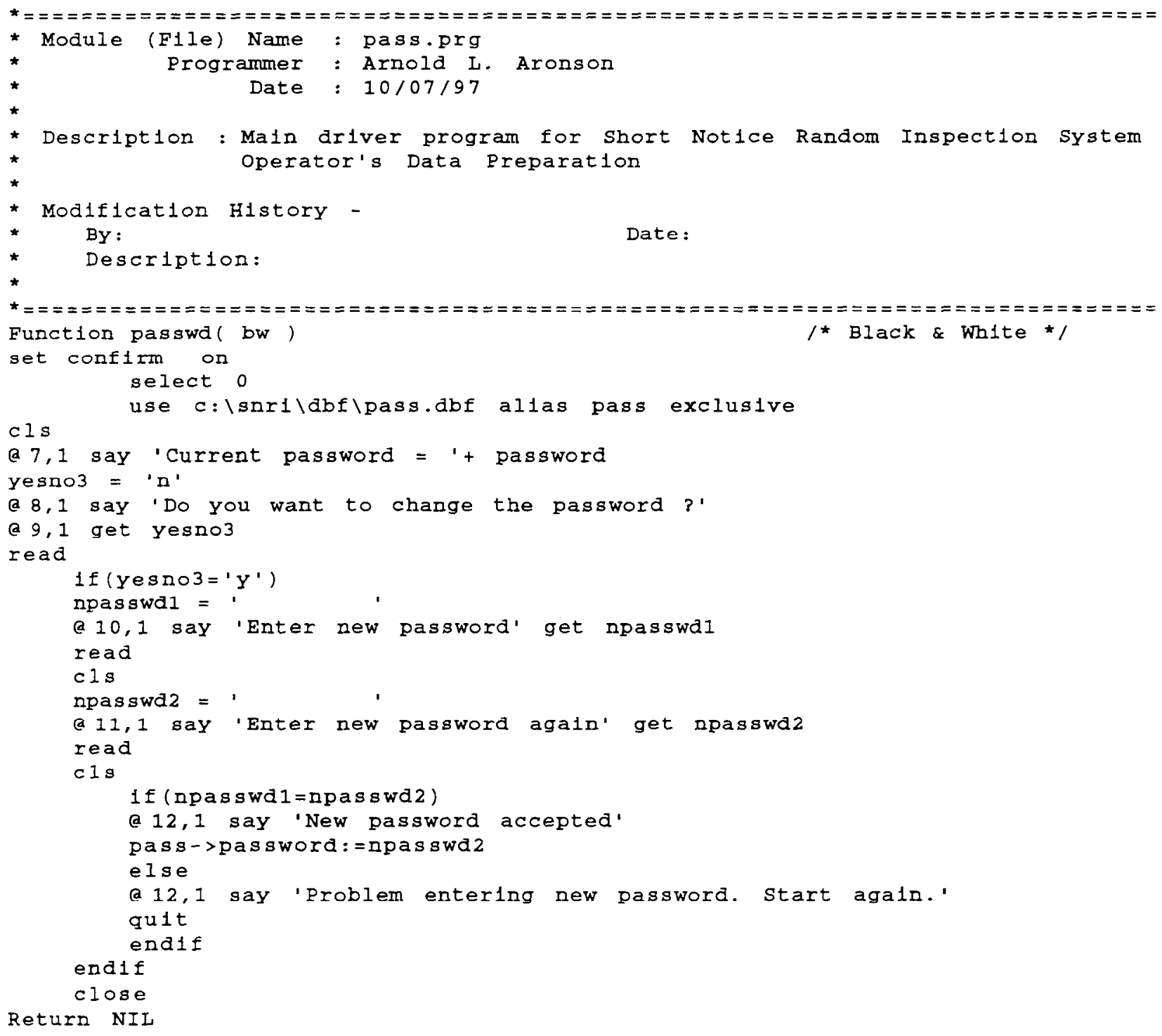




\section{Appendix $\mathrm{H}$}

2) Listing of input data to the CLIPPER RMAKE utility:

file c: Isnrilsrcberator pass.rmk

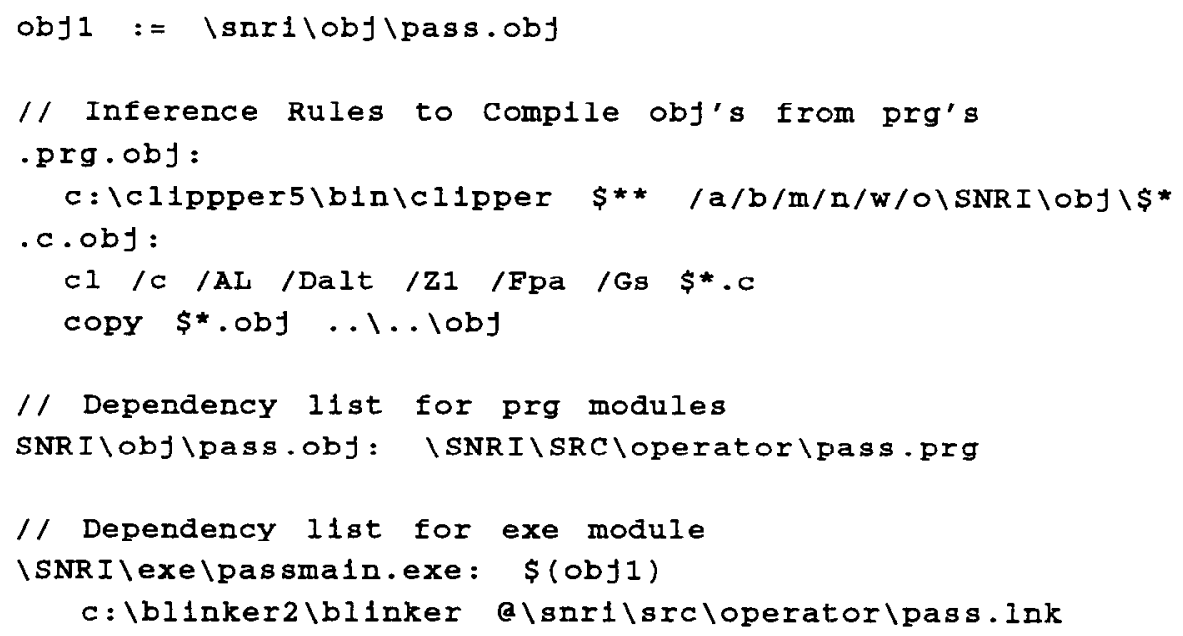

3) Listing of input to the BLINKER2 loader: file c: \snrissrcloperator $p a s s . l n k$

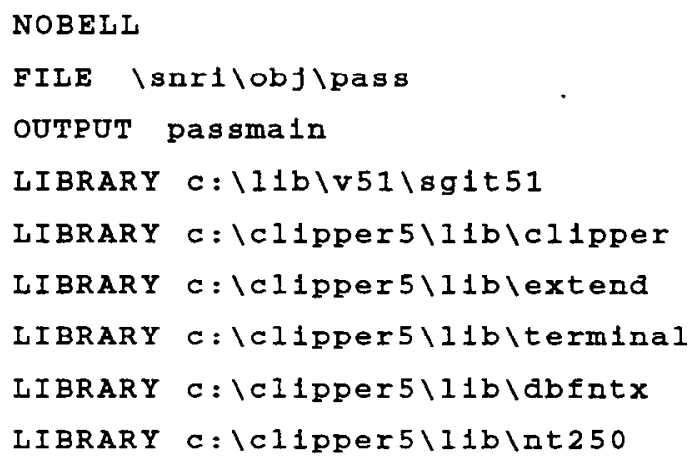




\section{Appendix $\mathrm{H}$}

4) Batch file to execute the PASSWORD program:

file c: pass.bat

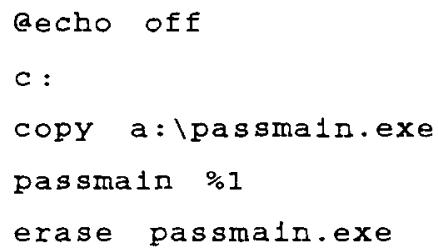

5) Structure of the database file PASS.DBF:

file c: tsnrildbfyass.dbf

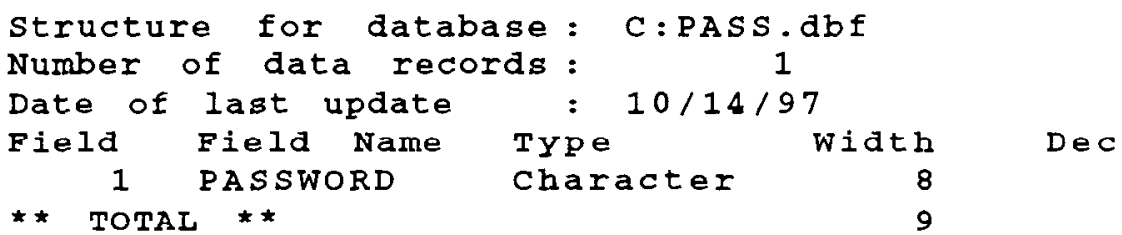




\section{Appendix I}

FLM Supervisor's Instructions for the Password Program

To see the current password for the plant data-entry program and/or change the password:

1. At the DOS prompt $(\mathrm{C}: \diamond)$, put the floppy diskette labeled "supervisor" into the " $\mathrm{A}$ " drive.

2. Type in the word "Pass" and press [ENTER]. Be patient!

3. Follow the instructions on the screen.

4. At the DOS prompt $(C: \supset)$, remove the floppy diskette from the "A" drive. 
(THIS PAGE INTENTIONALLY LEFT BLANK) 


\section{Appendix J}

The AUTOEXEC.BAT File for the "Mailbox" Computer

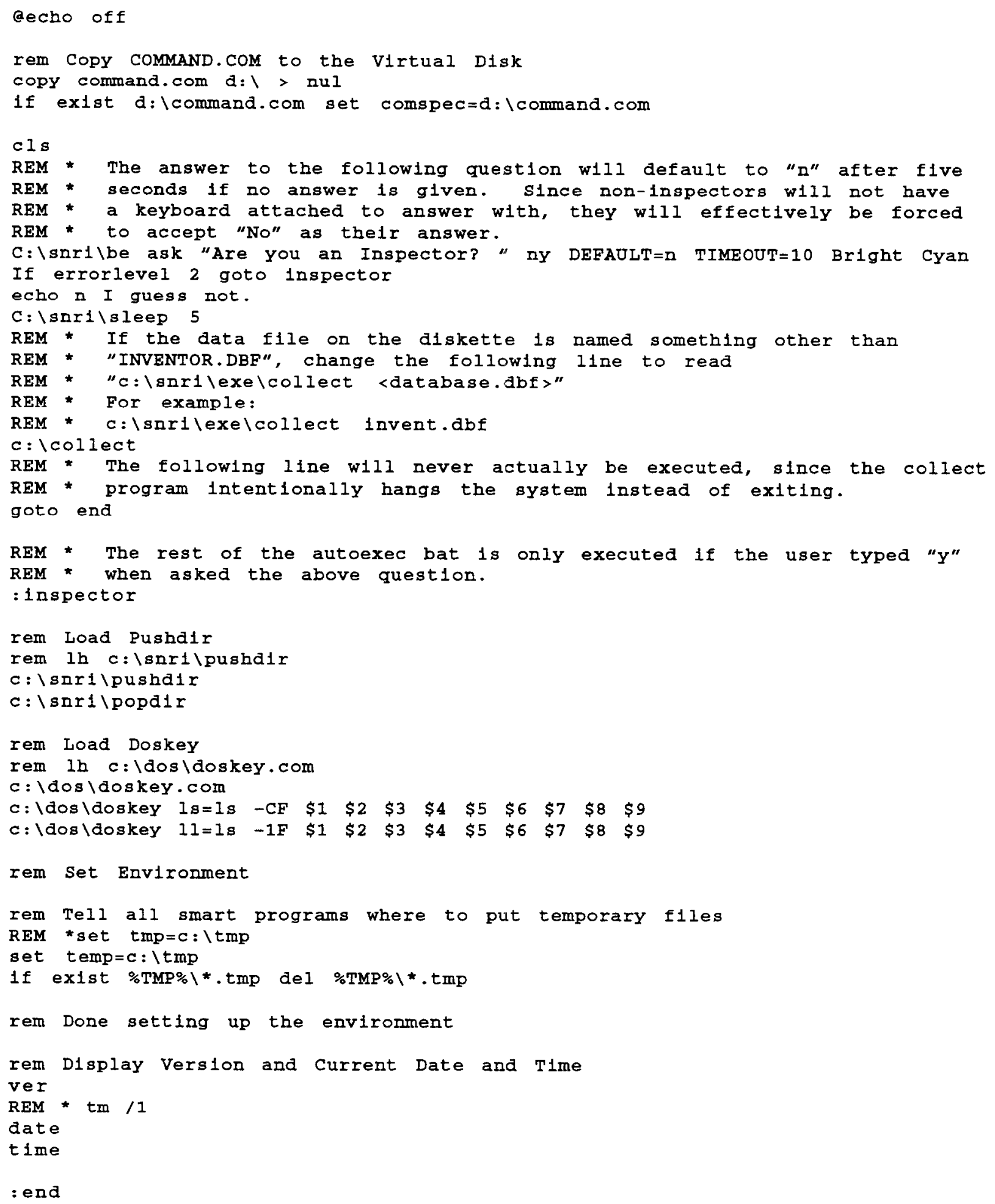


(THIS PAGE INTENTIONALLY LEFT BLANK) 


\section{Appendix K}

"Mailbox" Software to Collect the Plant Operator's Declaration

1) C-language source code programs file c: snrilsrchollectlcollect.c file c: Isnritsrchollectlcoma.c file c:Isnrilsrclcollectldbf_util.c file c: Isnrilsrclcollectfstruct.c file c:tsnnilsrckollecthharderr.c

2) Header file snri.h:

file c: isnritsrchollectsnri.h

3) Source code for the CLIPPER5 program APPEND.PRG:

file c: Isnrilsrclappend lappends.prg

4) Instructions to compile APPEND.PRG:

file c: Isnrilsrclappend lappends.bat

5 Input to the BLINKER2 loader for APPEND.PRG: file c: Isnrilsrclappend lappends.lnk 


\section{Appendix $\mathrm{K}$}

1) C-language source code programs

file c: \snritsrclcollectlcollect.c

file c: isnritsrclcollectlcoma.c

file c: snriłsrclcollectldbf_util.c

file c: Isnriisrclcollect fstruct.c

file c: Isnri\srclcollectharderr.c

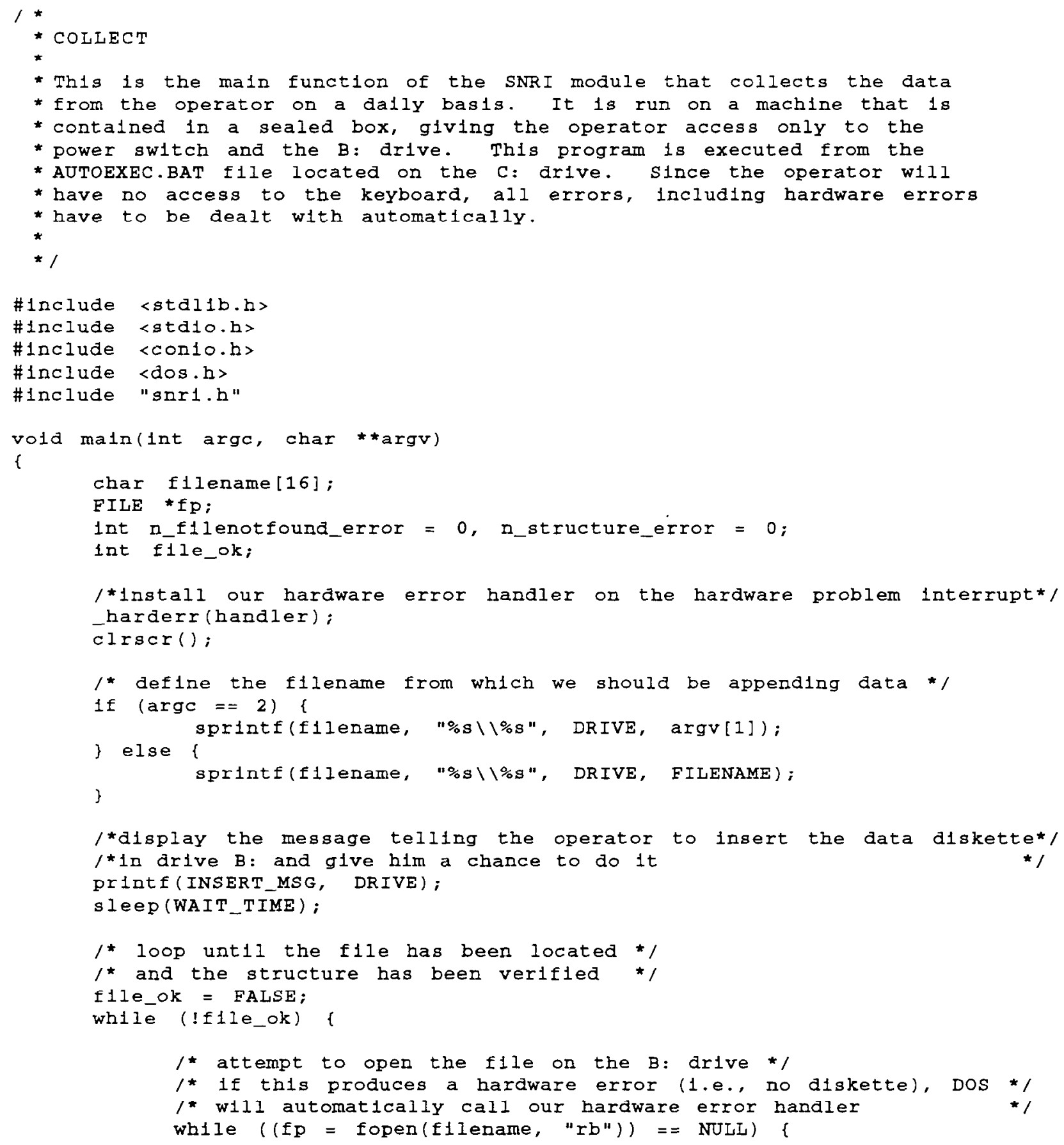




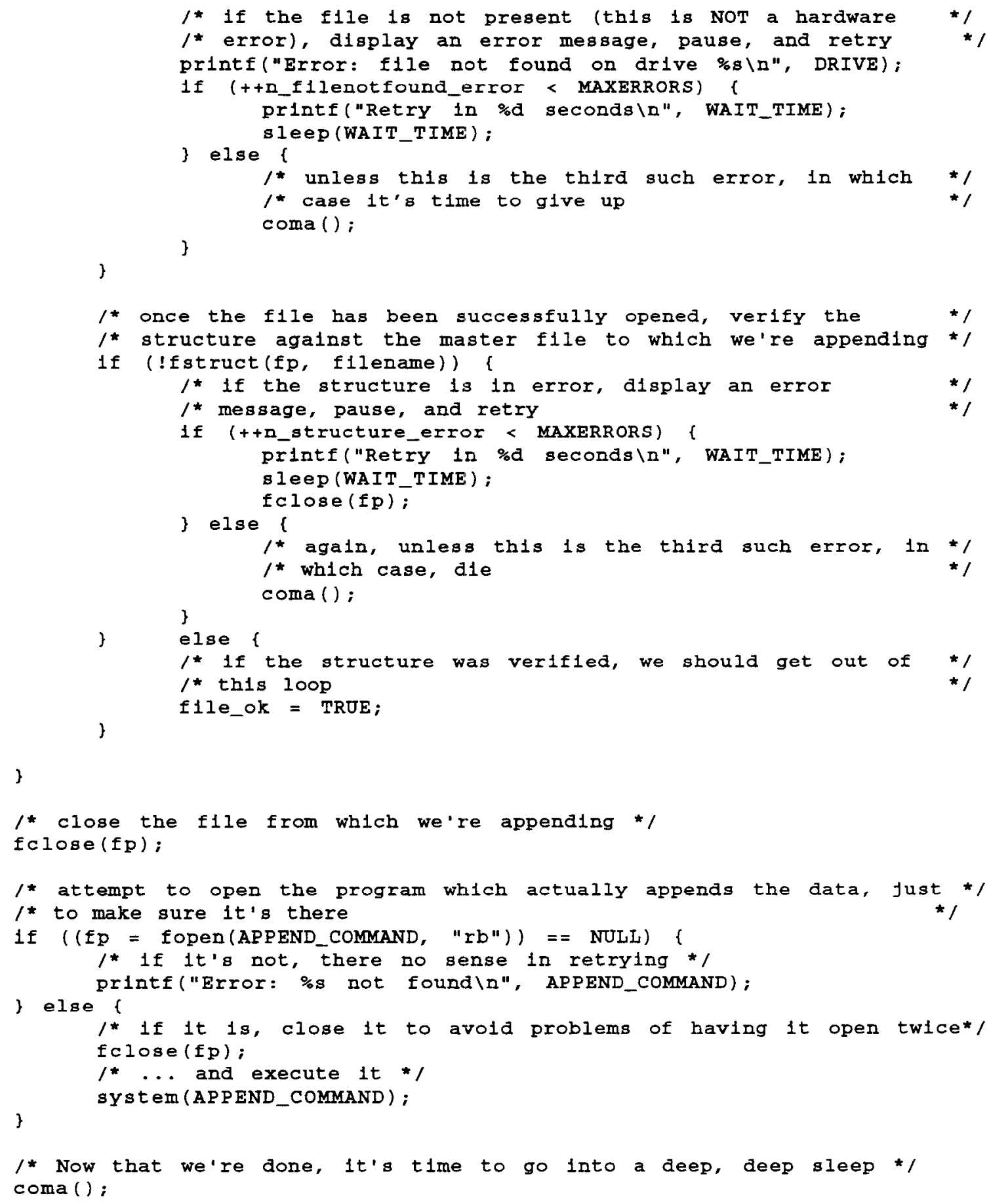




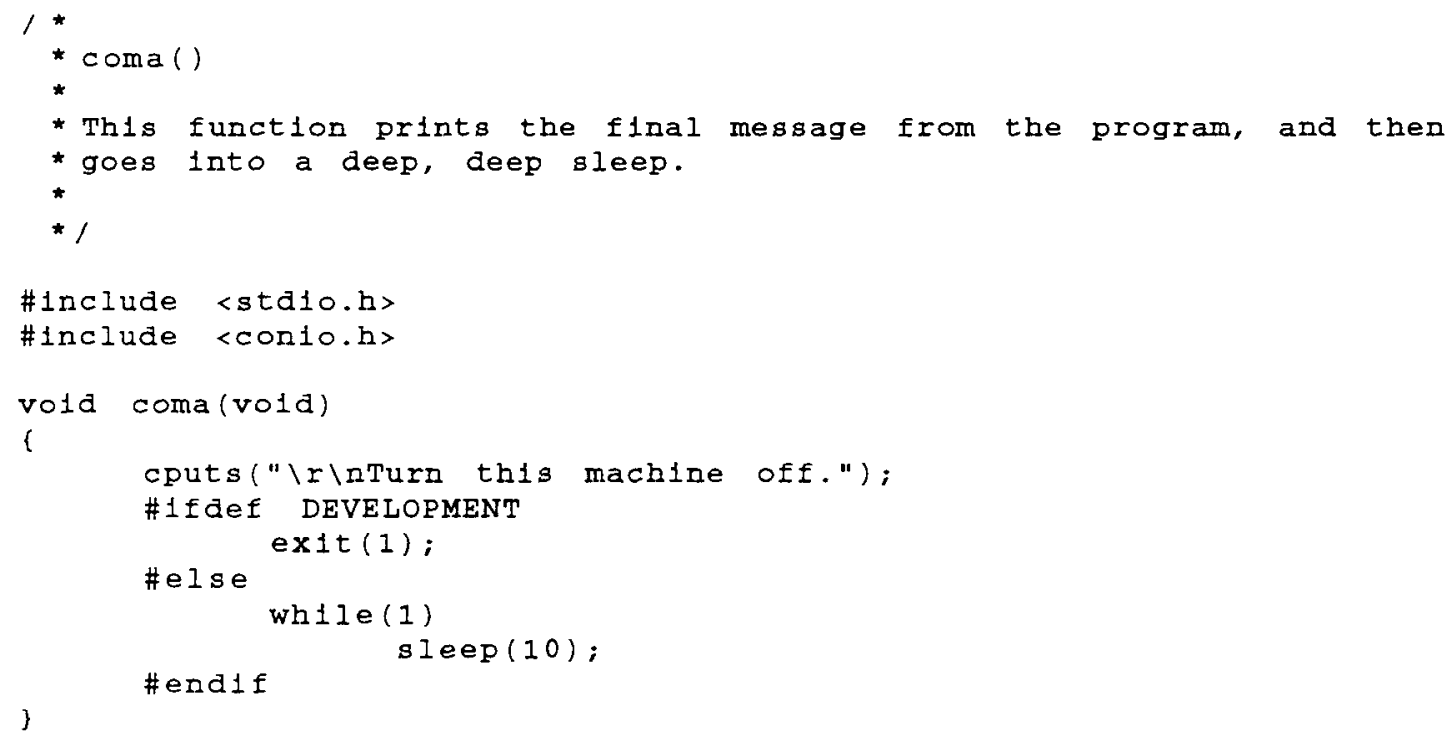




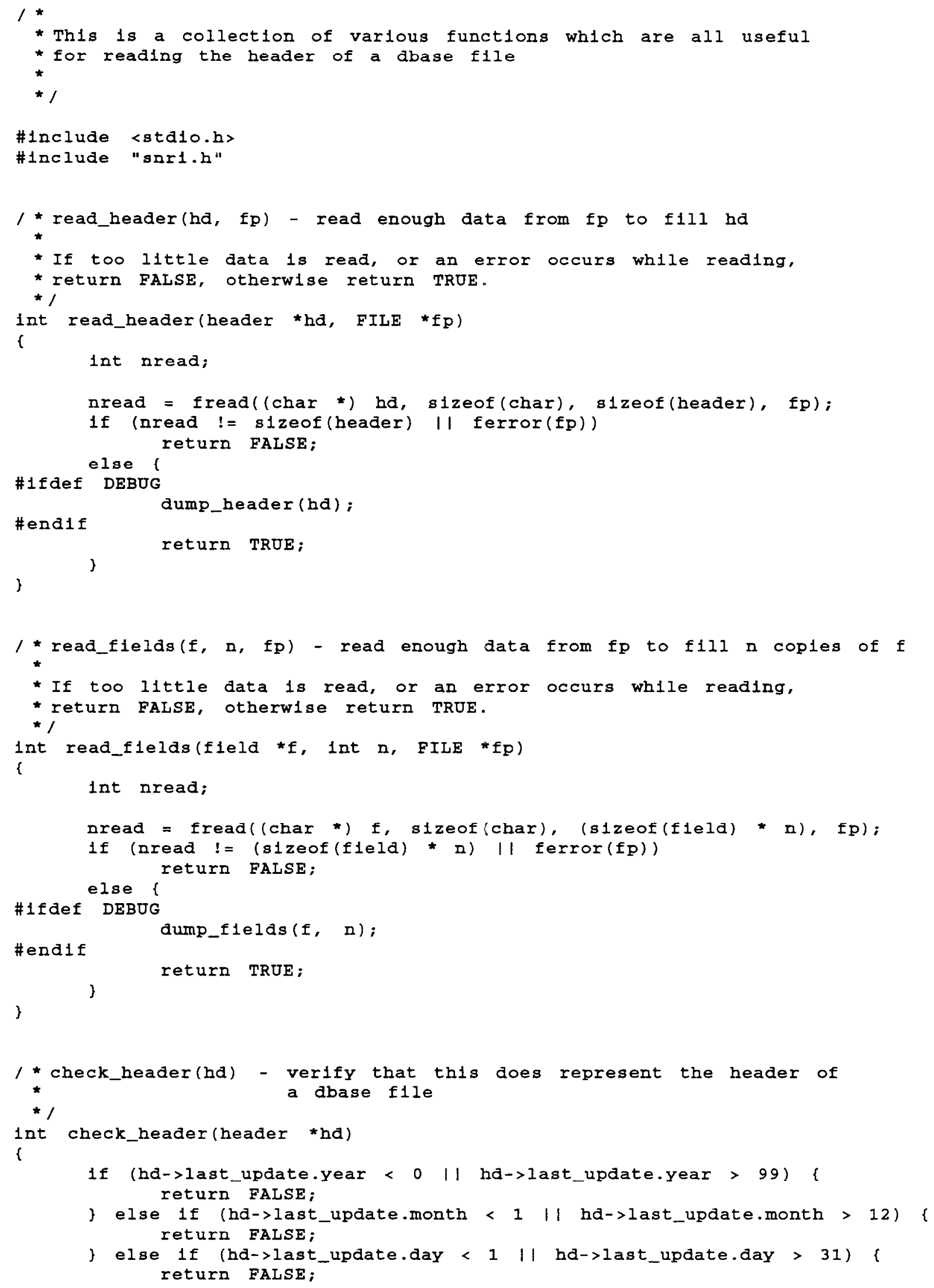




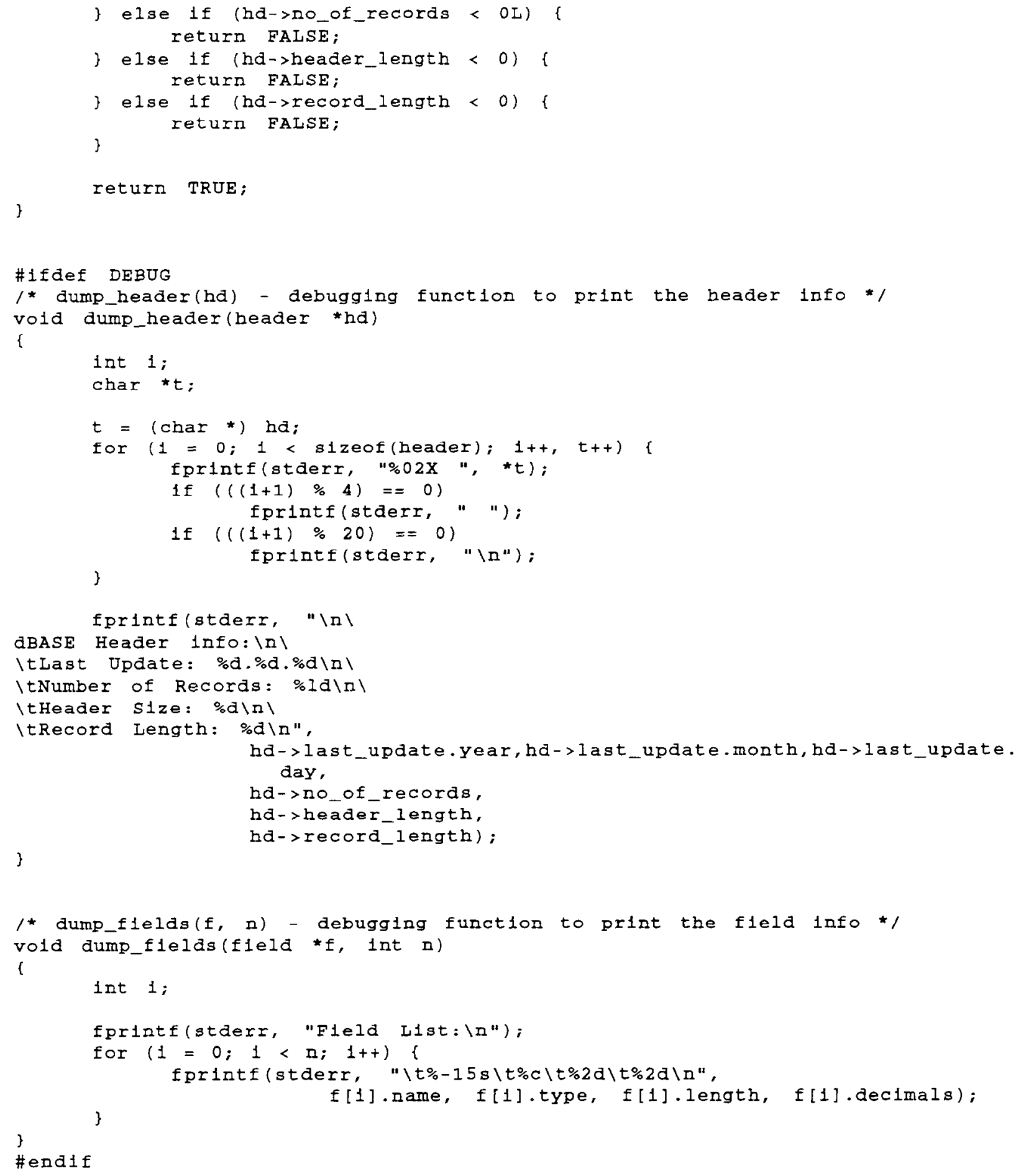




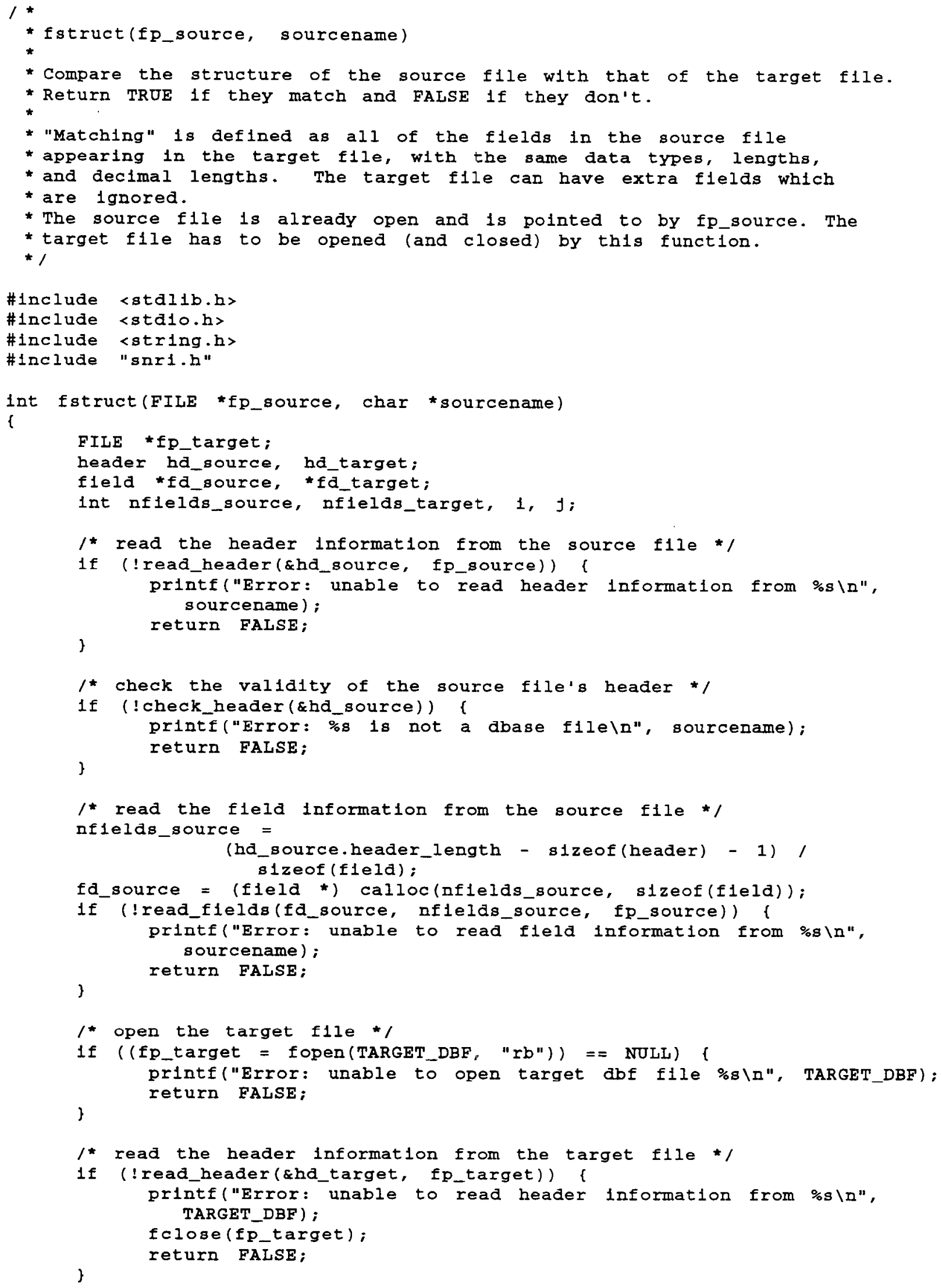




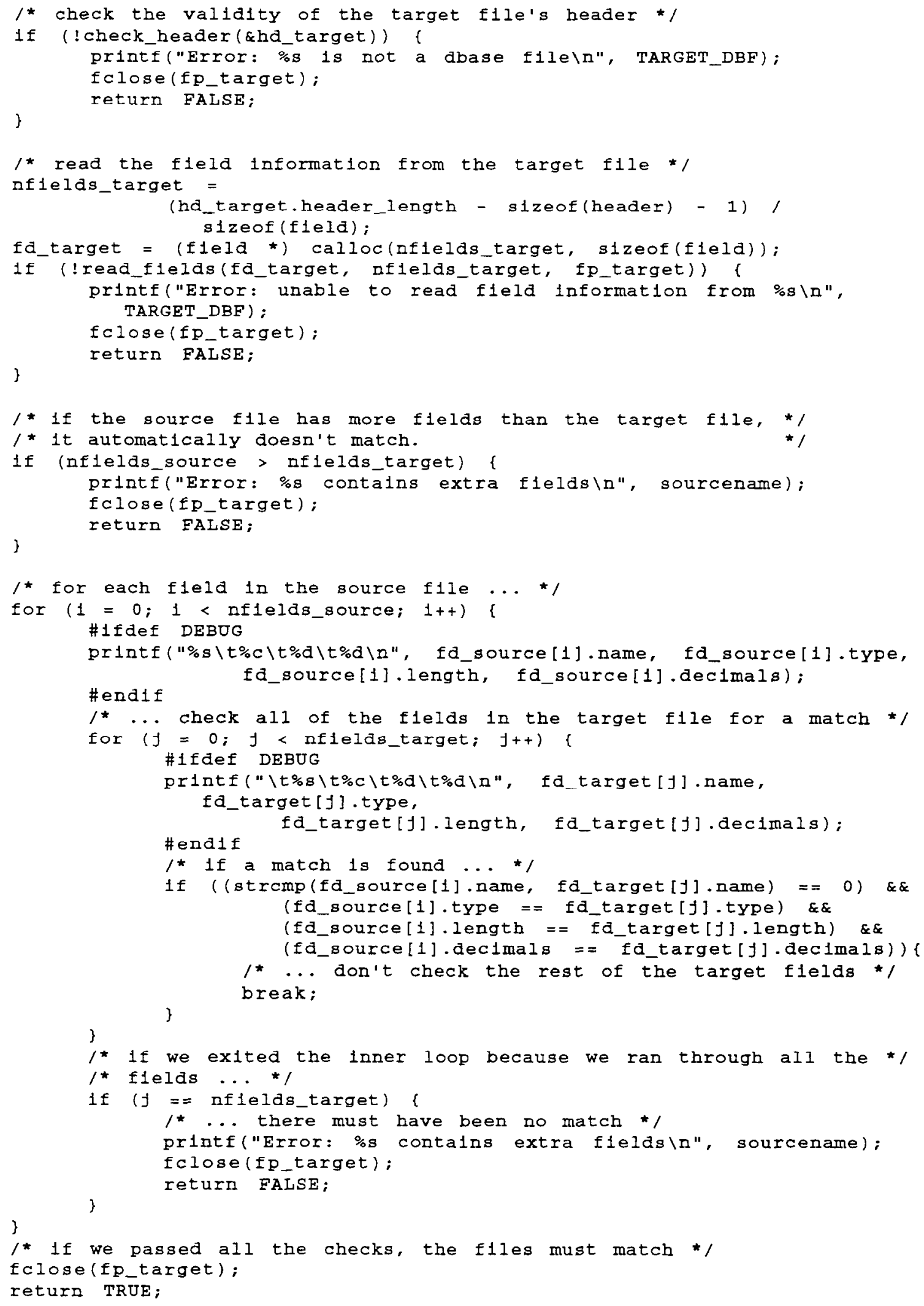




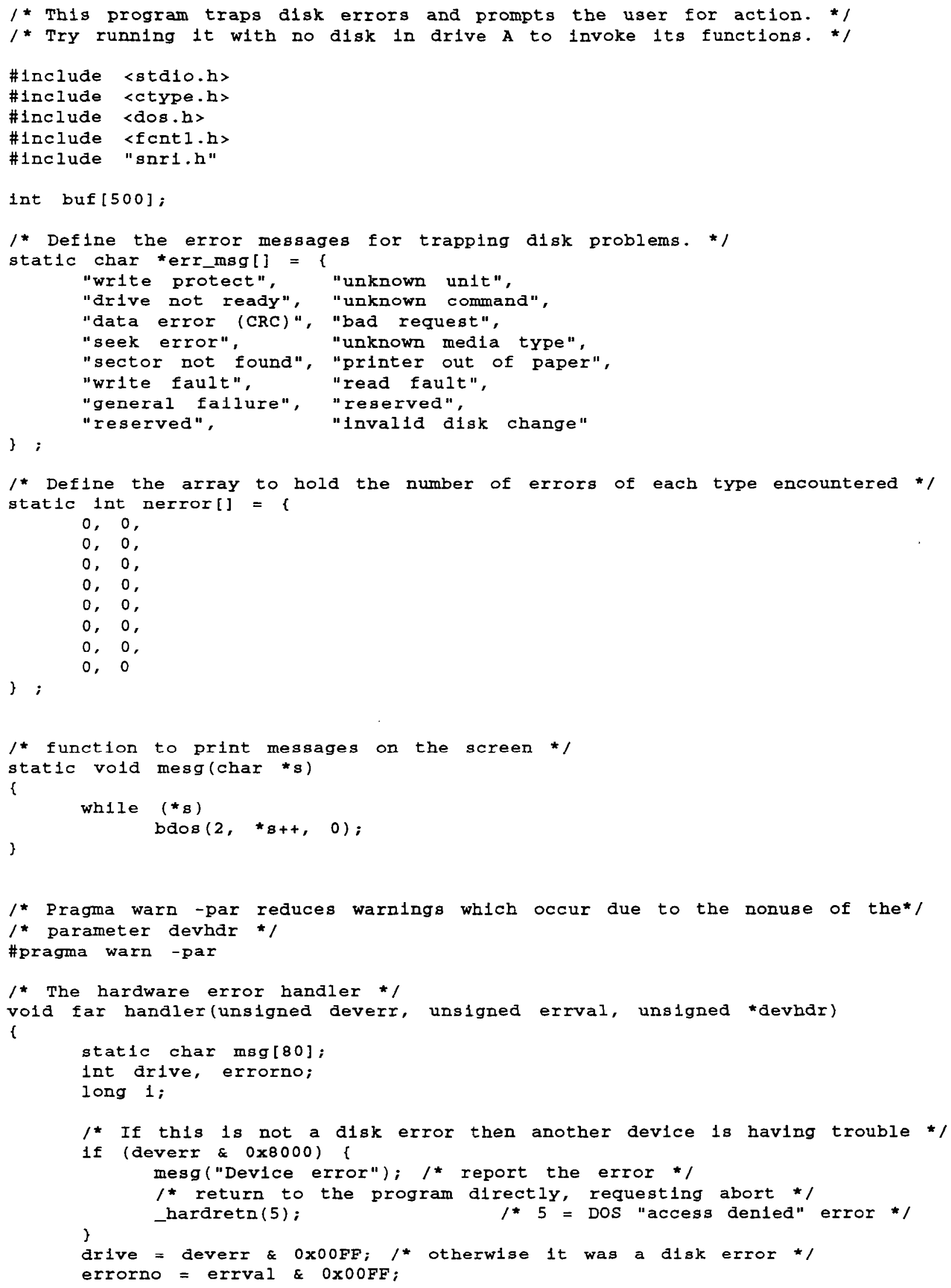




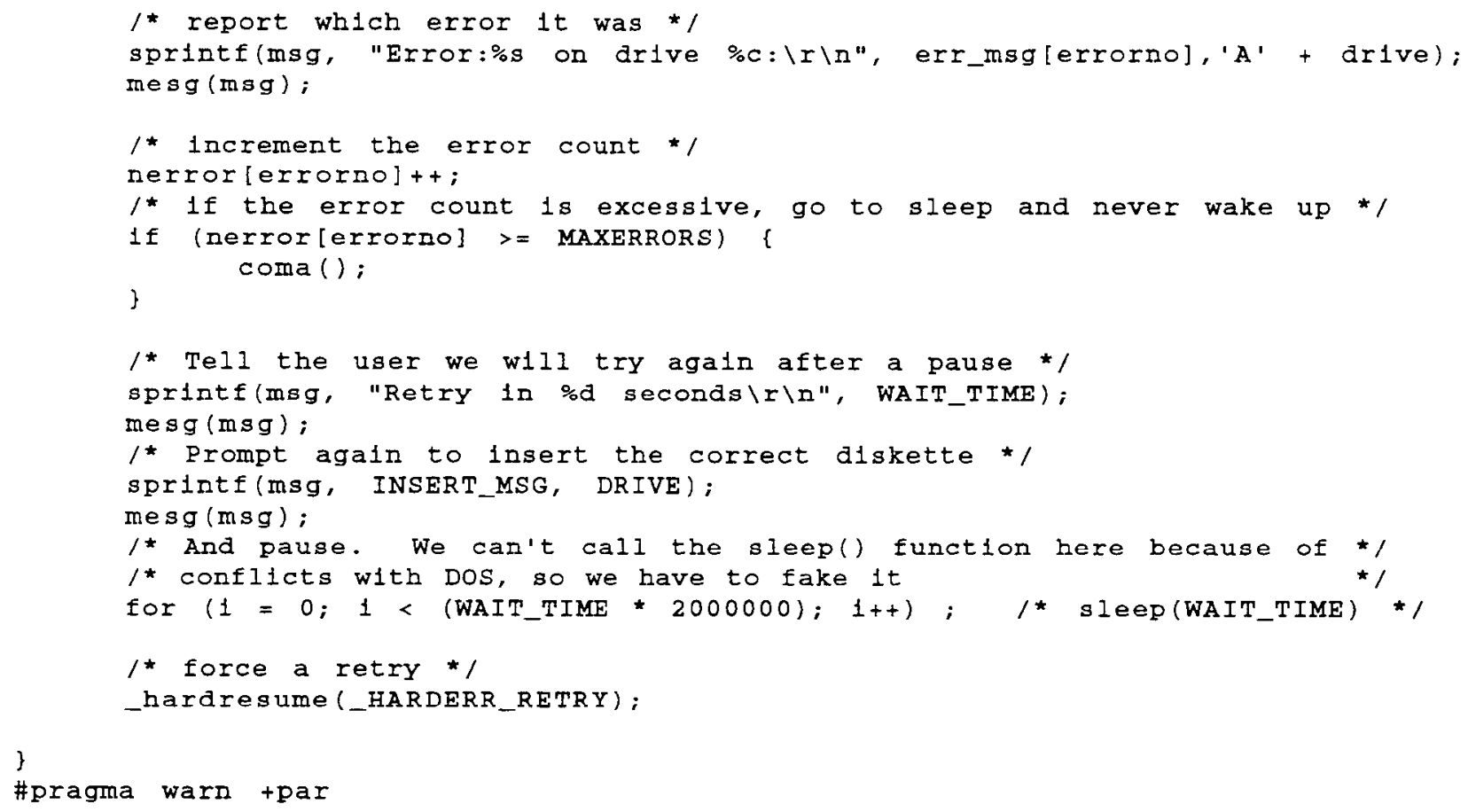




\section{Appendix K}

2) Header file snri.h

file c: isnrilsrclcollectssnri.h

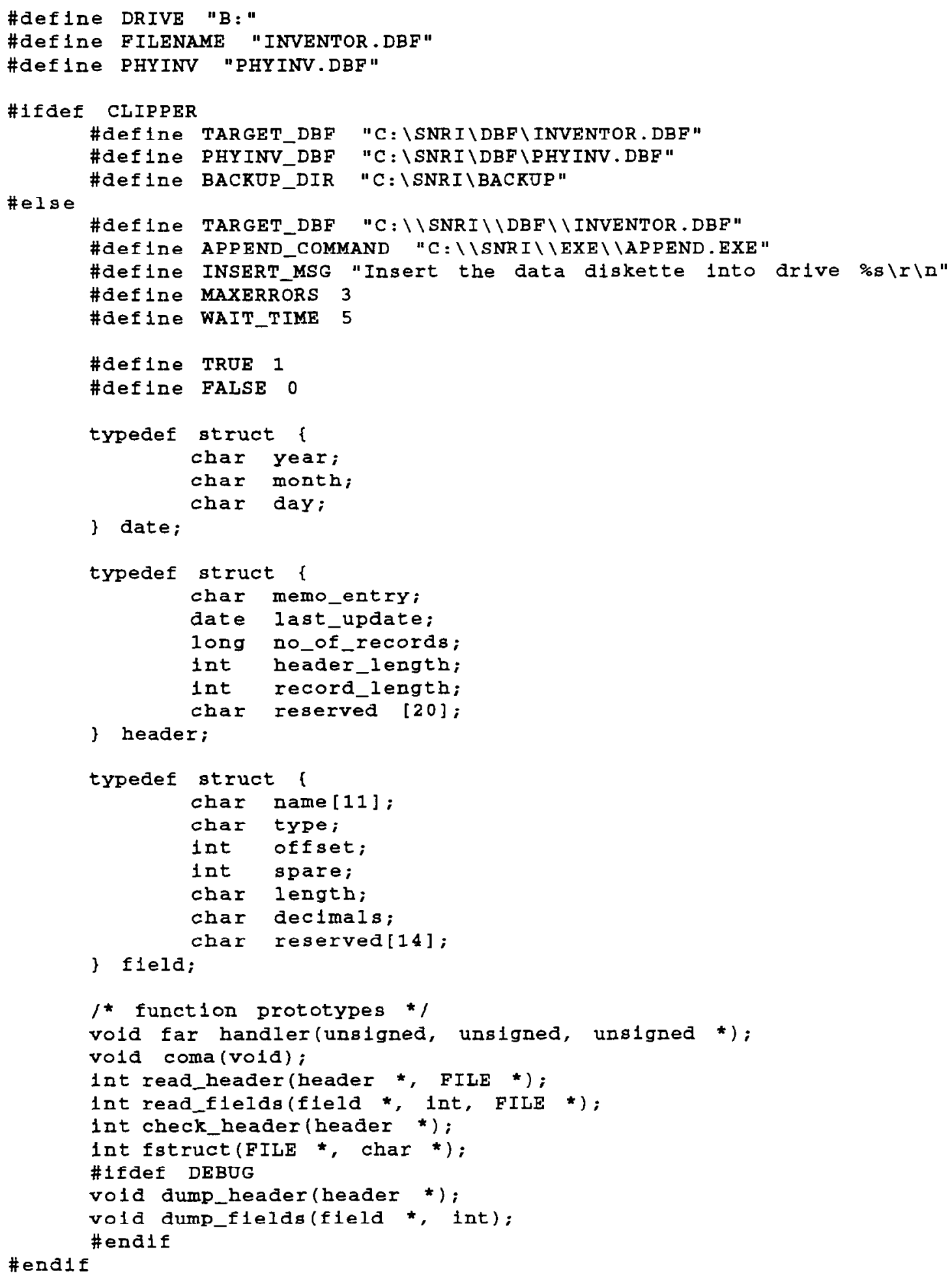




\section{Appendix K}

3) Source code for the CLIPPER5 program APPEND.PRG:

file c:tsnrilsrclappend lappends.prg

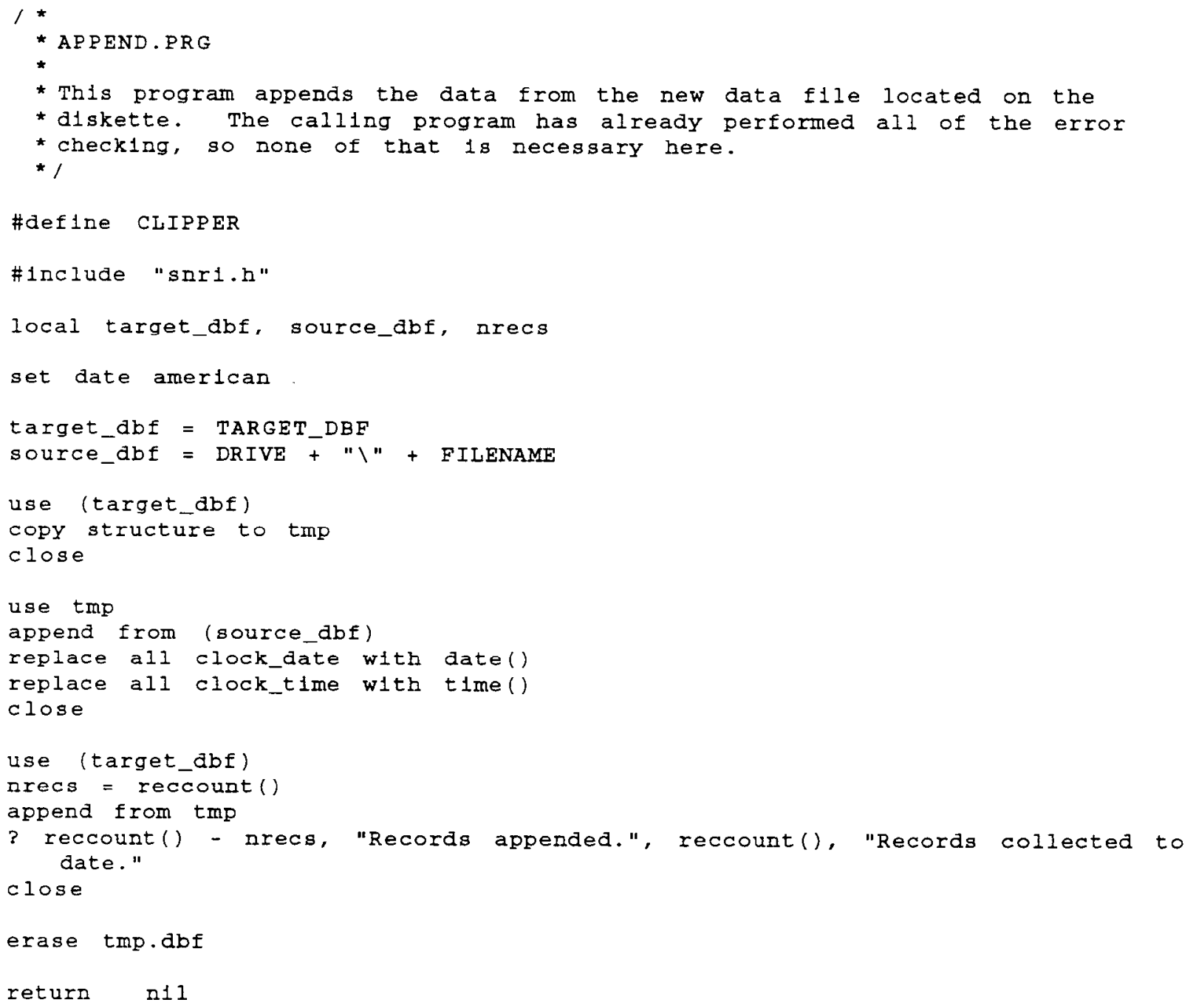




\section{Appendix K}

4) Instructions to compile APPEND.PRG:

file c: Isnritsrclappend happends.bat

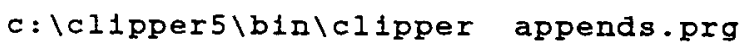

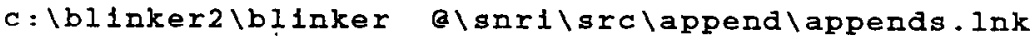

5) Input to the BLINKER2 loader for APPEND.PRG:

file c: Isnrilsrclappend lappends.lnk

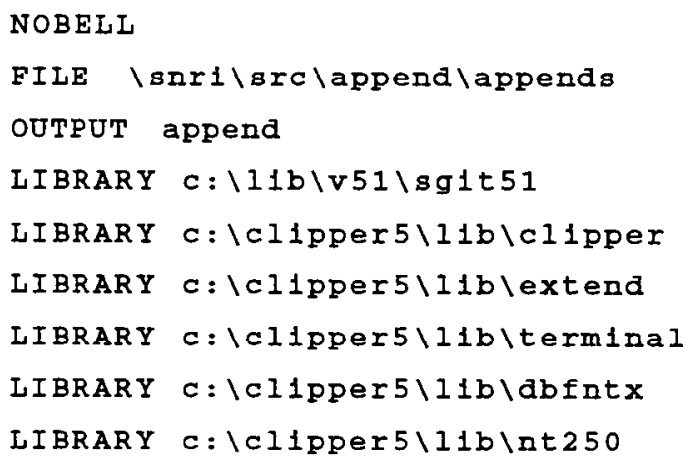


(THIS PAGE INTENTIONALLY LEFT BLANK)

$\mathrm{K}-14$ 


\title{
Appendix L
}

Batch File to Download the Plant Operator's Declaration from the "Mailbox" Computer to the IAEA Representative's Floppy Diskette

\author{
file c: Isnriłsrcldownload $d$ download.bat
}

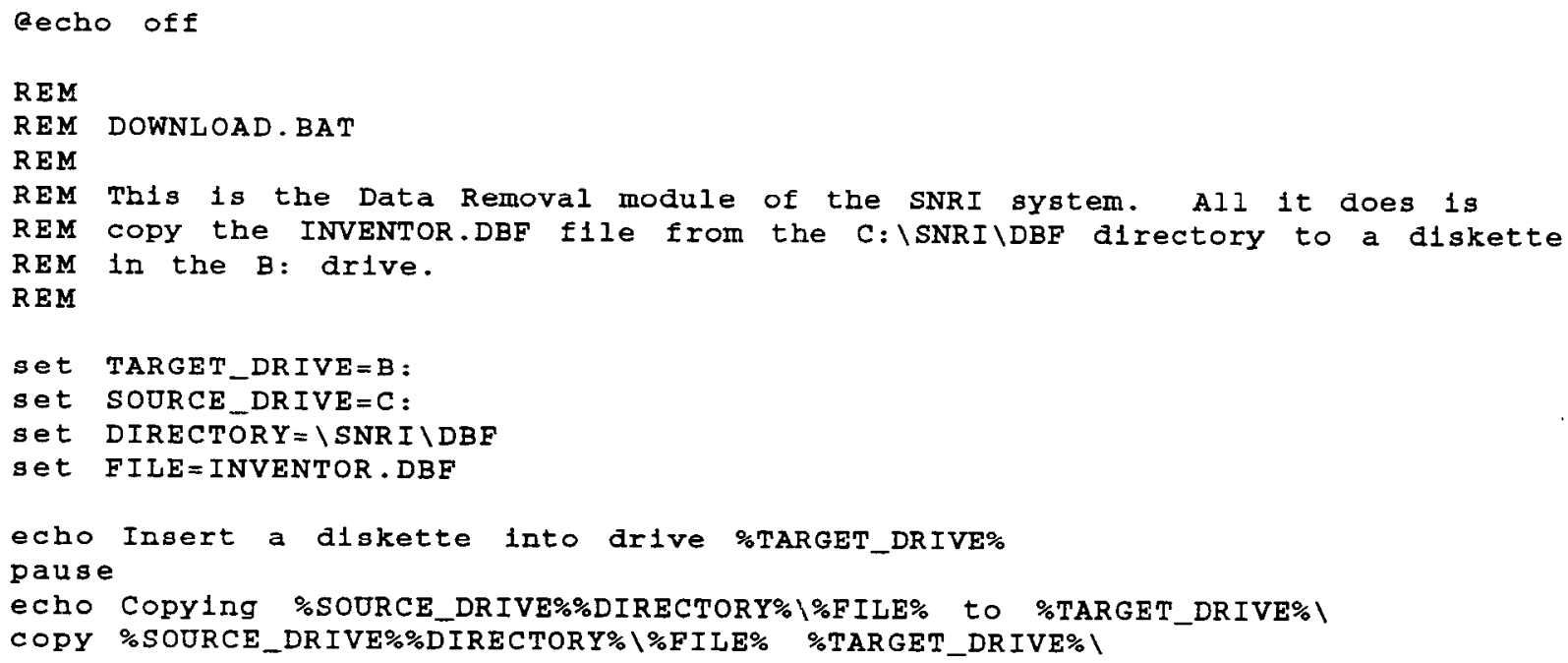


(THIS PAGE INTENTIONALLY LEFT BLANK) 


\section{Appendix M}

The RESET Program to Reset the "Mailbox"

1) CLIPPER5 source code for program RESET.PRG:

file c:Isnrilsrctresethreset.prg

2) Instructions to compile RESET.PRG:

file c:Isnrilsrclresettreset.bat

3) Input to the BLINKER2 loader for RESET.PRG:

file c:Isnrilsrctresettreset.Ink 


\section{Appendix M}

1) CLIPPER5 source code for program RESET.PRG:

file c: Isnrilsrclresetvreset.prg

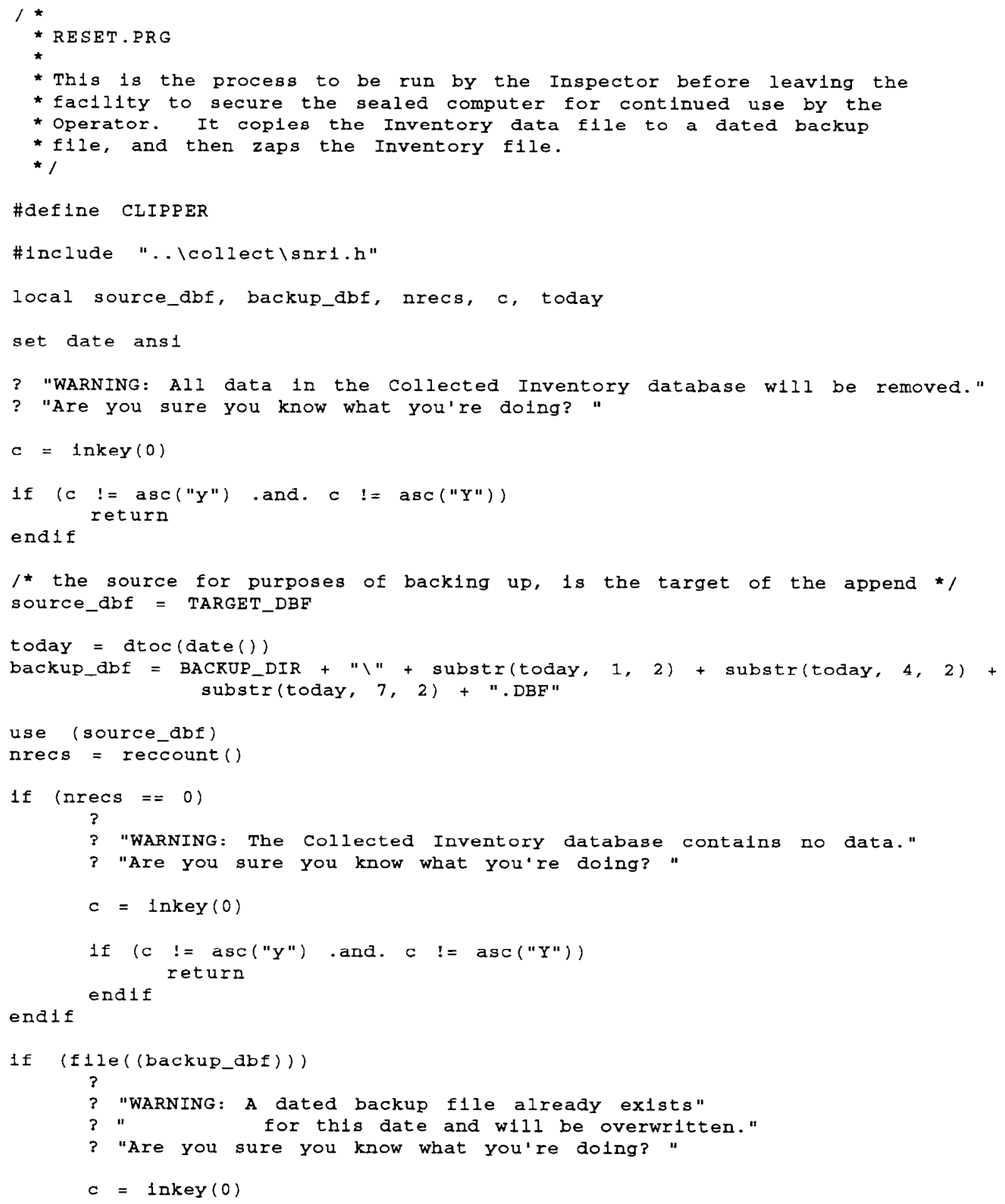




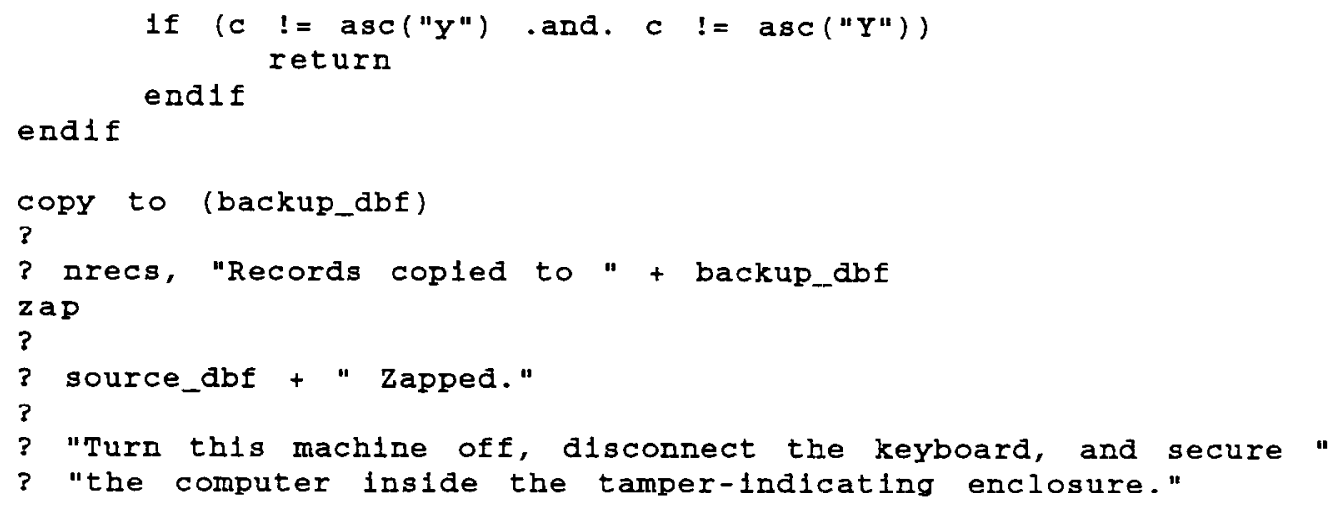




\section{Appendix M}

2) Instructions to compile RESET.PRG:

file c: Isnrilsrctresetvreset.bat

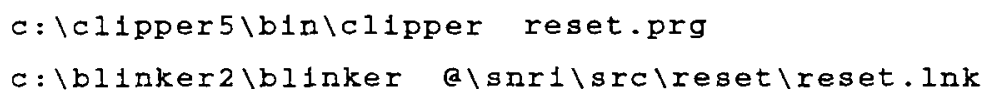

3) Input to the BLINKER2 loader for RESET.PRG:

file c: Isnrilsrcłeset treset.lnk

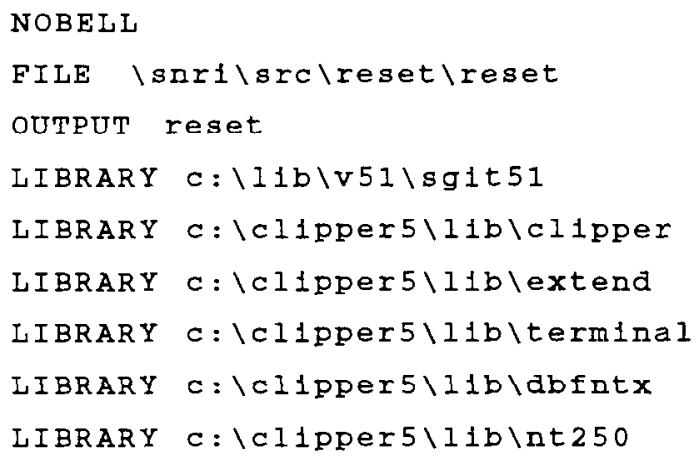


Programs to Incorporate the Plant Operator's Declarations

of

Purity (Uranium Weight Percent) and Assay (U-235 Weight Percent)

1) CLIPPER5 source code for program DECLARE1.PRG:

file c: Isnrilsrc preproldeclare1.prg

2) Instructions to the CLIPPER5 RMAKE utility to compile DECLARE1.PRG:

file c:Isnrilsrc \preproldecl1.rmk

3) Input to the BLINKER2 loader for DECLARE1.PRG:

file c: Isnrilsrc preprołdecl1.lnk

4) The batch file to execute DECL1MN.EXE:

file c: Isnritsrc preprolaccount.bat

5) Structure of the database file ACCOUNT.DBF:

file c: Isnrildbflaccount.dbf

6) Structure of the database file DECLARE.DBF:

file c: Isnrildbfideclare.dbf 


\section{Appendix $\mathrm{N}$}

\section{1) CLIPPER5 source code for program DECLARE1.PRG \\ file c: $s n r i l s r c \nmid p r e p r o l d e c l a r e 1 . p r g$}

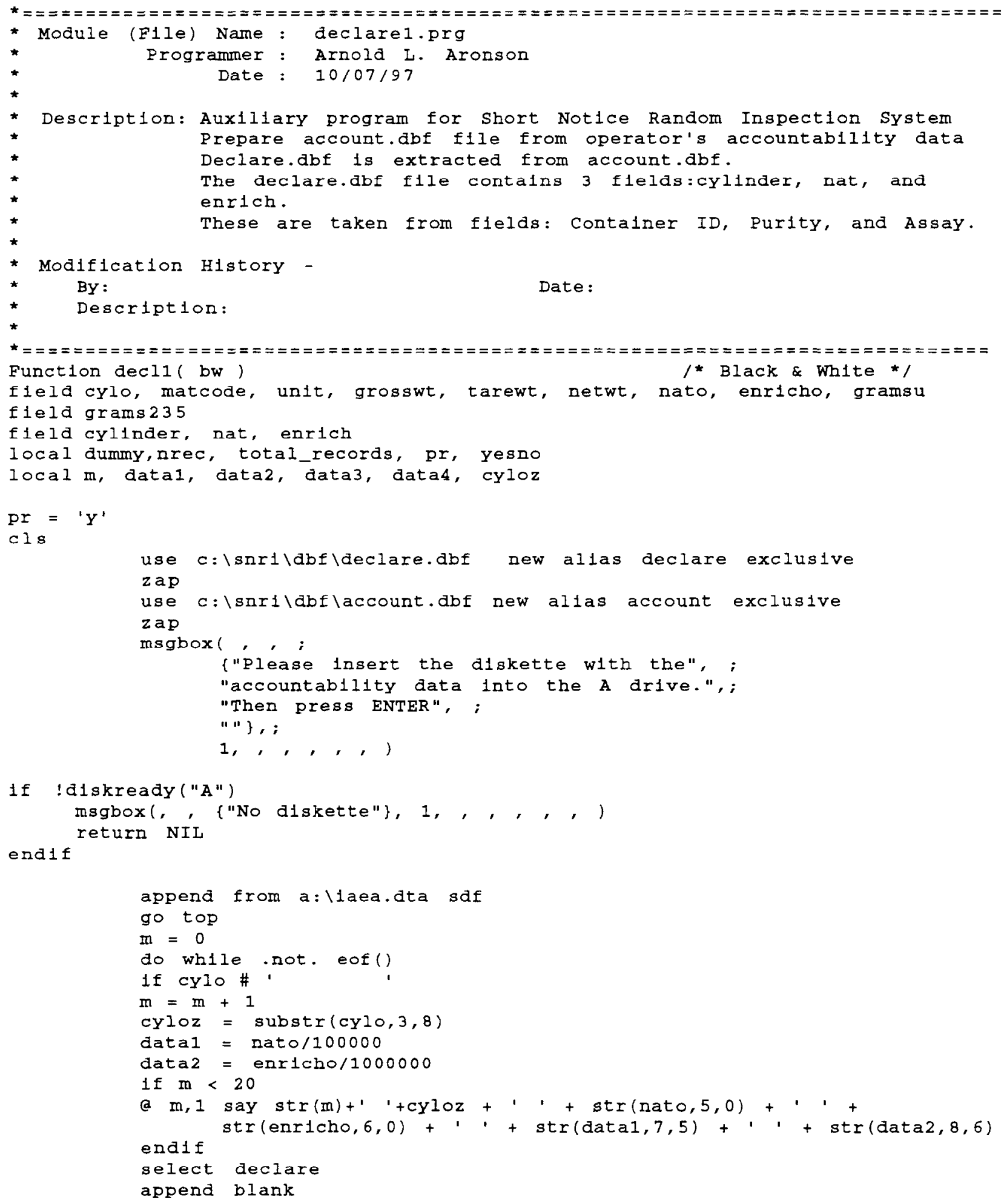




\section{Appendix $\mathrm{N}$}

2) Instructions to the CLIPPER5 RMAKE utility to compile DECLARE1.PRG file c: Isnri src \preproldecl1.rmk

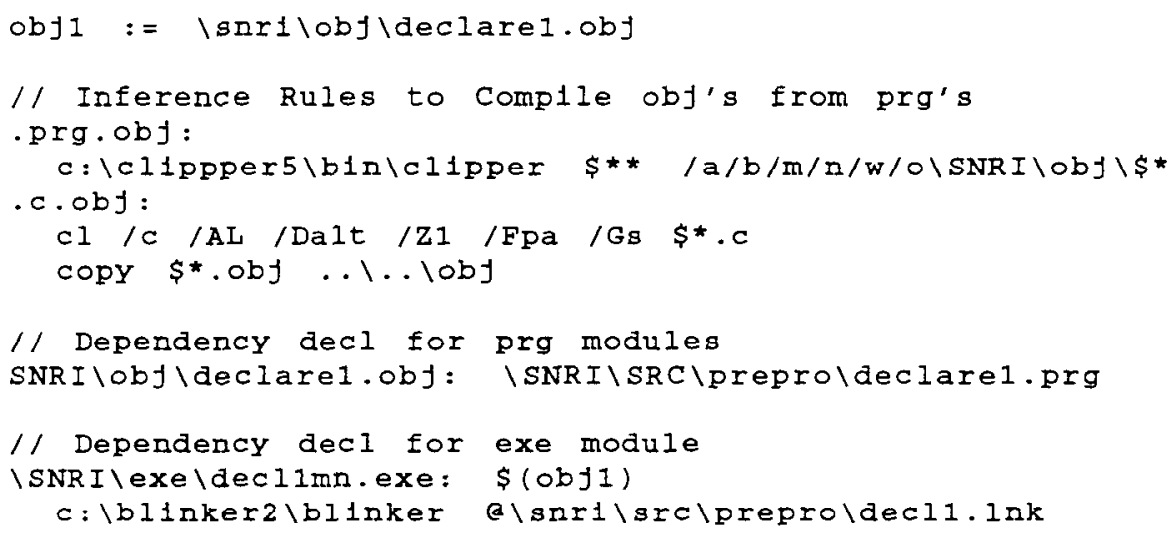

3) Input to the BLINKER2 loader for DECLARE1.PRG file c:Isnriłsrc preprołdecl1.lnk

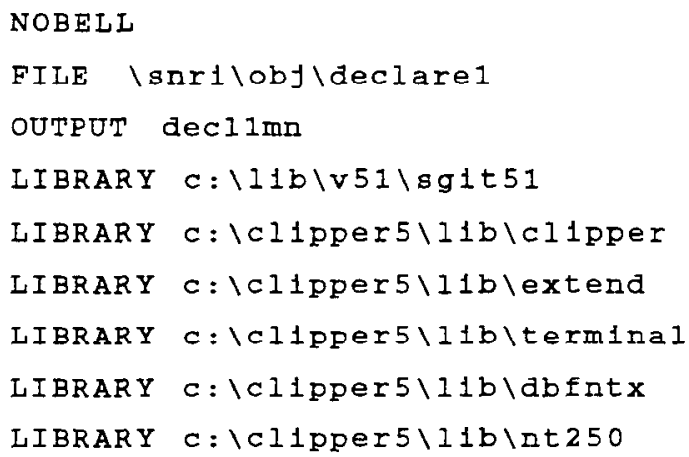

4) The batch file to execute DECL1MN.EXE file c: Isnrilsrc preprolaccount.bat

Qecho off

cd \SNRI\src\prepro

declimn $\% 1$ 
5) Structure of the database file ACCOUNT.DBF:

file c: Isnrildbflaccount.dbf

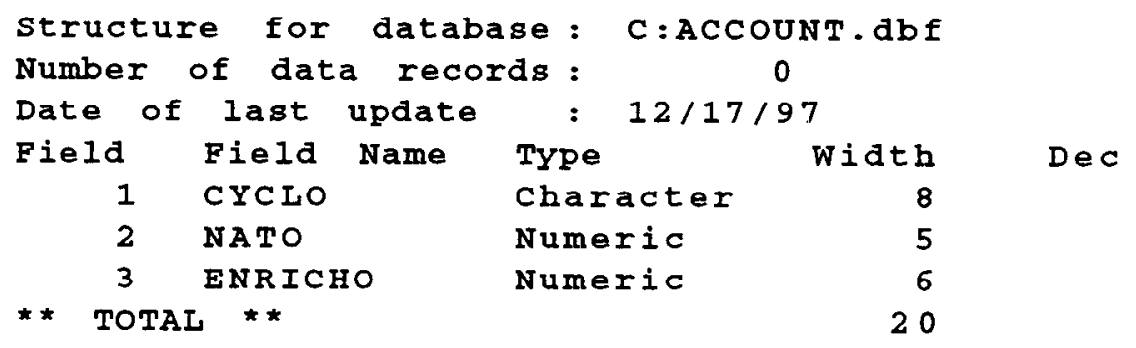

6) Structure of the database file DECLARE.DBF:

file c: isnrildbfideclare.dbf

\begin{tabular}{|c|c|c|c|c|c|c|}
\hline structure & \multirow{2}{*}{$\begin{array}{l}\text { for } \\
\text { dat }\end{array}$} & \multicolumn{2}{|c|}{ database } & \multicolumn{2}{|c|}{$C: D E C L A R E \cdot d b f$} & \\
\hline Number of & & a reco & ds : & & & \\
\hline Date of & 1ast & update & : & $01 / 30$ & & \\
\hline Field & Field & Name & Type & & width & Dec \\
\hline 1 & CYIIN & DER & Cha & acter & 6 & \\
\hline 2 & NAT & & Num & ric & 7 & 5 \\
\hline 3 & ENRIC & & Num & ric & 8 & 6 \\
\hline TOTA & $\star \star *$ & & & & 22 & \\
\hline
\end{tabular}


(THIS PAGE INTENTIONALLY LEFT BLANK) 


\section{Appendix O}

Programs to Incorporate the Plant Operator's Declarations

of

Minimum Residence Times for $\mathrm{UF}_{6}$ Cylinders Attached at Feed Stations

1) CLIPPER5 source code for program RES.PRG:

file c: snriłsrcłpreprotres.prg

2) Instructions to the CLIPPER5 RMAKE utility to compile RES.PRG:

file c: Isnrilsrclpreprotres.rmk

3) Input to the BLINKER2 loader for RES.PRG:

file c: Isnrilsrclpreprołres.lnk

4) The batch file to execute RESMAIN.EXE:

file c: tsnritsrclpreprotres.bat

5) Structure of the Database File N5RES.DBF:

file c: $\backslash$ snrildbfin 5 res.dbf

6) Structure of the Database File N8RES.DBF:

file c: isnrildbfn8res.dbf

7) Structure of the Database File N12RES.DBF:

file c: snnrildbfun12res.dbf 


\section{Appendix $\mathrm{O}$}

1) CLIPPER5 source code for program RES.PRG

file c:Isnrissrclpreprotres.prg

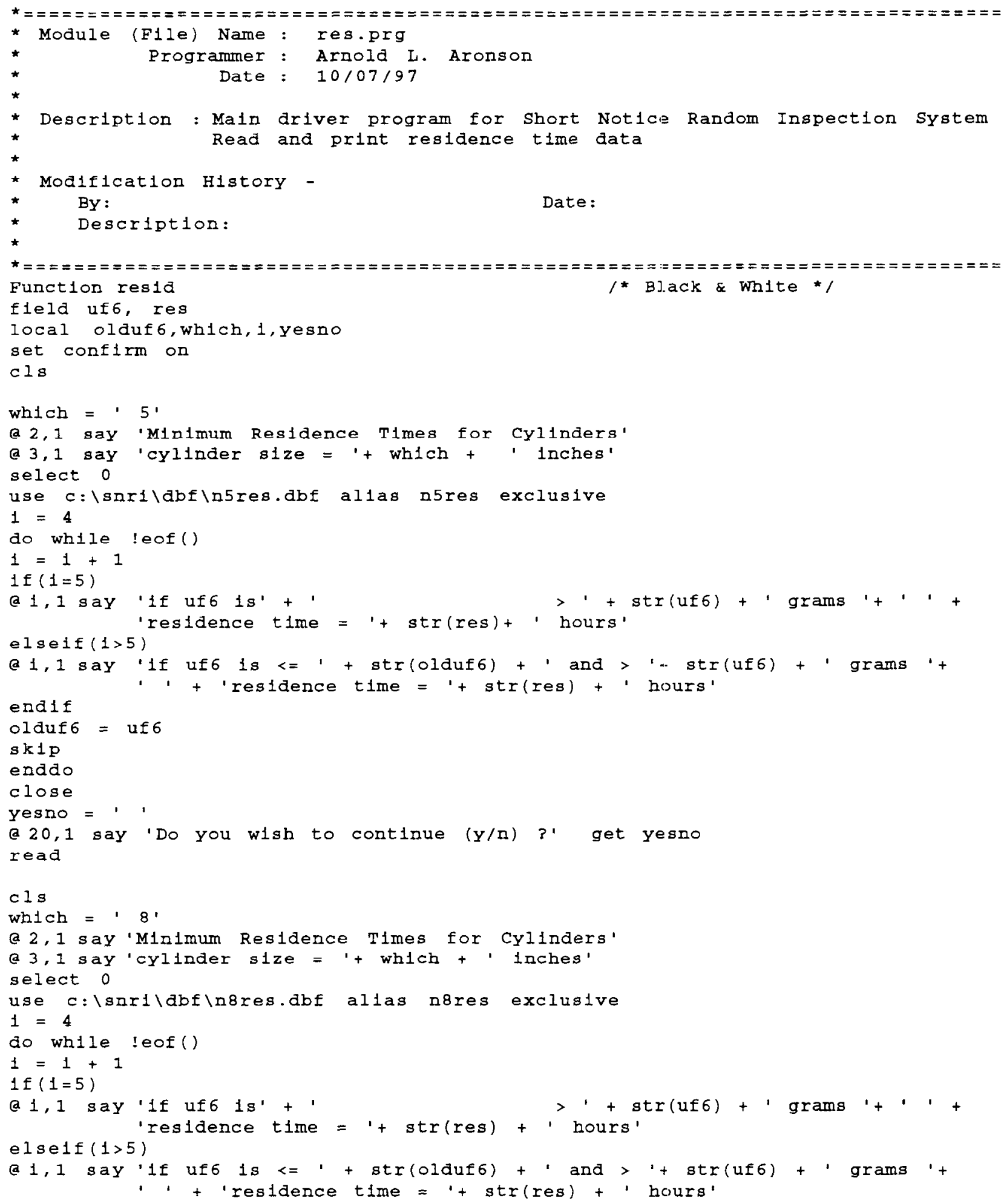




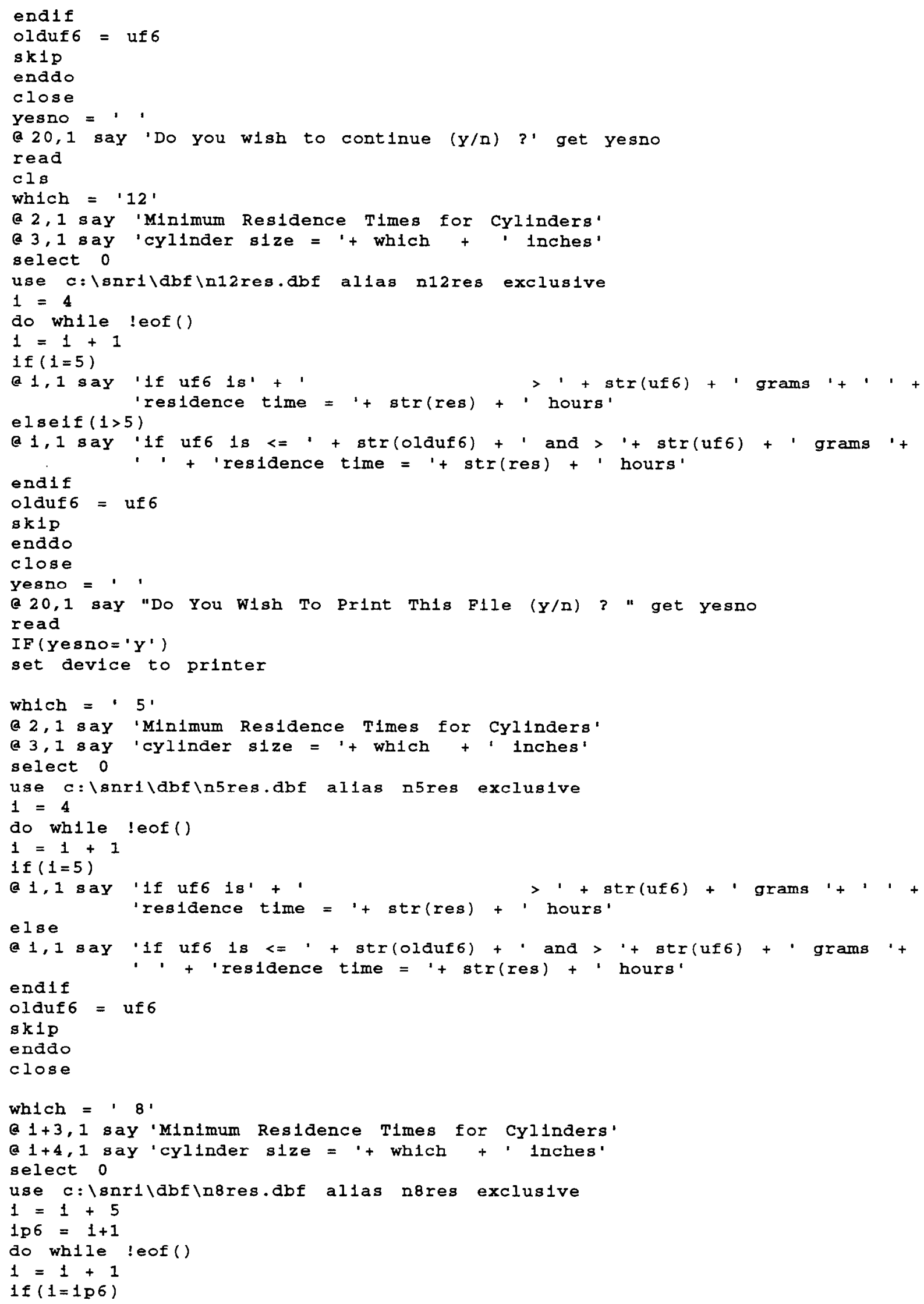




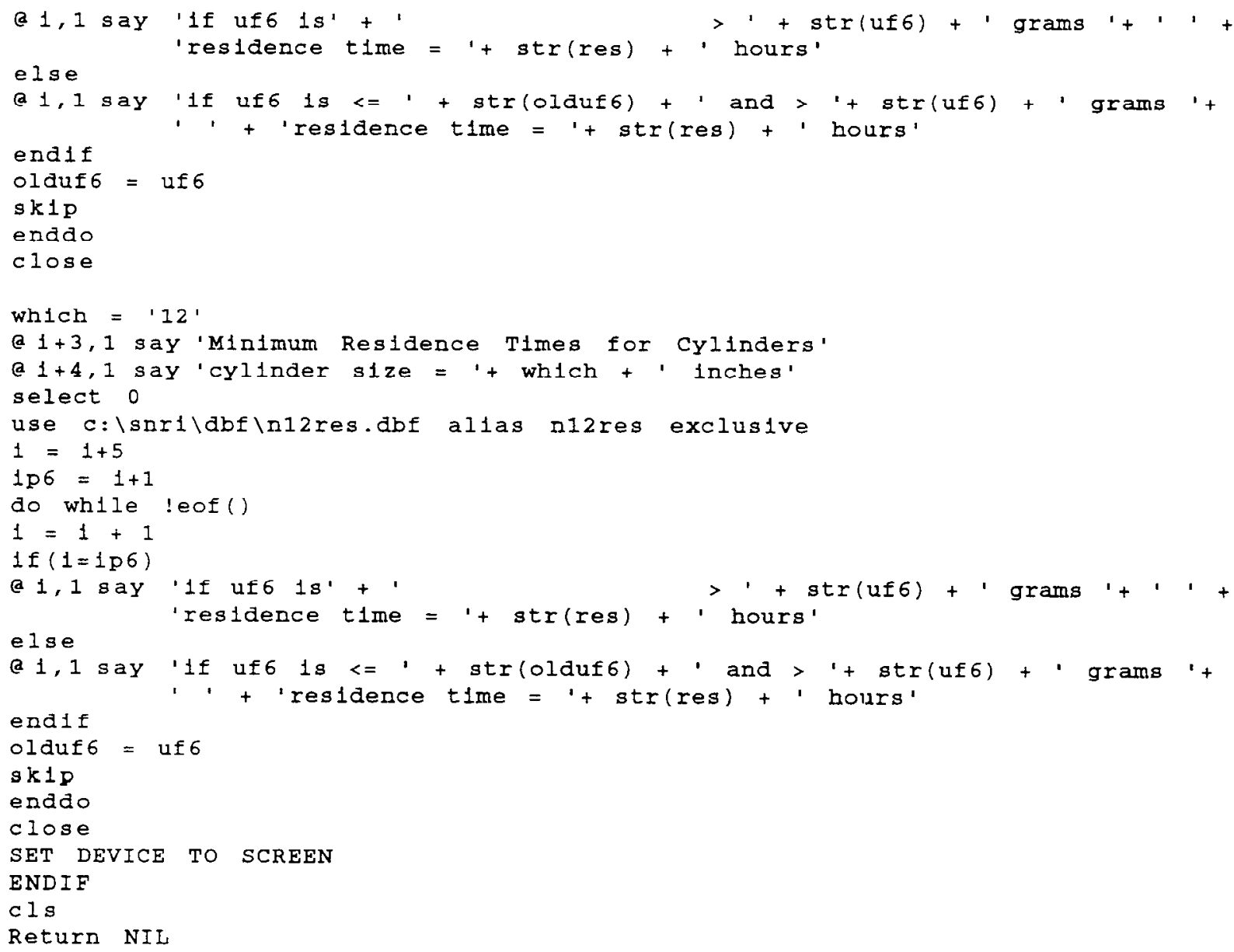




\section{Appendix $\mathrm{O}$}

2) Instructions to the CLIPPER5 RMAKE utility to compile RES.PRG:

file c: $\backslash s n r i$ src preprobes.rmk

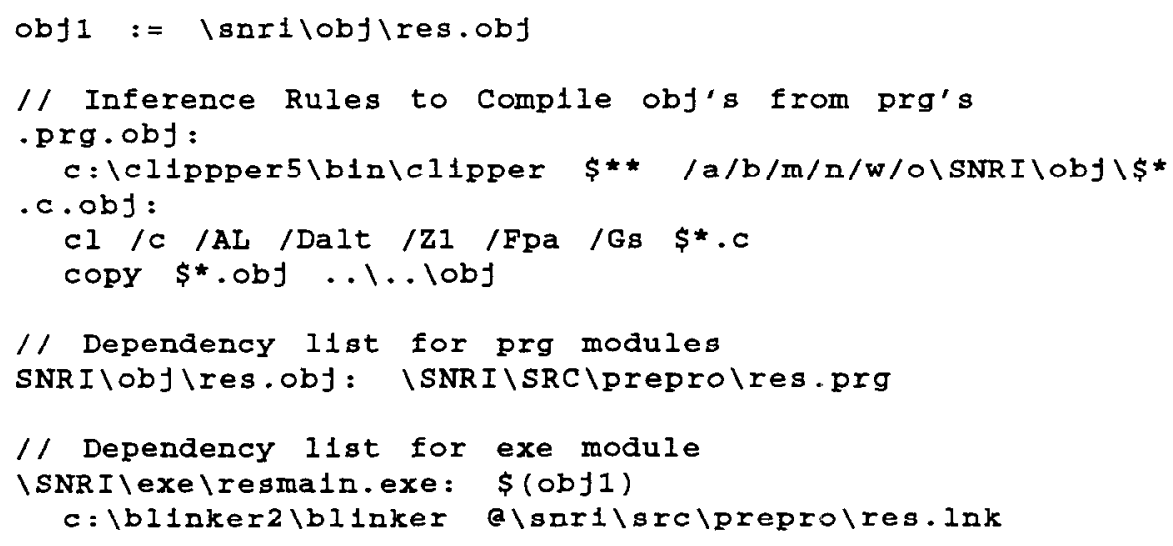

3) Input to the BLINKER2 loader for RES.PRG:

file c: Isnritsrc'preprotres.lnk

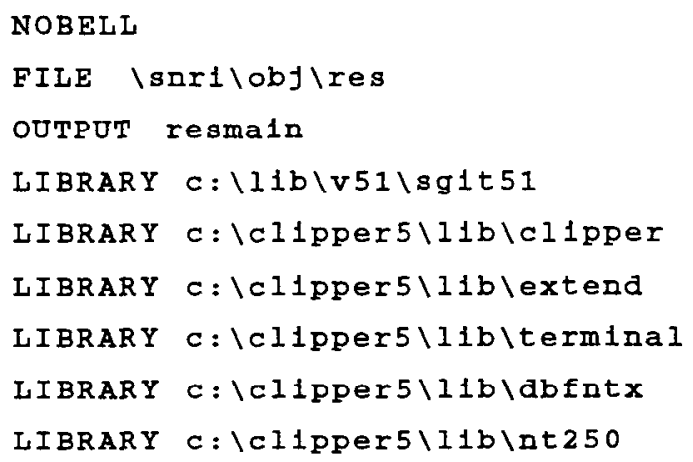

4) The batch file to execute RESMAIN.EXE:

fille c: isnrilsrcłpreproves.bat

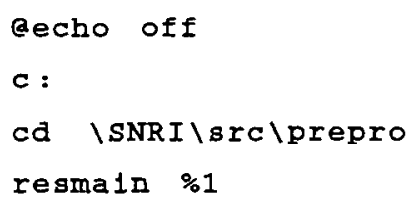


5) Structure of the Database File N5RES.DBF:

file c: Isnrildbfn5res.dbf

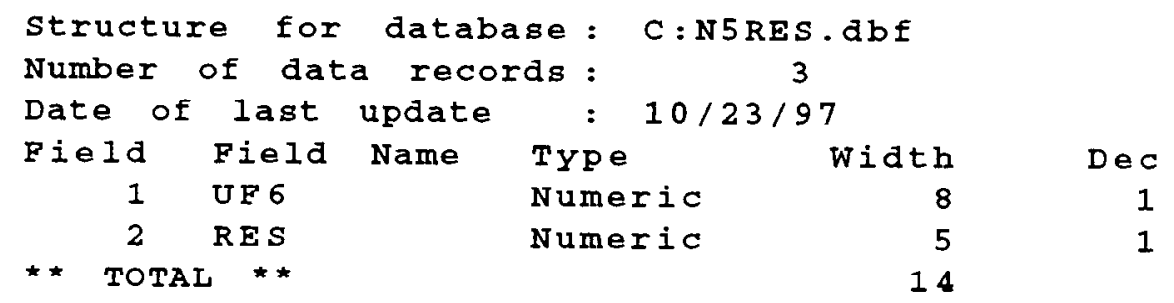

6) Structure of the Database File N8RES.DBF:

file c: $\backslash$ snrildbfungres.dbf

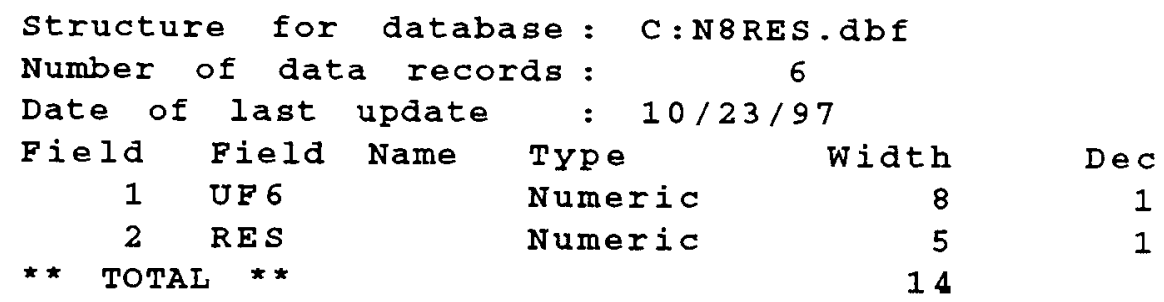

7) Structure of the Database File N12RES.DBF:

file c: $t s n r i l d b f n 12$ res.dbf

\begin{tabular}{|c|c|c|c|c|c|c|}
\hline structu & for & datab & se & $C: N$ & $s \cdot d b f$ & \\
\hline Number & dat & a reco & $d s$ & & & \\
\hline Date of & last & update & & $10 /$ & & \\
\hline Field & Field & Name & TYl & & Width & Dec \\
\hline 1 & UF 6 & & Nur & eric & 8 & 1 \\
\hline 2 & RES & & Nun & eric & 5 & 1 \\
\hline * * TOTA & L $\quad *$ & & & & 14 & \\
\hline
\end{tabular}


Appendix P

The Pre-Processor Programs

1) CLIPPER5 source code for the PREPRO main program file c:lsnritsrcyreprołprepro.prg

2) CLIPPER5 source code for the COPYINV program file c:Snrilsrclpreprolcopyinv.prg

3) CLIPPER5 source code for the ELIMDUPS program file c:Isnrilsrclpreprolelimdups.prg

4) CLIPPER5 source code for the FILLUP program file c:Isnrilsrclpreprolfillup.prg

5) CLIPPER5 source code for the PHYINV program file c:Isnrilsrclpreprołphyinv.prg

6) CLIPPER5 source code for the CORRECT program file c:Isnrilsrclpreprolcorrect.prg

7) CLIPPER5 source code for the LISTCYL program file c:Isnriłsrclpreprovistcyls.prg

8) CLIPPER5 source code for the CYCLO program file c:Isnrisrclpreprolcyclos.prg

9) Listing of input data to the CLIPPER RMAKE utility file c:Snriisrcłpreprołprepro.rmk

10) Listing of input to the BLINKER2 loader file c:Isnrilsrclpreprołprepro.lnk

11) Batch file to execute the PREPRO program file c: tprepro.bat

12) Structure of the database file INVENTOR.DBF file c:lsnrildbflinventor.dbf

13) Structure of the database file CYL.DBF file c: isnri dbflcyl.dbf

14) Structure of the database file CYL2.DBF file c:lsnrildbfcyl2.dbf 


\section{Appendix P}

1) CLIPPER5 source code for the PREPRO rnain program file c: Isnritsrcłpreprołprepro.prg

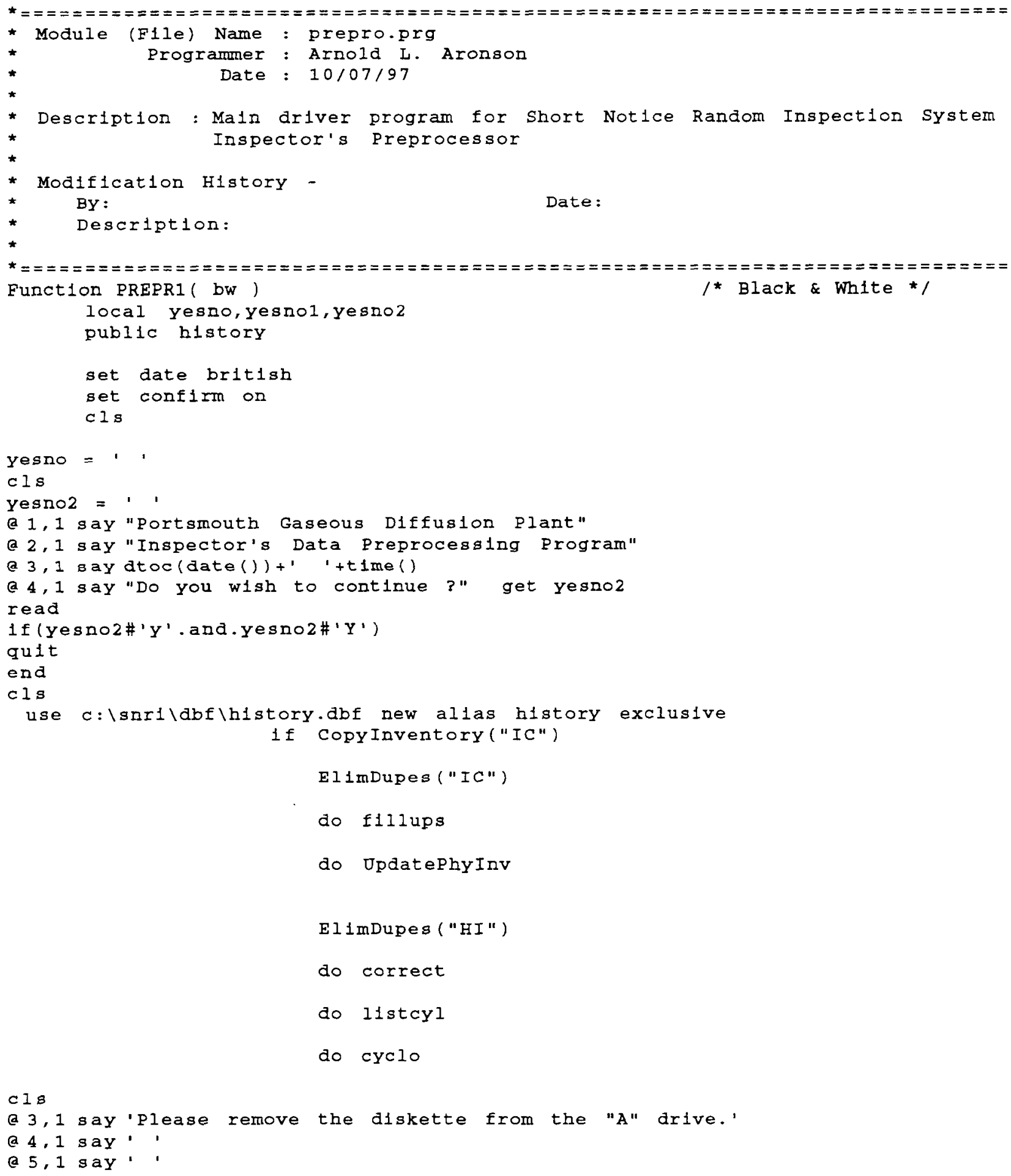

endif 


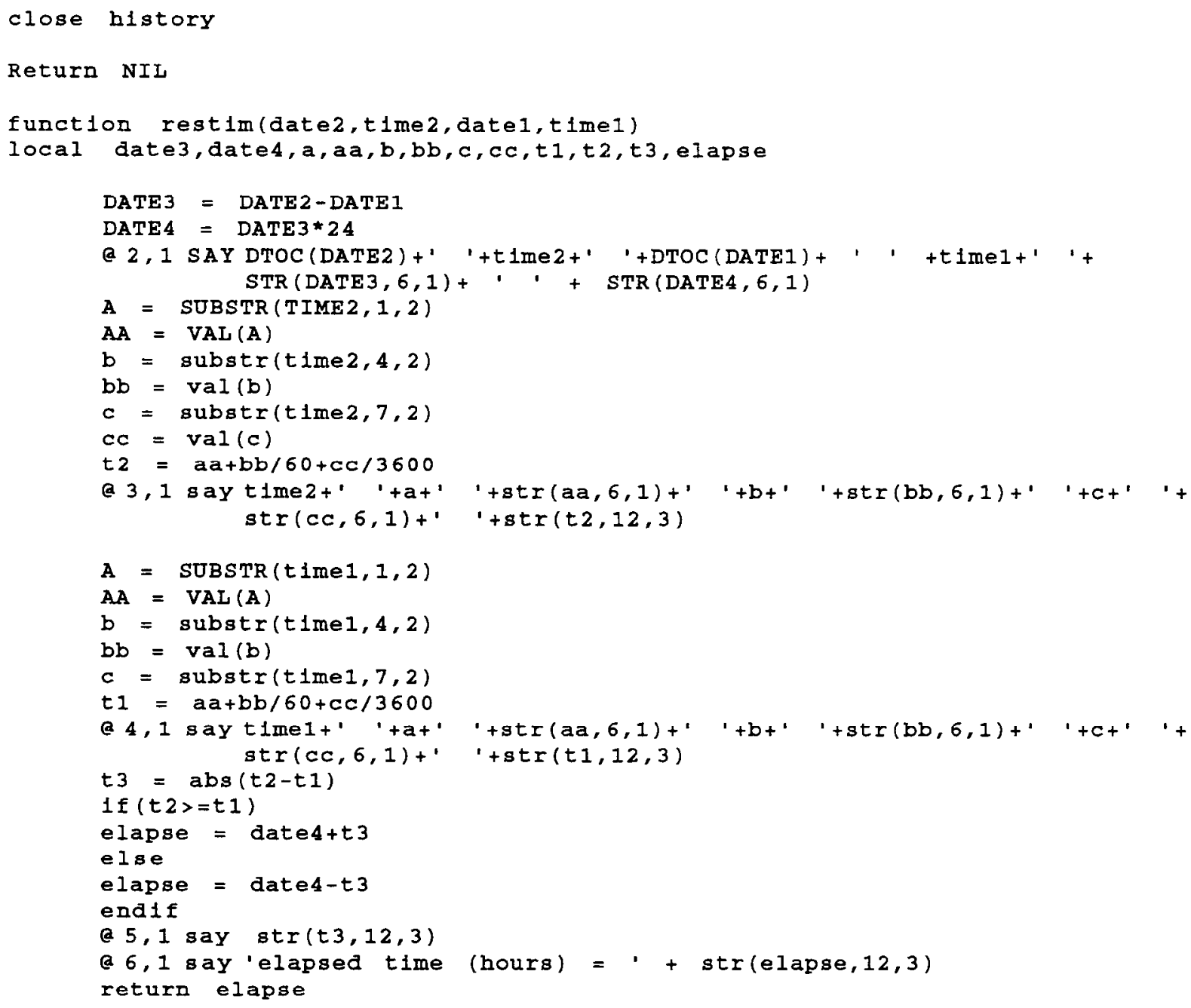




\section{Appendix $\mathrm{P}$}

\section{2) CLIPPER5 source code for the COPYINV program}

file c: snrilsrcłreprolcopyinv.prg

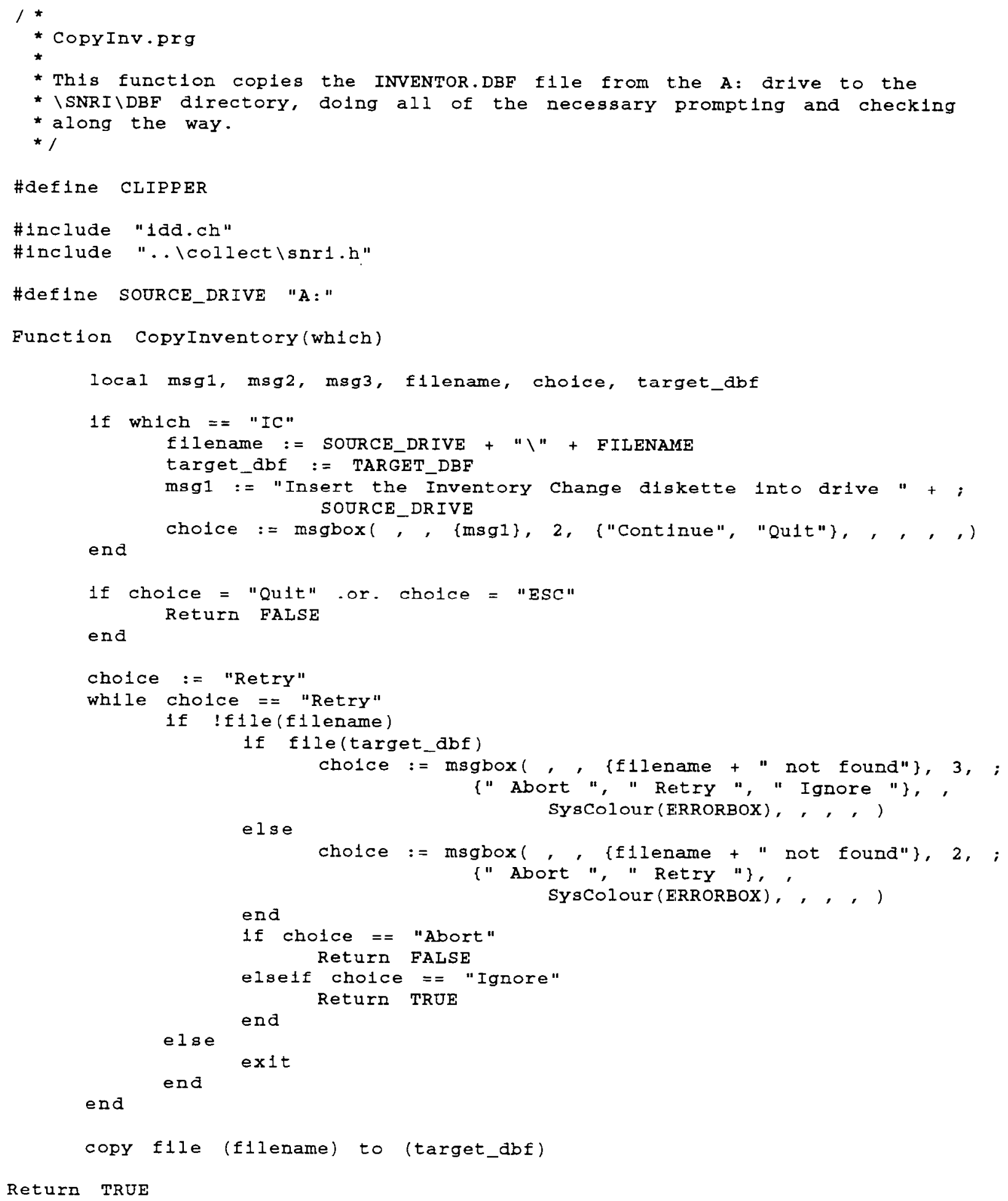




\section{Appendix P}

\section{3) CLIPPER5 source code for the ELIMDUPS program file c: Isnriłsrclpreprolelimdups.prg}

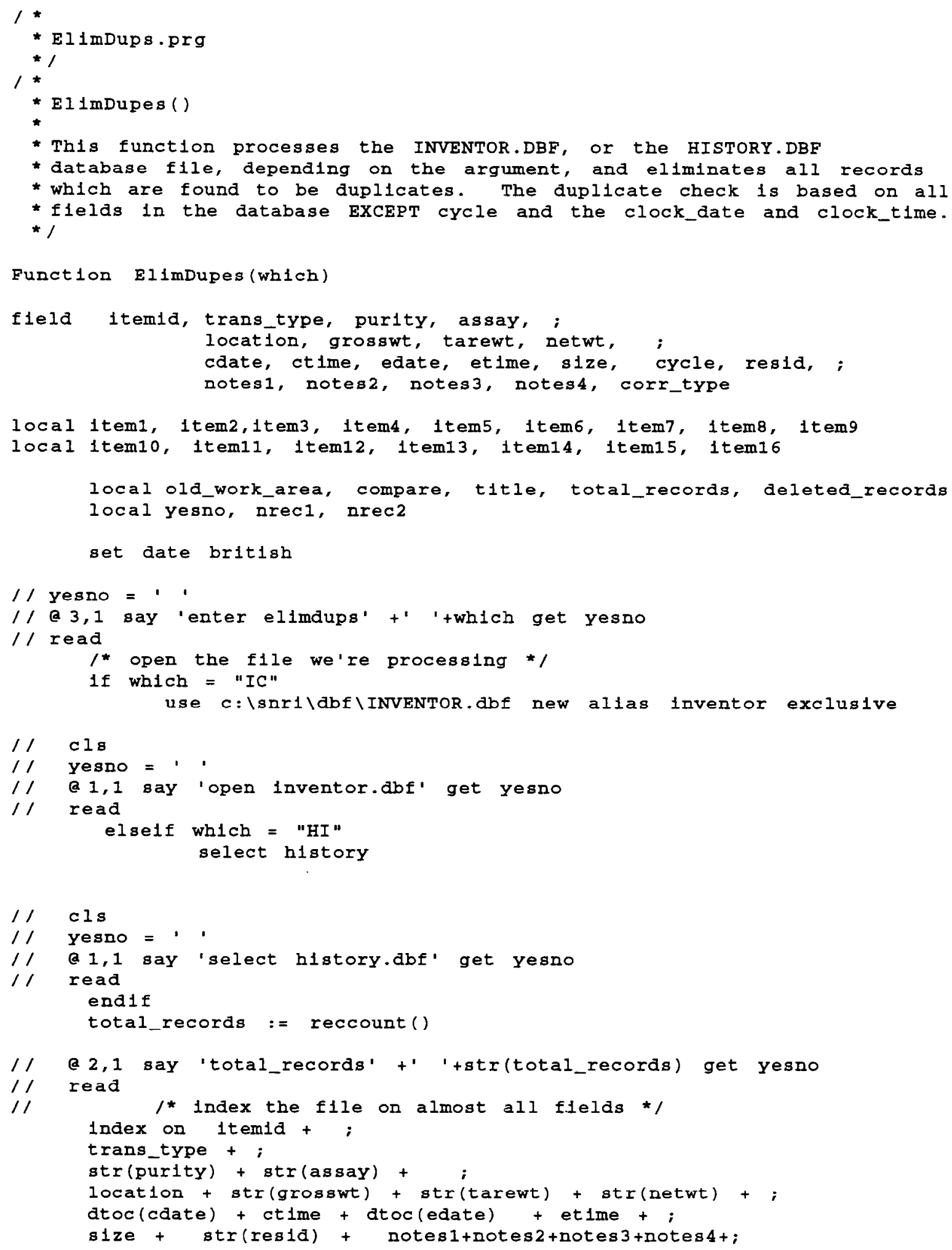




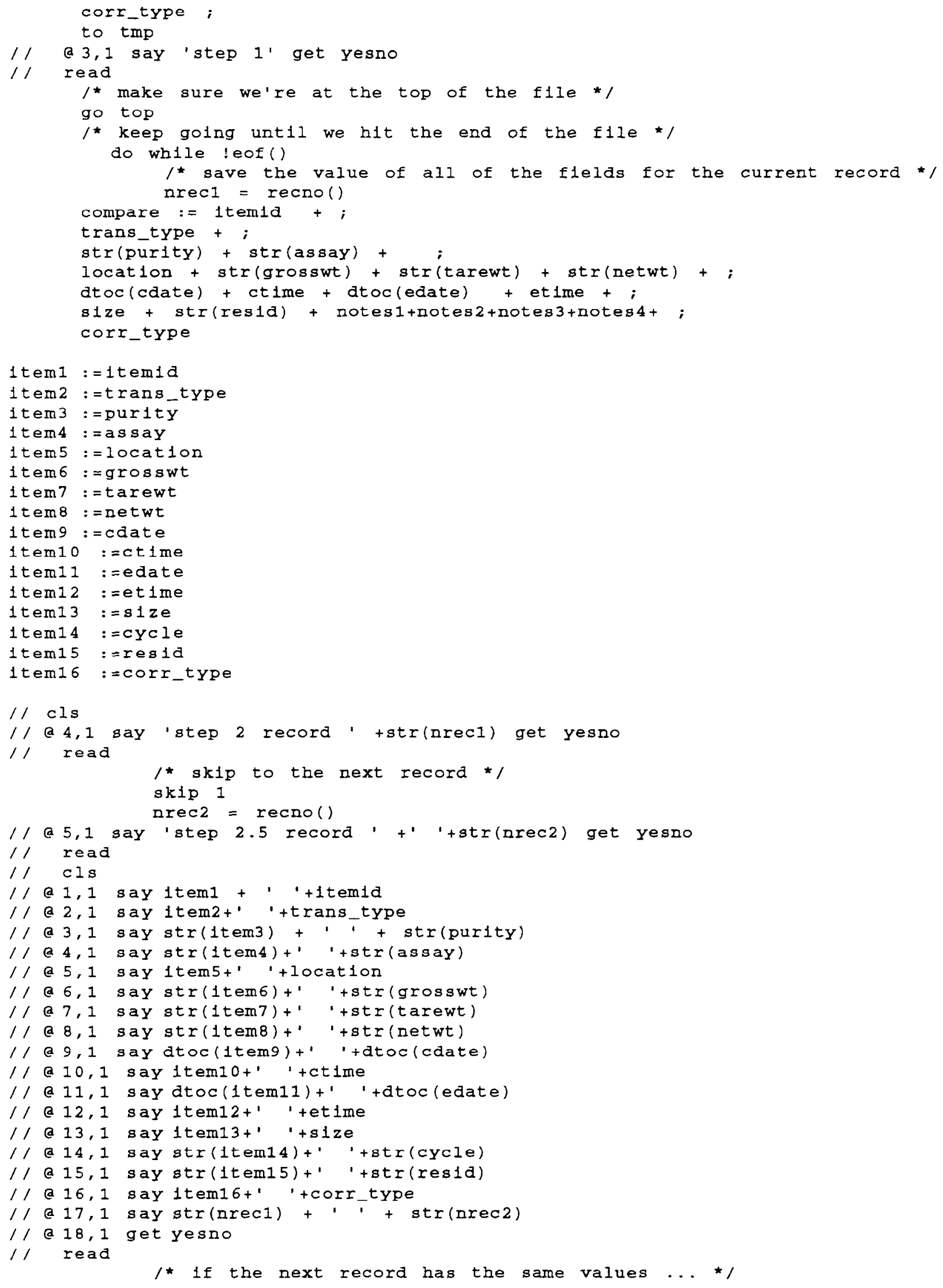




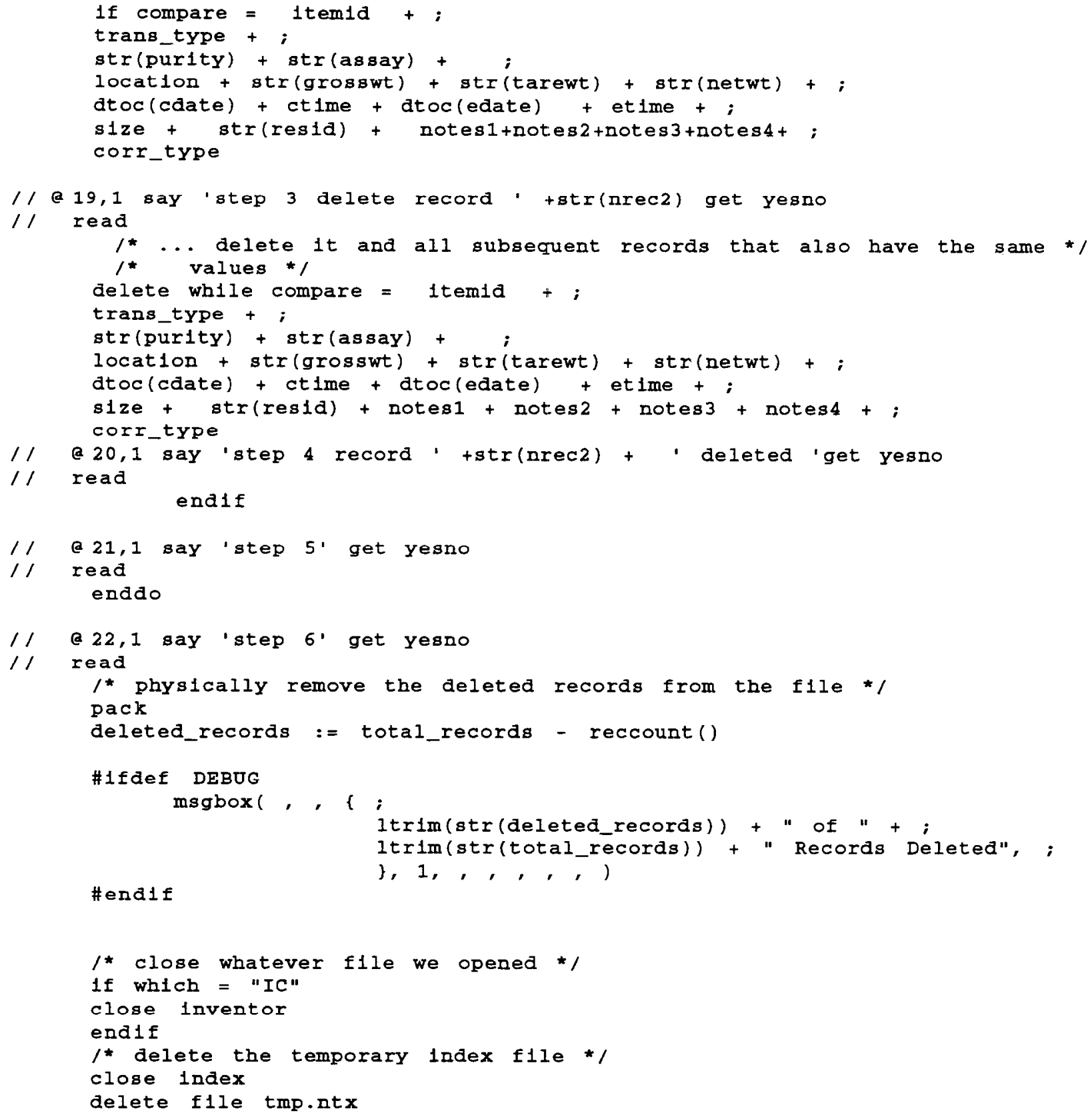

Return NIL 


\section{Appendix P}

\section{4) CLIPPER5 source code for the FILLUP program}

file c:Isnrilsrc $p r e p r o \backslash f i l l u p . p r g$

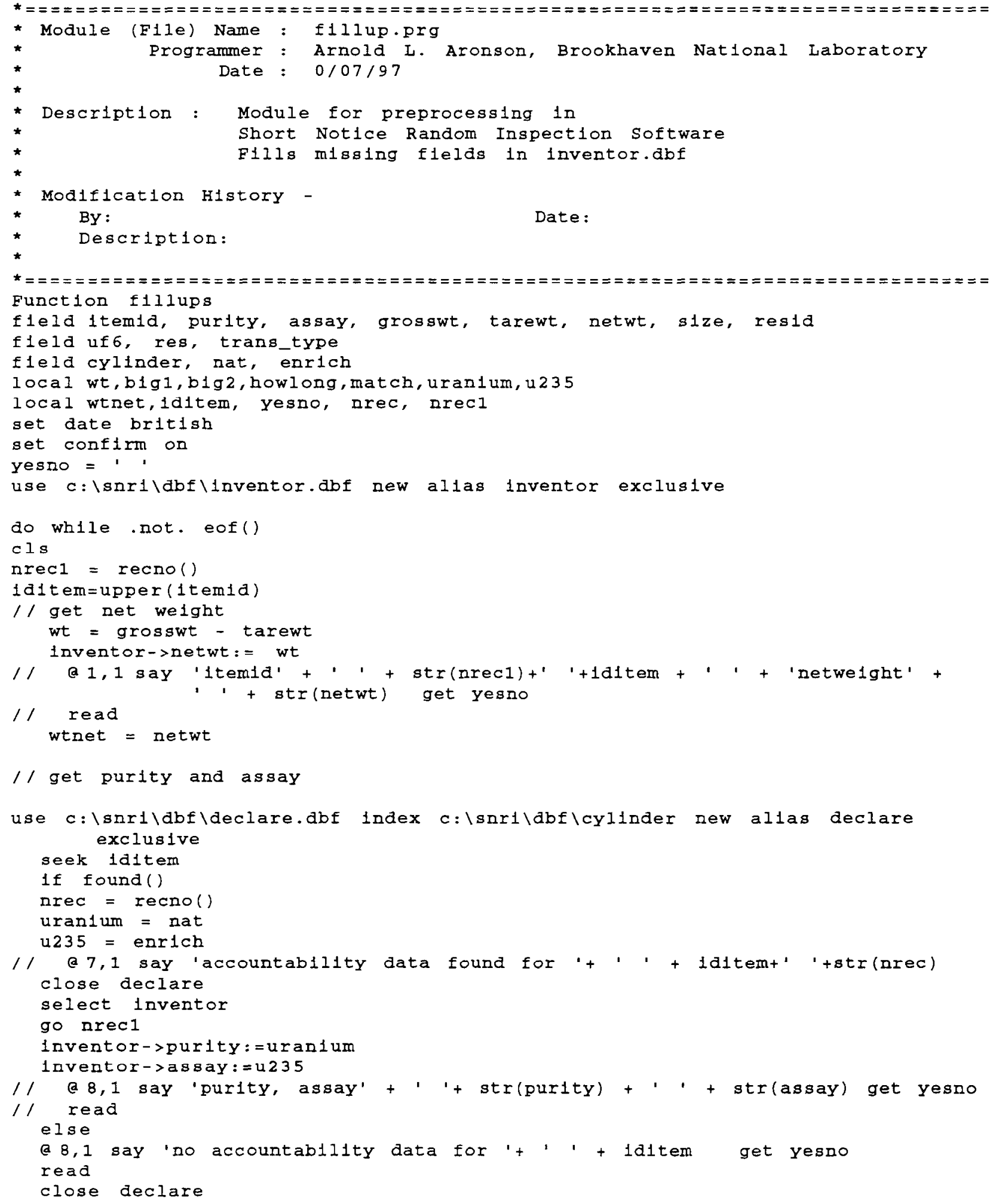




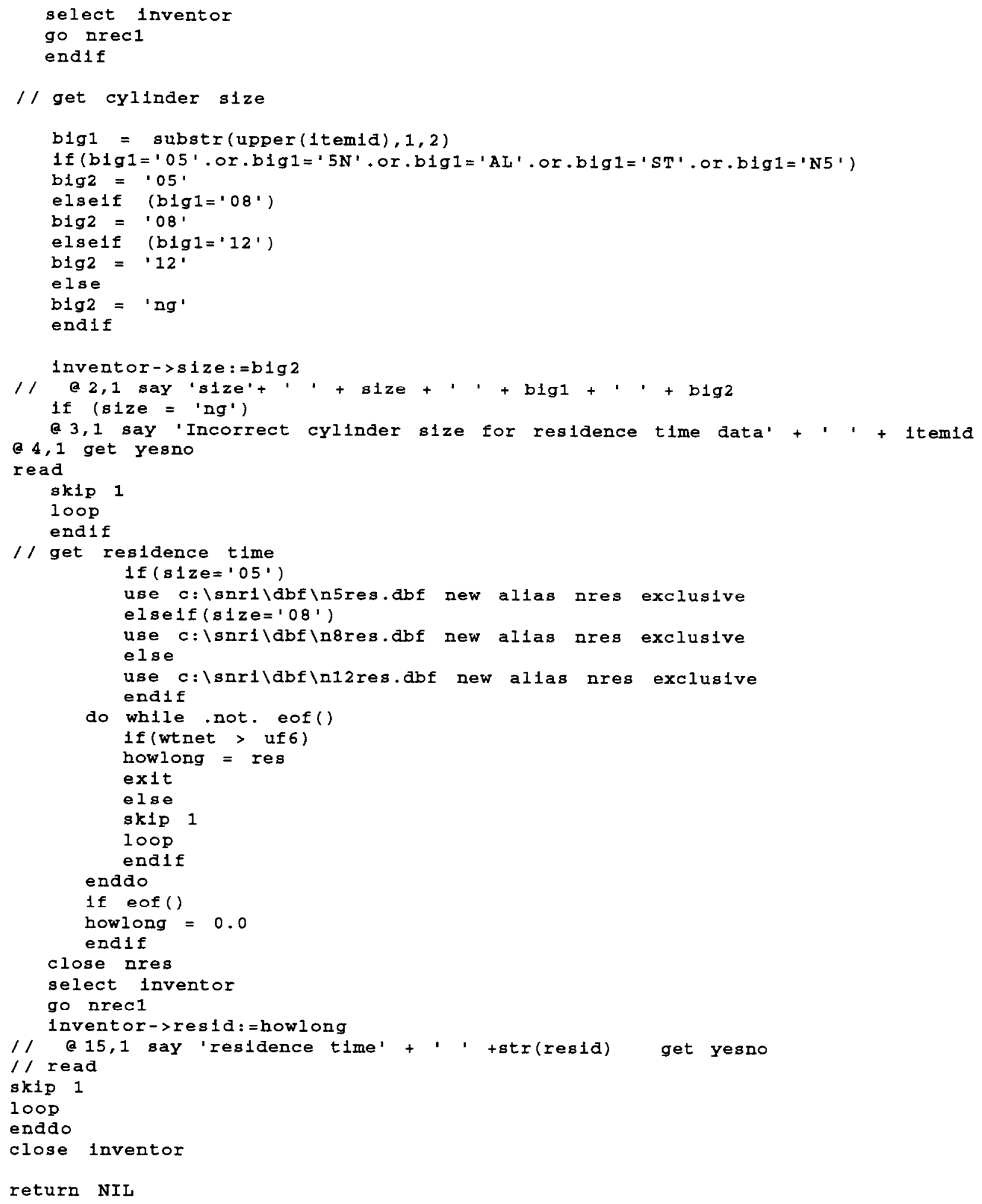




\section{Appendix P}

\section{5) CLIPPER5 source code for the PHYINV program}

file c: $\backslash s n r i \backslash s r c \nmid p r e p r o\lfloor p h y i n v . p r g$

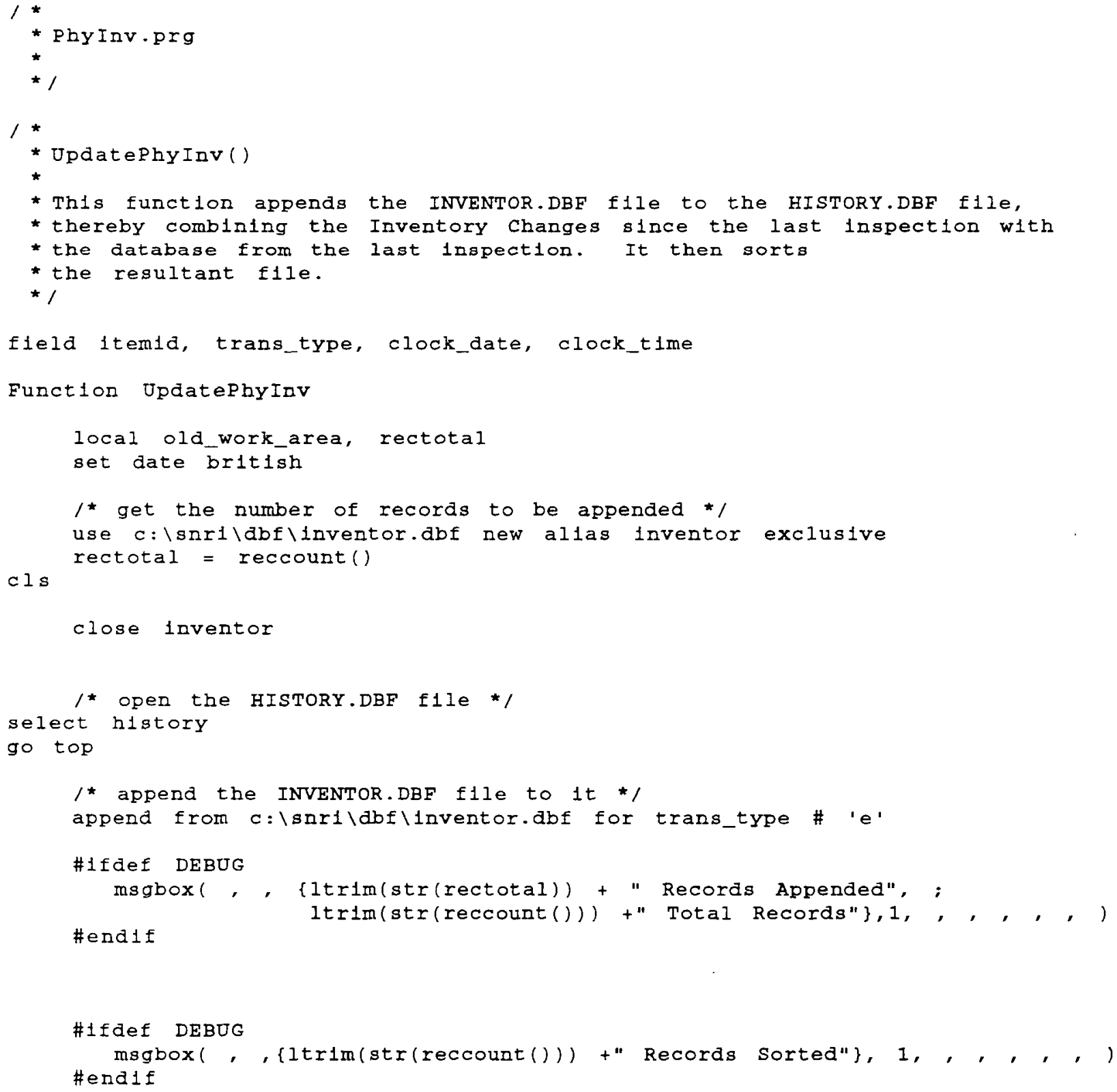




\section{Appendix P}

6) CLIPPER5 source code for the CORRECT program file c: Isnrilsrcłpreprolcorrect.prg

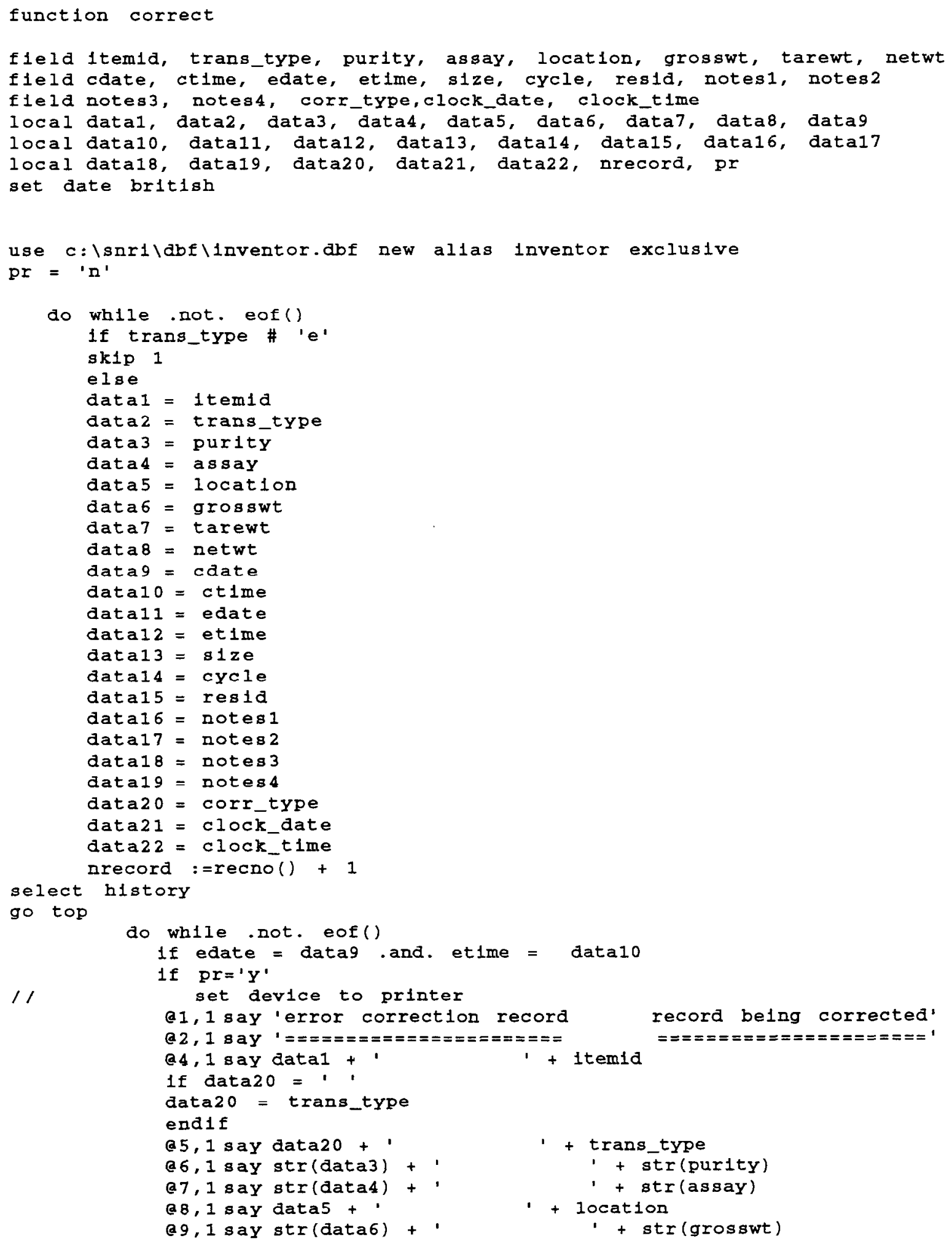



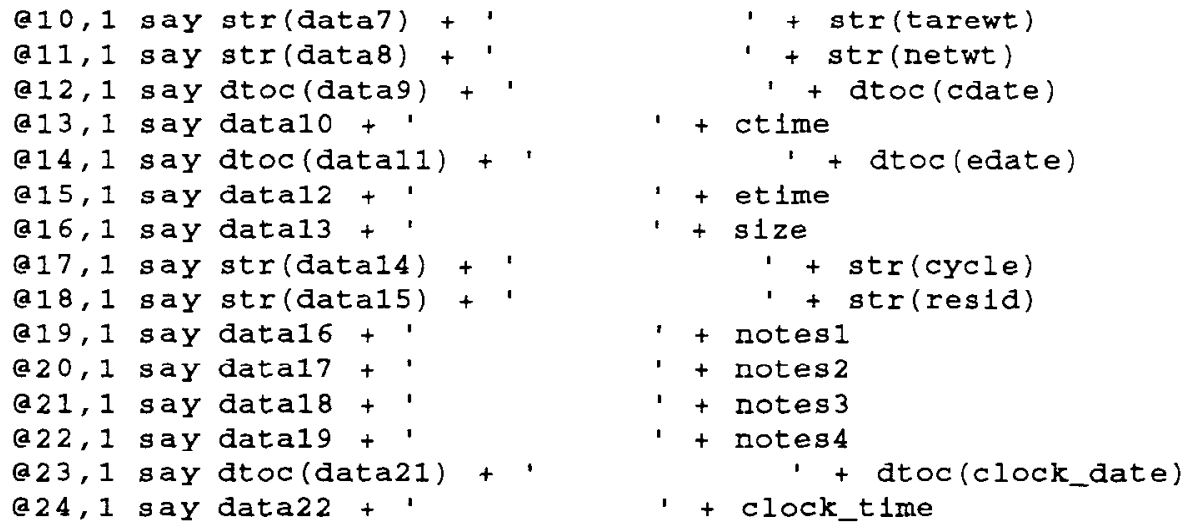


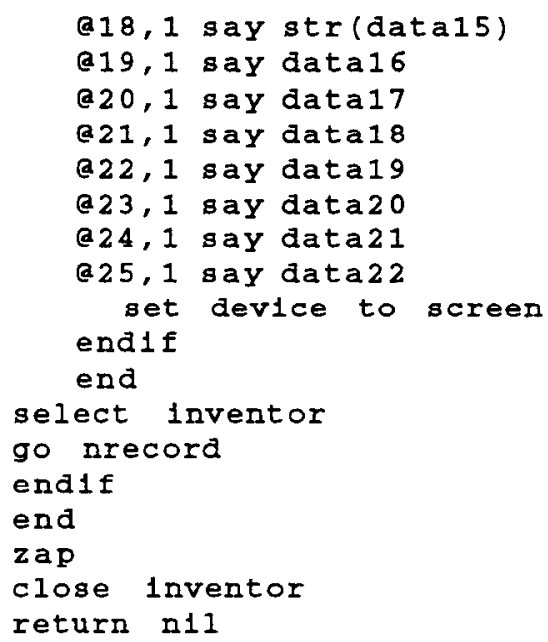




\section{Appendix $\mathrm{P}$}

7) CLIPPER5 source code for the LISTCYL program file c: Isnri \srclpreproVistcyls.prg

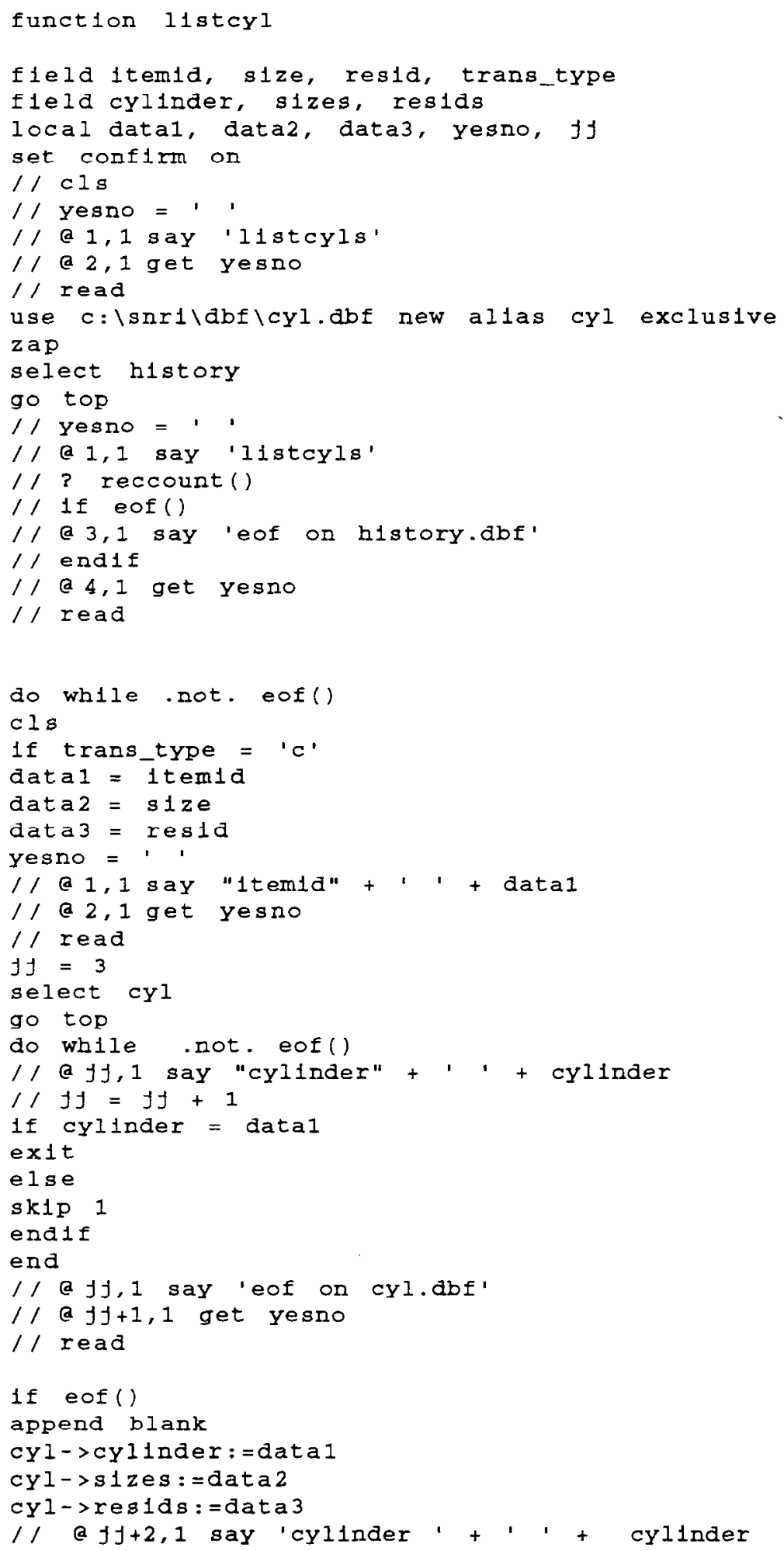




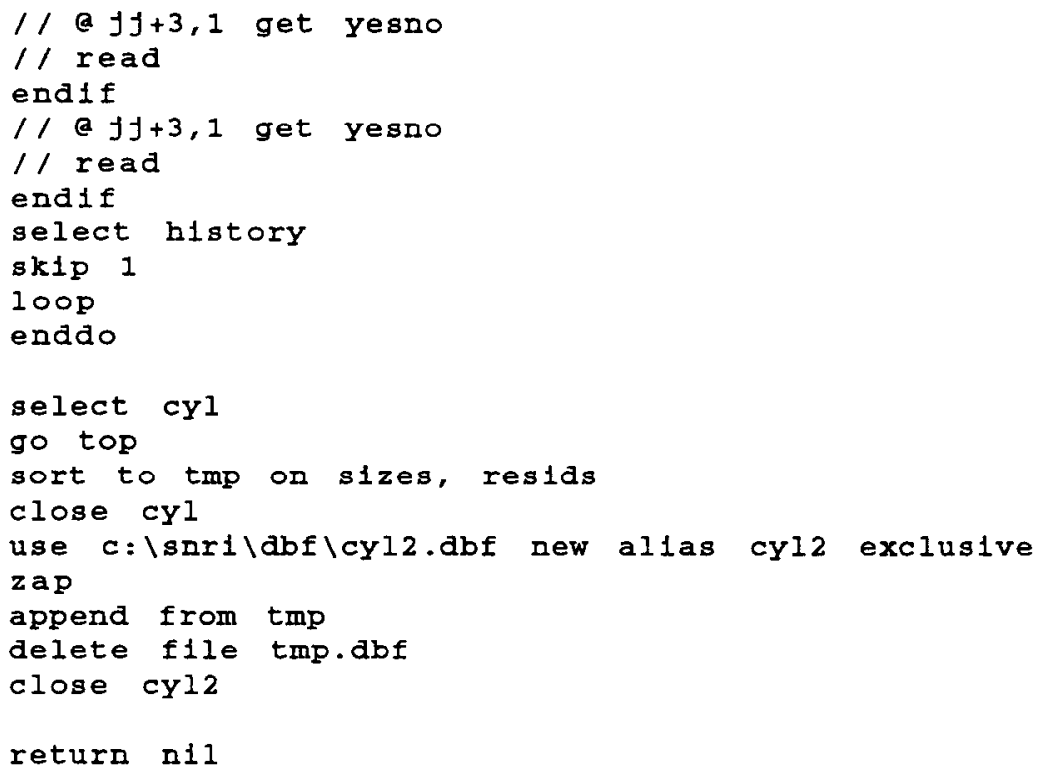




\section{Appendix $\mathrm{P}$}

8) CLIPPER5 source code for the CYCLO program

file c: \snriłsrcłpreprolcyclos.prg

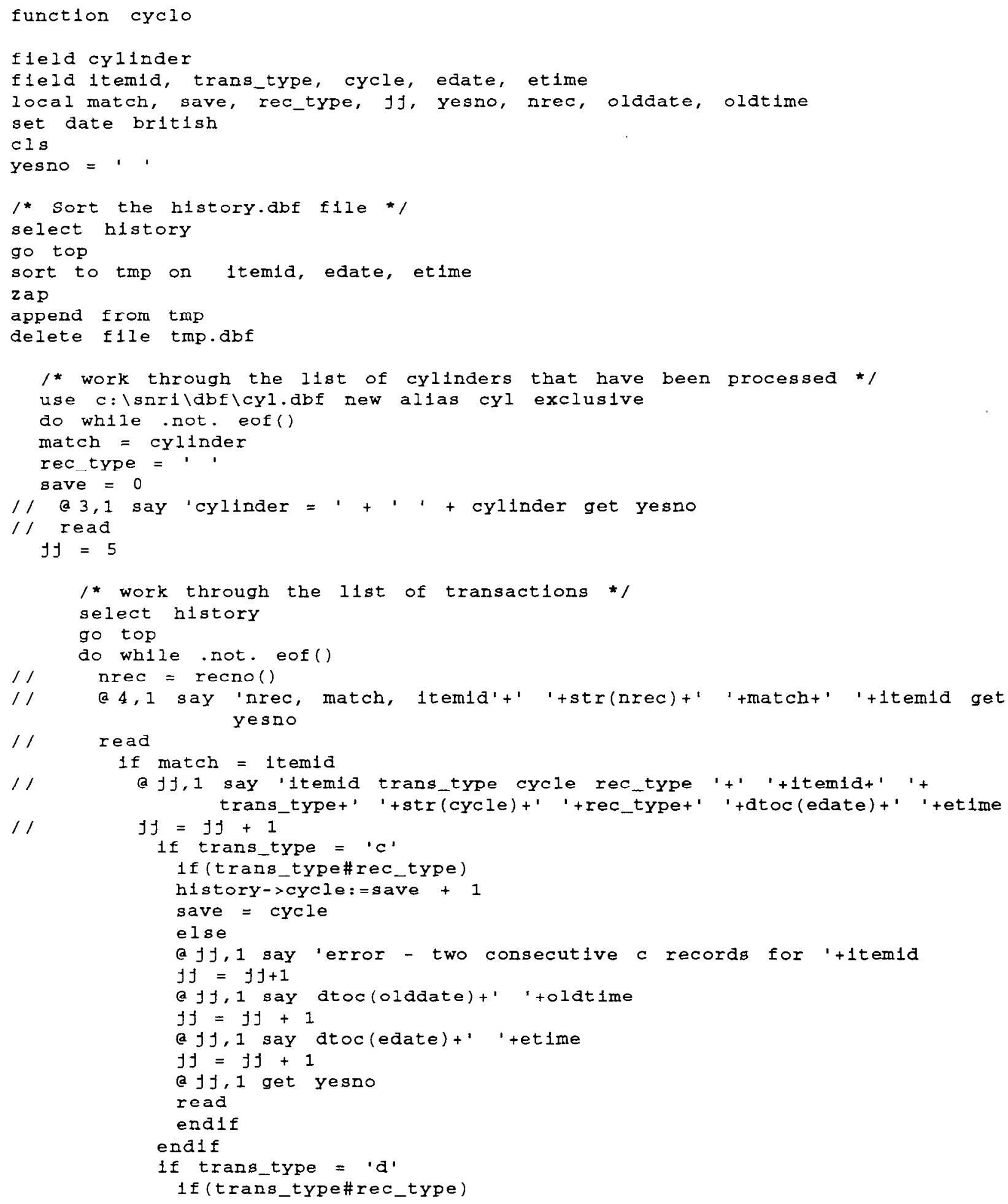




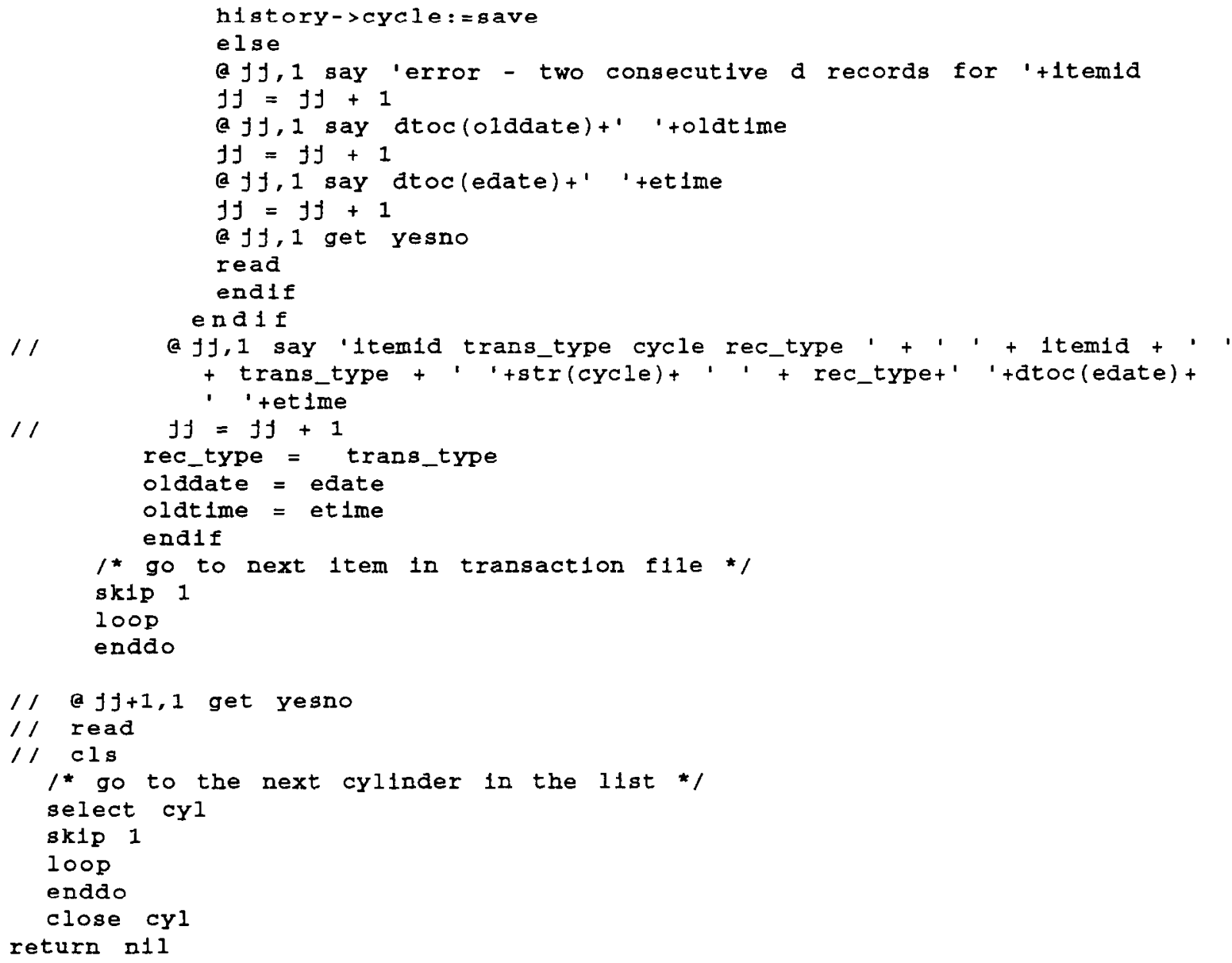




\section{Appendix $\mathrm{P}$}

9) Listing of input data to the CLIPPER RMAKE utility

file c: Isnrilsrcłpreprołrepro.rmk

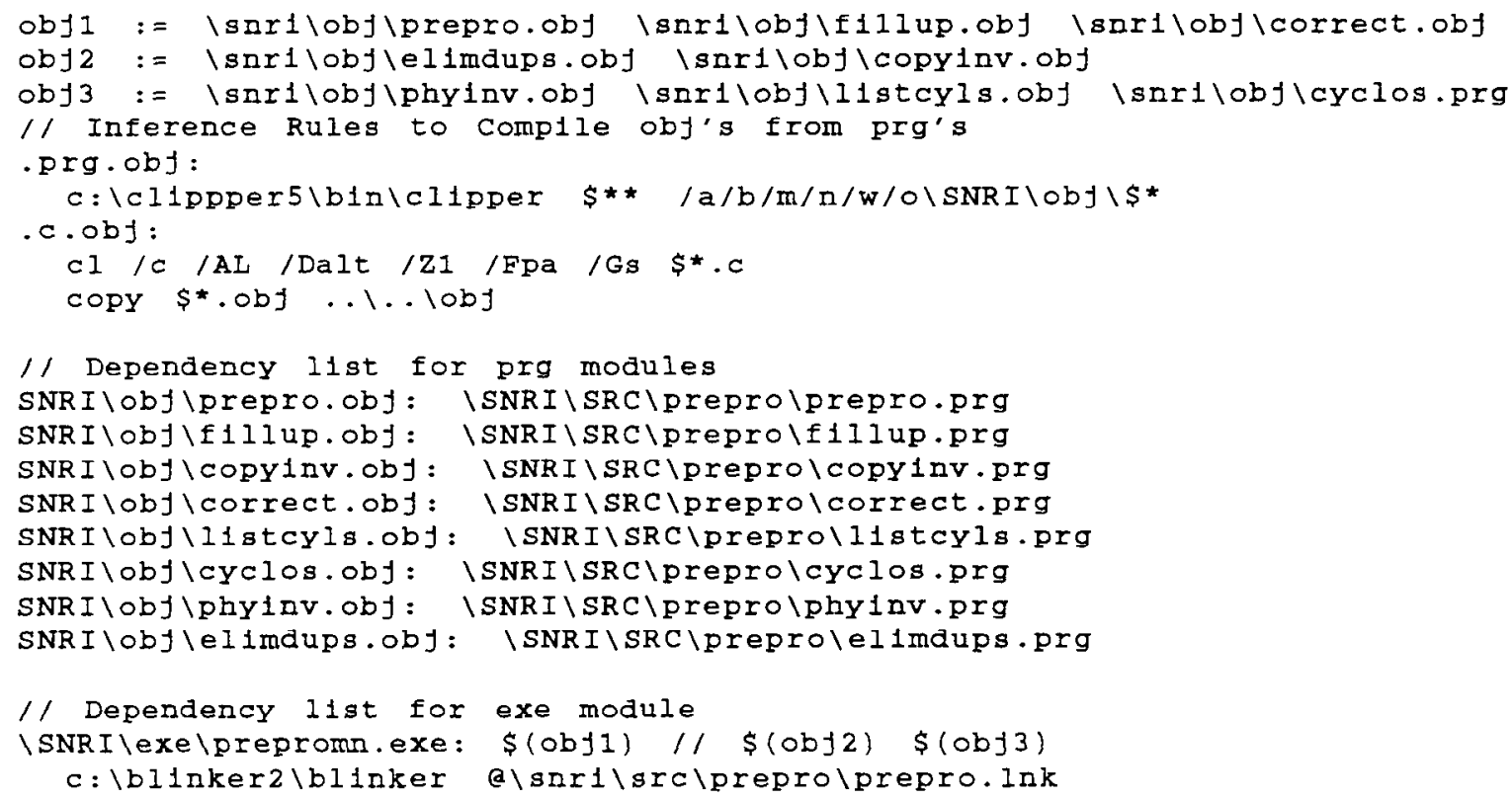

10) Listing of input to the BLINKER2 loader file c: Isnrilsrc preprołprepro.lnk

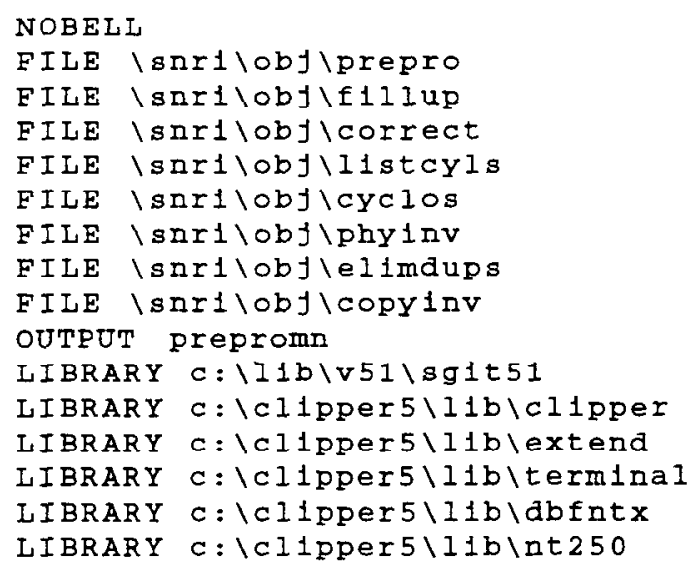

11) Batch file to execute the PREPRO program file c: prepro.bat

eecho off

$c: \backslash \sin 1 \backslash$ src \prepro\prepromn 


\section{Appendix P}

12) Structure of the database file INVENTOR.DBF file c: snrildbfinventor.dbf

\begin{tabular}{|c|c|c|c|c|}
\hline \multicolumn{5}{|c|}{ for database: C:INVENTOR. dbf } \\
\hline \multicolumn{5}{|c|}{ Number of data records: } \\
\hline Date of & last update & $: 12 / 01$ & 7 & \\
\hline Field & Field Name & Type & wiath & Dec \\
\hline 1 & ITEMID & character & 6 & \\
\hline 2 & TRANS_TYPE & Character & 1 & \\
\hline 3 & PURITY & Numeric & 7 & 4 \\
\hline 4 & ASSAY & Numeric & 7 & 4 \\
\hline 5 & LOCATION & Character & 2 & \\
\hline 6 & GROSSWT & Numeric & 15 & 3 \\
\hline 7 & TAREWT & Numeric & 15 & 3 \\
\hline 8 & NETWT & Numeric & 15 & 3 \\
\hline 9 & CDATE & Date & 8 & \\
\hline 10 & CTIME & Character & 8 & \\
\hline 11 & EDATE & Date & 8 & \\
\hline 12 & ETIME & Character & 8 & \\
\hline 13 & SIZE & Character & 2 & \\
\hline 14 & CYCLE & Numeric & 2 & \\
\hline 15 & RESID & Numeric & 3 & \\
\hline 16 & NOTES 1 & Character & 80 & \\
\hline 17 & NOTES 2 & Character & 80 & \\
\hline 18 & NOTES 3 & character & 80 & \\
\hline 19 & NOTES 4 & character & 80 & \\
\hline 20 & CORR_TYPE & character & 1 & \\
\hline 21 & CLOCK_DATE & Date & 8 & \\
\hline 22 & CLOCK_TIME & Character & 8 & \\
\hline TOTAI & $I \quad * *$ & & 445 & \\
\hline
\end{tabular}




\section{Appendix P}

13) Structure of the database file CYL.DBF

file c: \snribbfcyl.dbf

\begin{tabular}{|c|c|c|c|c|c|c|}
\hline structure & \multirow{2}{*}{$\begin{array}{l}\text { for } \\
\text { aat }\end{array}$} & \multicolumn{2}{|c|}{ database } & \multicolumn{2}{|c|}{$c: C Y L \cdot d b f$} & \multirow[b]{4}{*}{ Dec } \\
\hline & & reco & ds & & & \\
\hline $\begin{array}{l}\text { Number } \\
\text { Date of }\end{array}$ & \multirow{2}{*}{$\begin{array}{c}\text { last } \\
\text { Field }\end{array}$} & \multirow{2}{*}{$\begin{array}{l}\text { update } \\
\text { Name }\end{array}$} & : & \multicolumn{2}{|c|}{$12 / 02 / 97$} & \\
\hline Fiela & & & \multirow{2}{*}{\multicolumn{2}{|c|}{ Type }} & width & \\
\hline 1 & \multicolumn{2}{|c|}{ CYLINDER } & & & 6 & \\
\hline 2 & SIZES & & Cha & acter & 2 & \\
\hline 3 & RESID & & Num & ric & 3 & \\
\hline TOTAI & $\mathrm{L} \quad * \star$ & & & & 12 & \\
\hline
\end{tabular}

14) Structure of the database file CYL2.DBF

file c: Isnrildbfcyl2.dbf

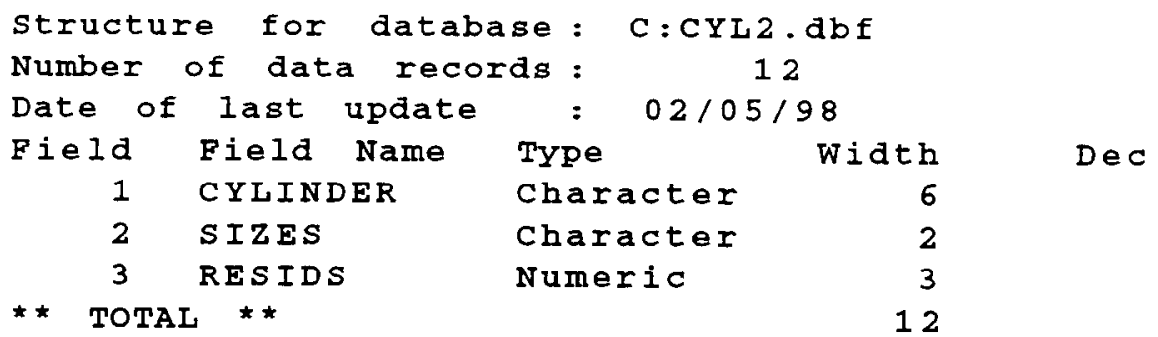


Appendix Q

The Report Generator Programs

1) CLIPPER5 source code for the Report Generator main program:

file c: Isnrilsrcliaealiaea.prg

2) CLIPPER5 source code for the program to generate reports for cylinders that should be attached to feed stations because the residence time has not been exceeded file c:Isnrilsrcliaealone.prg

3) CLIPPER5 source code for the program to generate reports for cylinders that should be attached to feed stations because there is no disconnect recorded file c:Isnrilsrcliaeattwo.prg

4) CLIPPER5 source code for the program to generate detailed reports of the accumulated amount of material removed from cylinders over a specified period file c:Isnrissrciaealthree.prg

5) CLIPPER5 source code for the program to generate reports of actual residence time compared with declared residence time for normal refeed file c:Isnrilsrcliaealfour.prg

6) CLIPPER5 source code for the program to generate a compact printed table of the material removed from all cylinders over a specified period file c:Isnrilsrcliaealfive.prg

7) Listing of input data to the CLIPPER RMAKE utility file c: Isnrisrcliaealiaea.rmk

8) Listing of input to the BLINKER2 loader file c: Isnrilsrcliaealiaea.lnk

9) Batch file to execute the report generator program file c: Vreports.bat 


\section{Appendix Q}

1) CLIPPER5 source code for the Report Generator main program file c: Isnriłsrcliaealiaea.prg

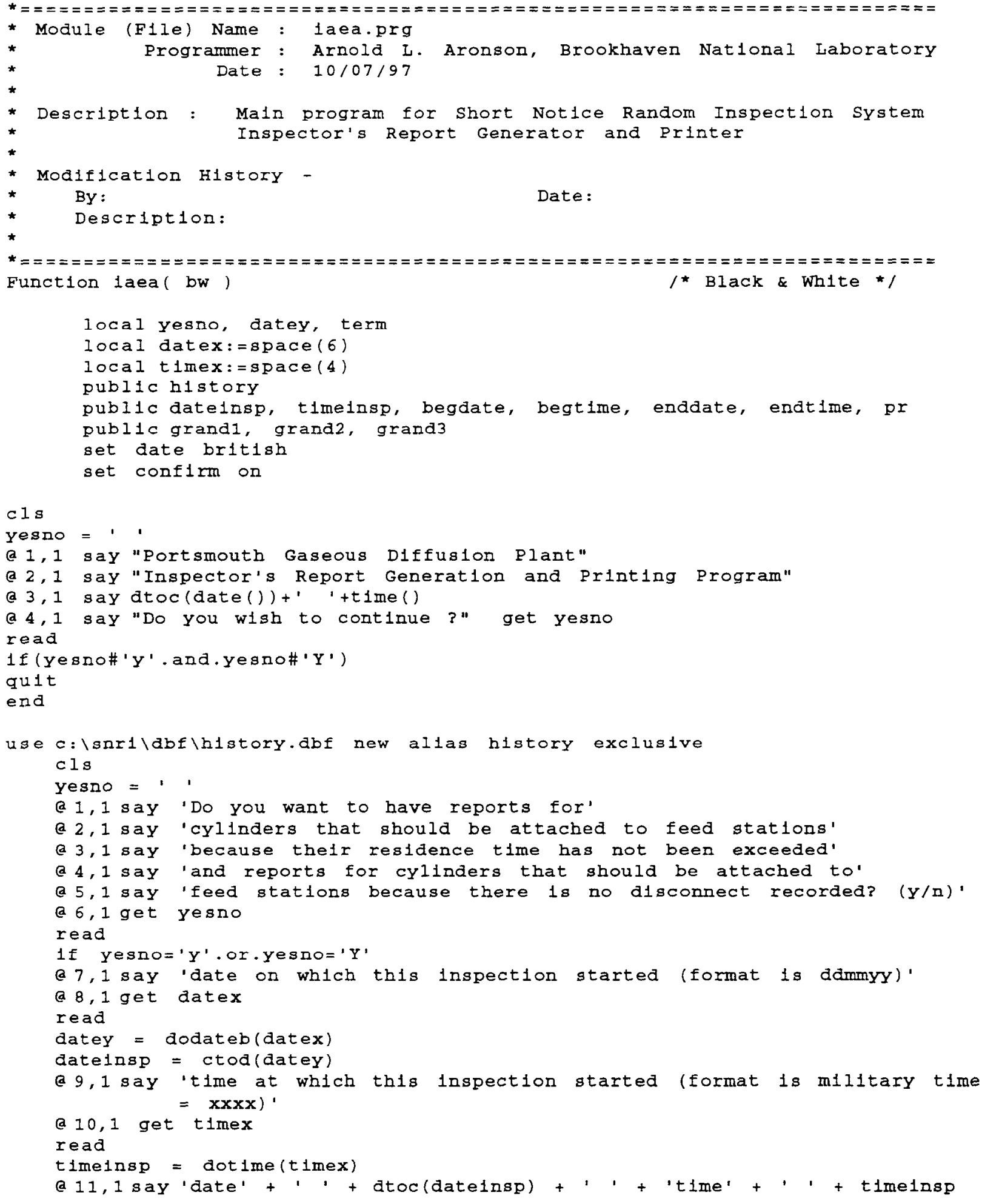




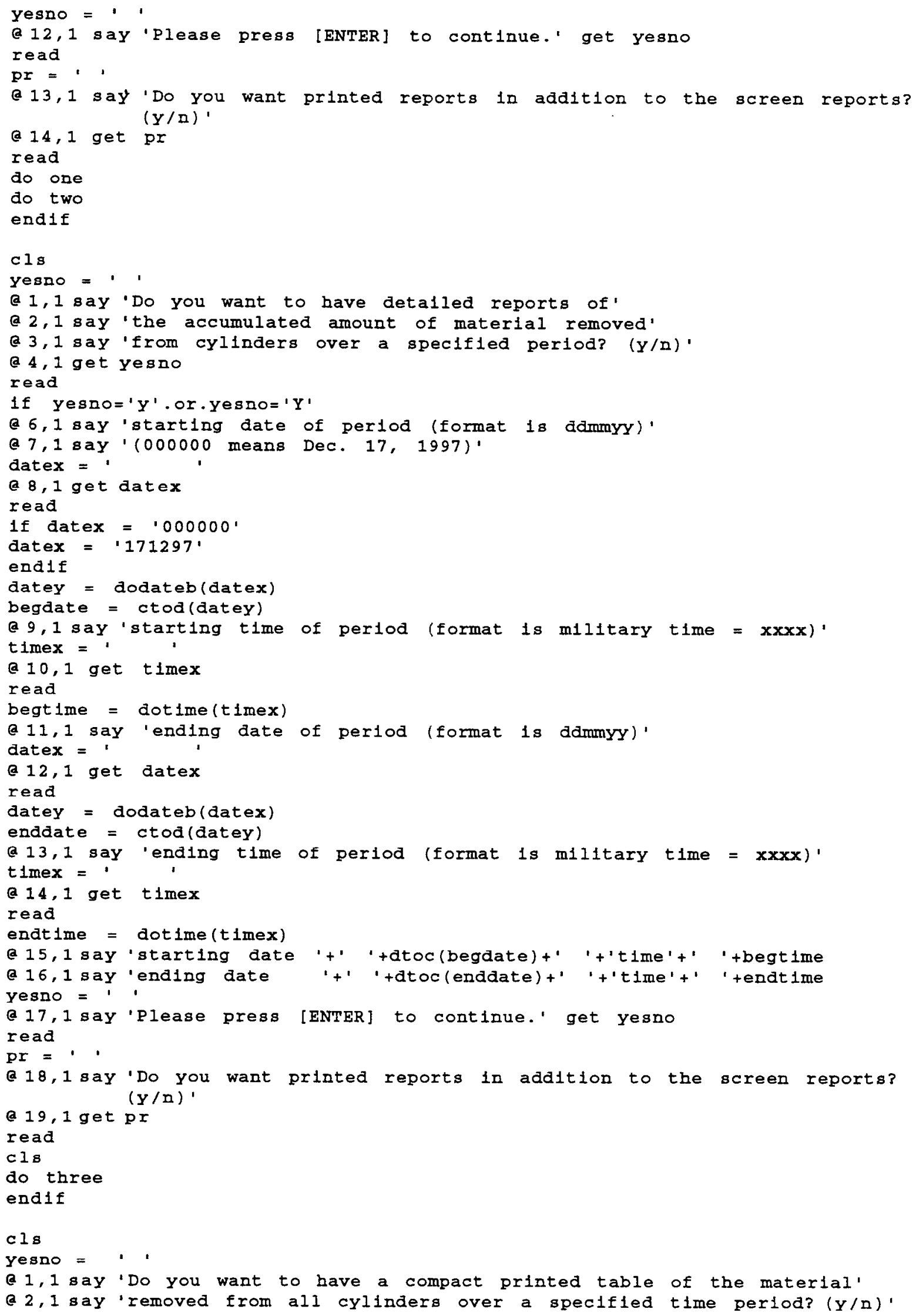




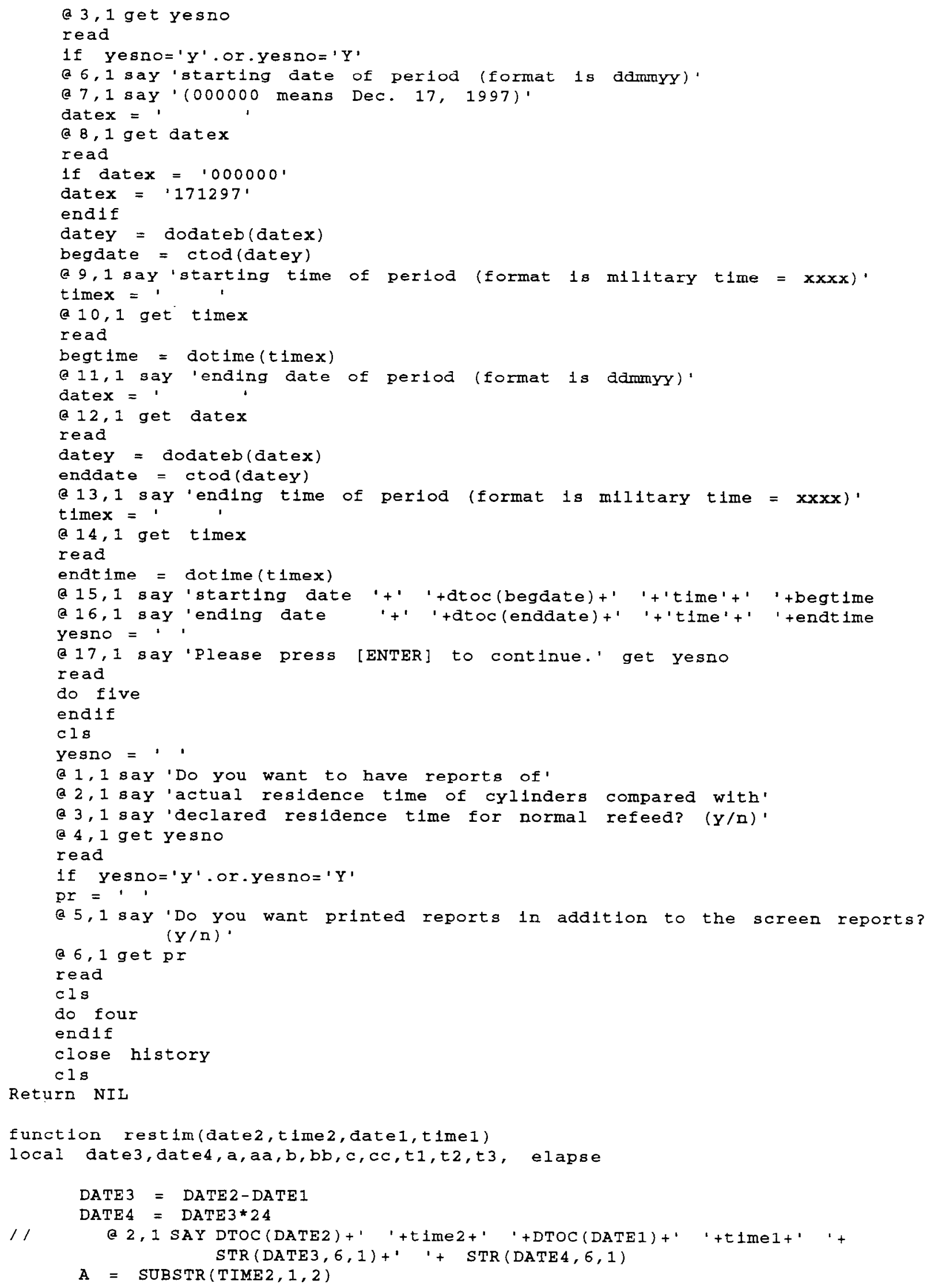




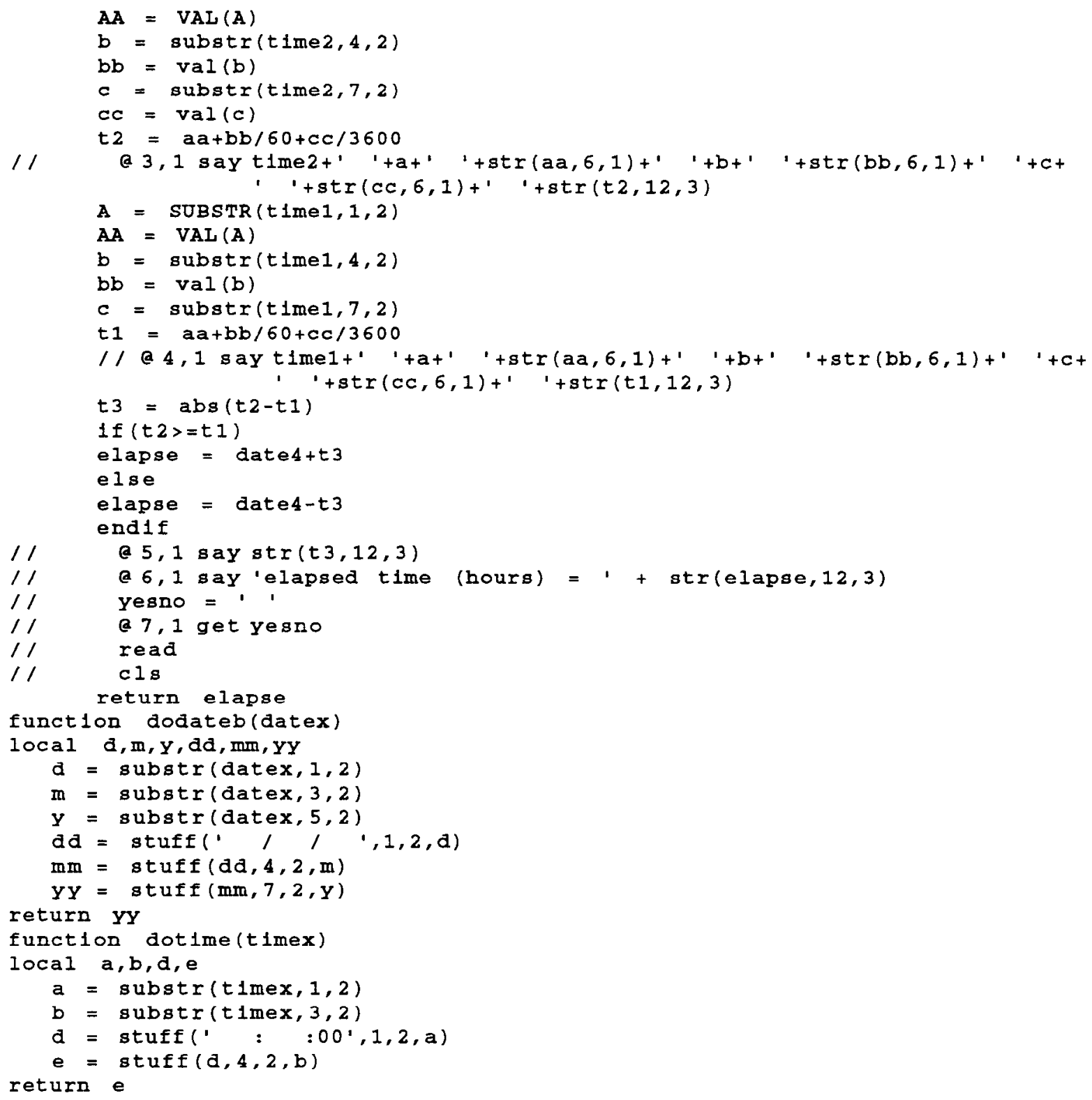




\section{Appendix Q}

2) CLIPPER5 source code for the program to generate reports for cylinders that should be attached to feed stations because the residence time has not been exceeded

file c: Isnrilsrcliaealone.prg

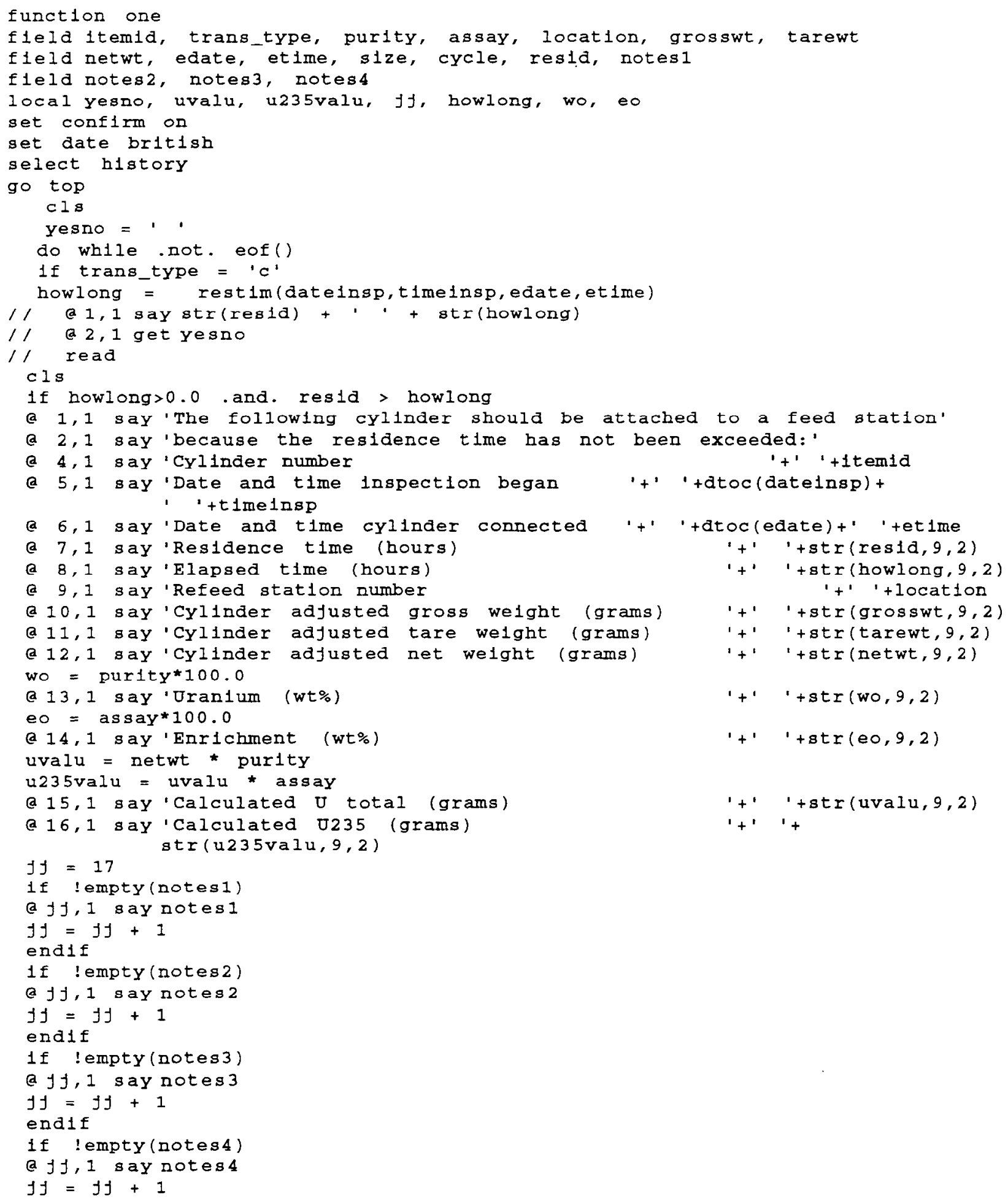




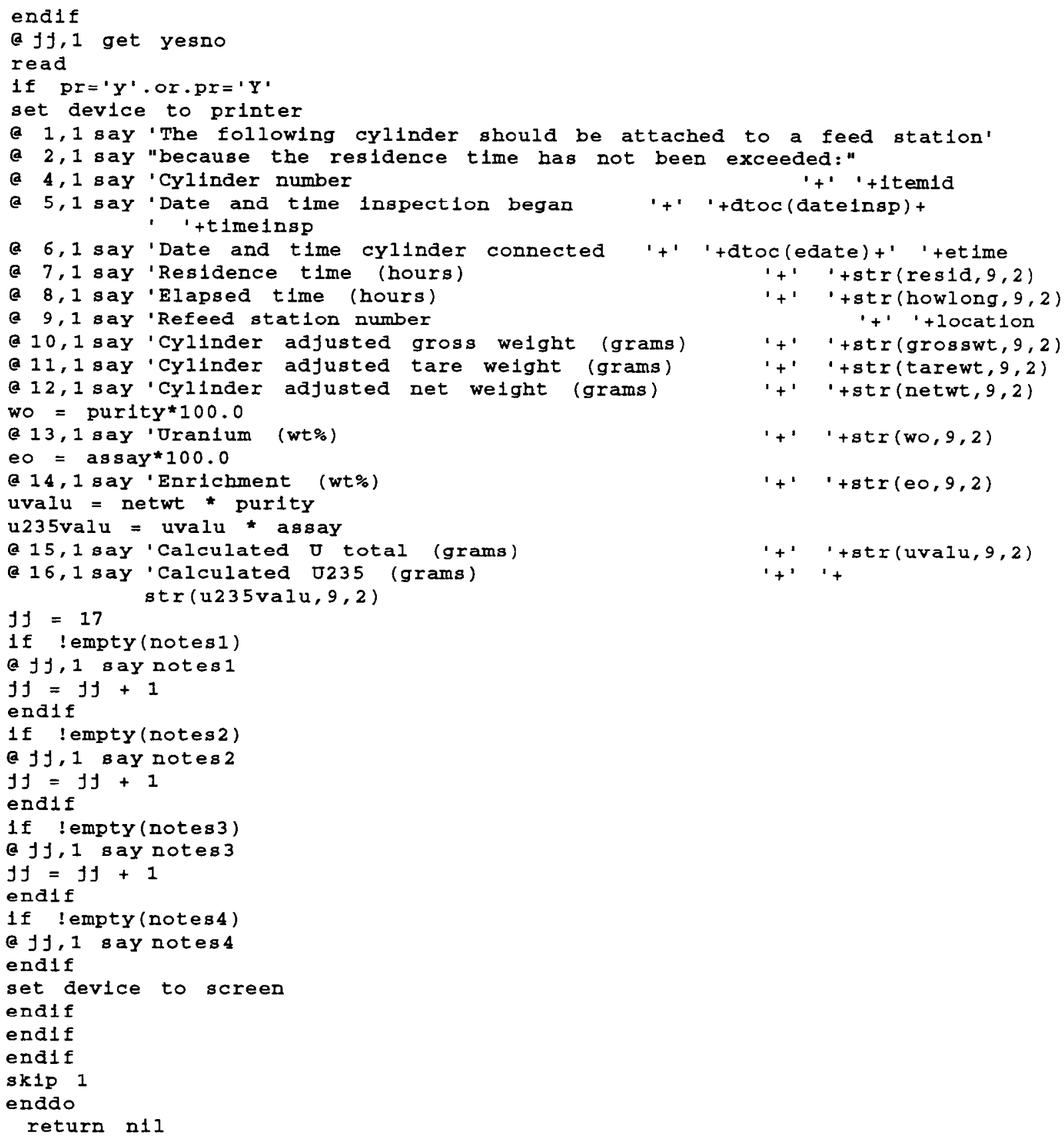




\section{Appendix Q}

3) CLIPPER5 source code for the program to generate reports for cylinders that should be attached to feed stations because there is no disconnect recorded

file c: Isnri \srcliaealtwo.prg

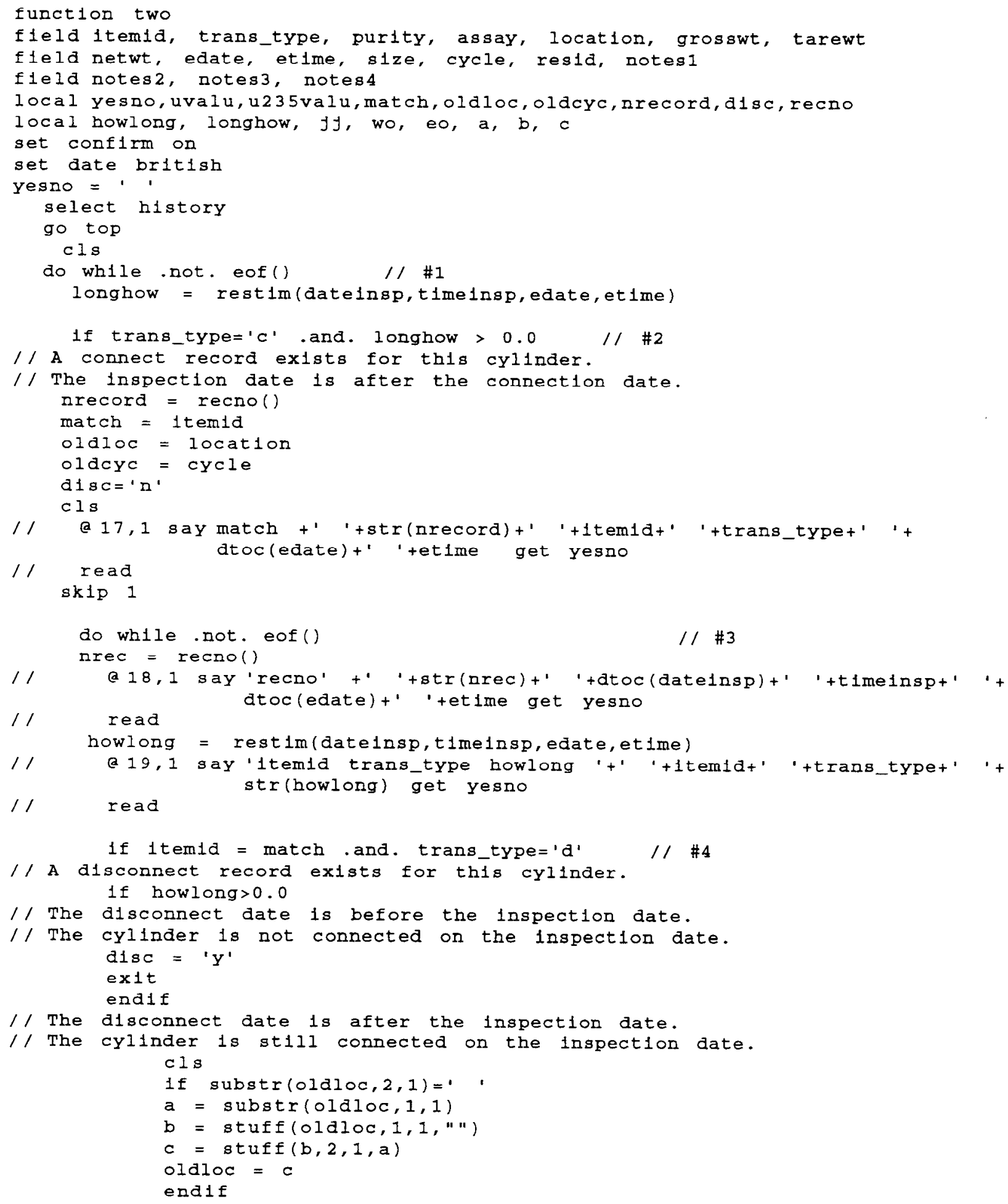




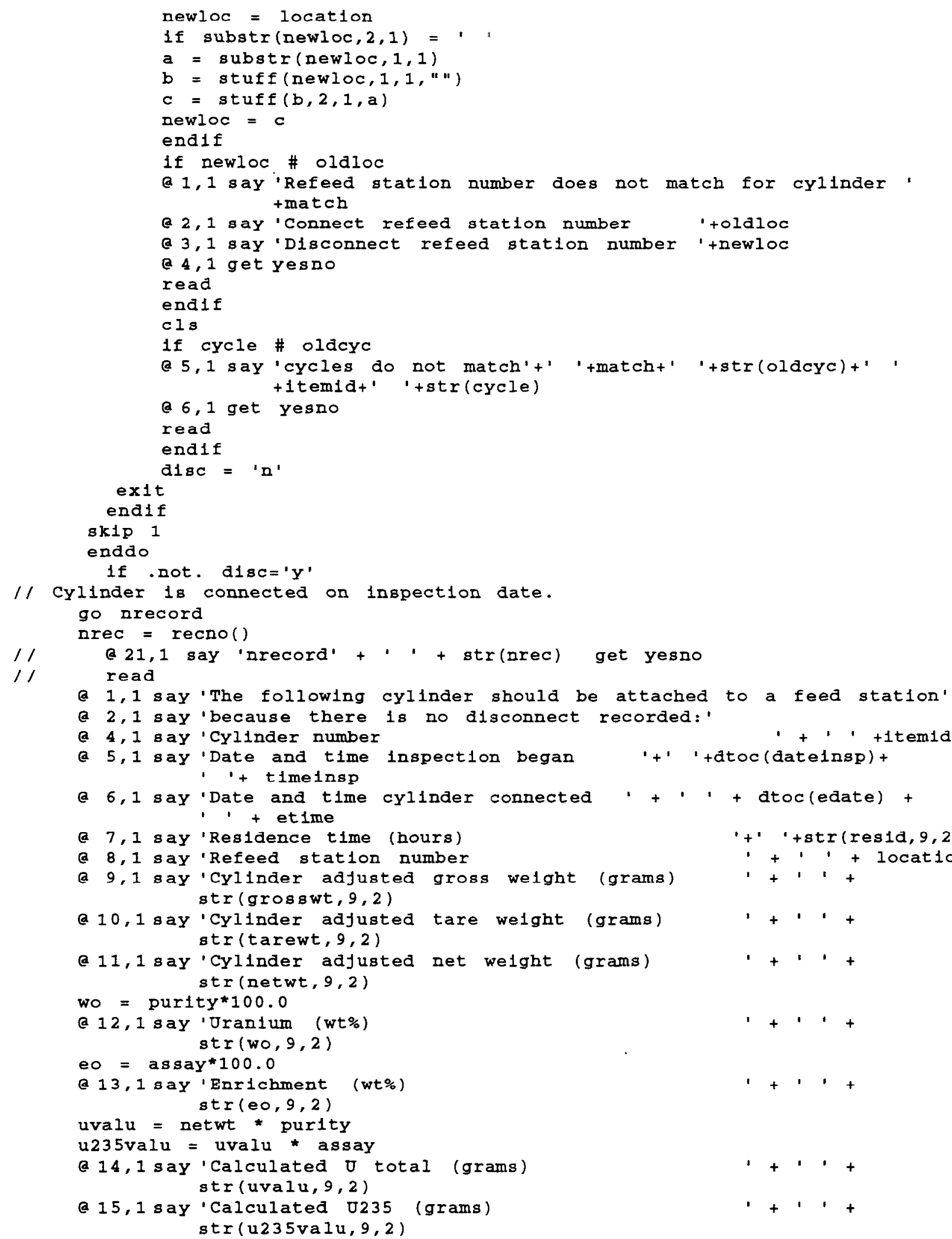




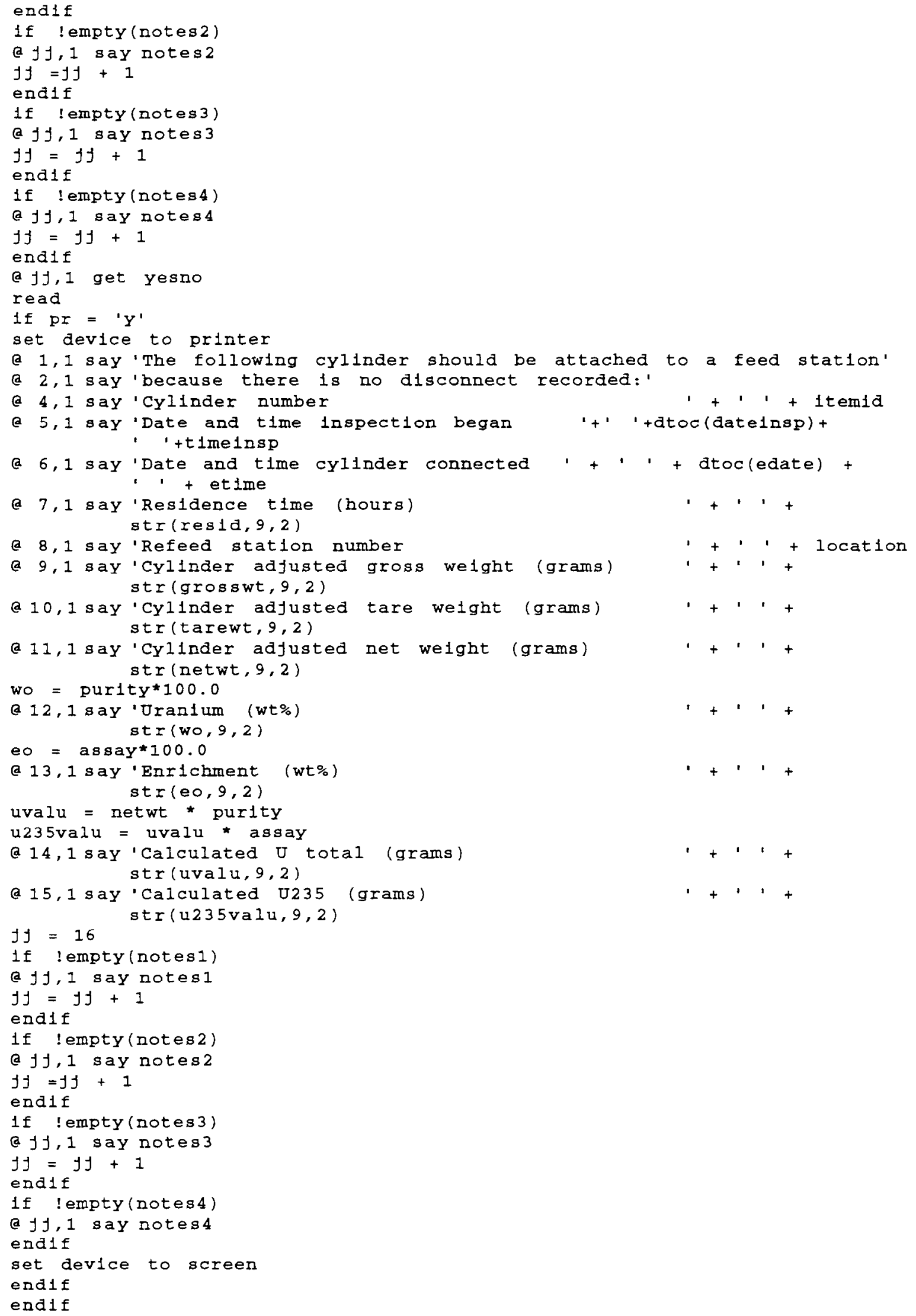


$1 /$ a 20,1 say 'end of outer loop recno' get yesno

$1 /$ read go nrecord

endif

skip 1

enddo

return $n 11$ 


\section{Appendix Q}

4) CLIPPER5 source code for the program to generate detailed reports of the accumulated amount of material removed from cylinders over a specified period

file c: Isnritsrcliaealthree.prg

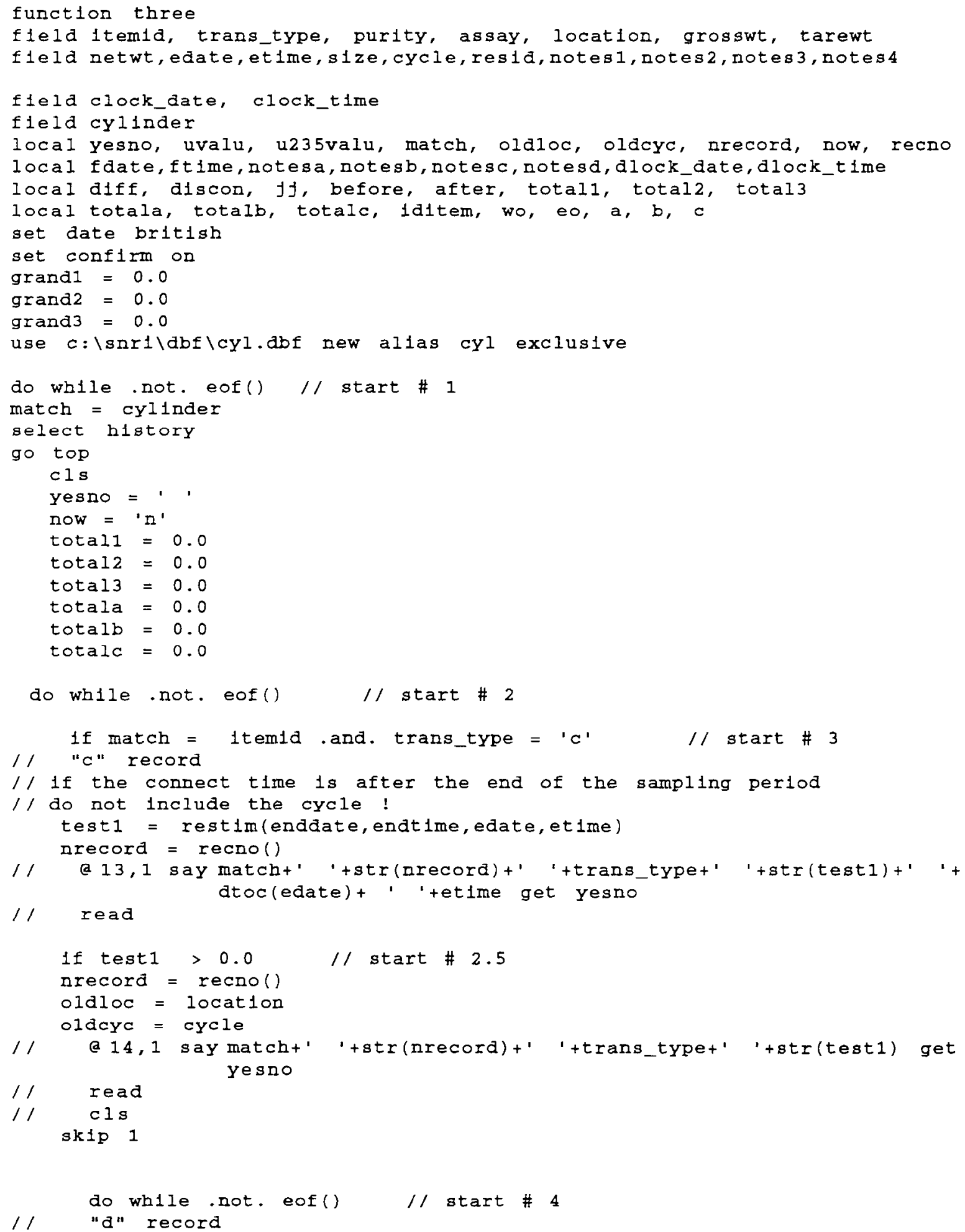




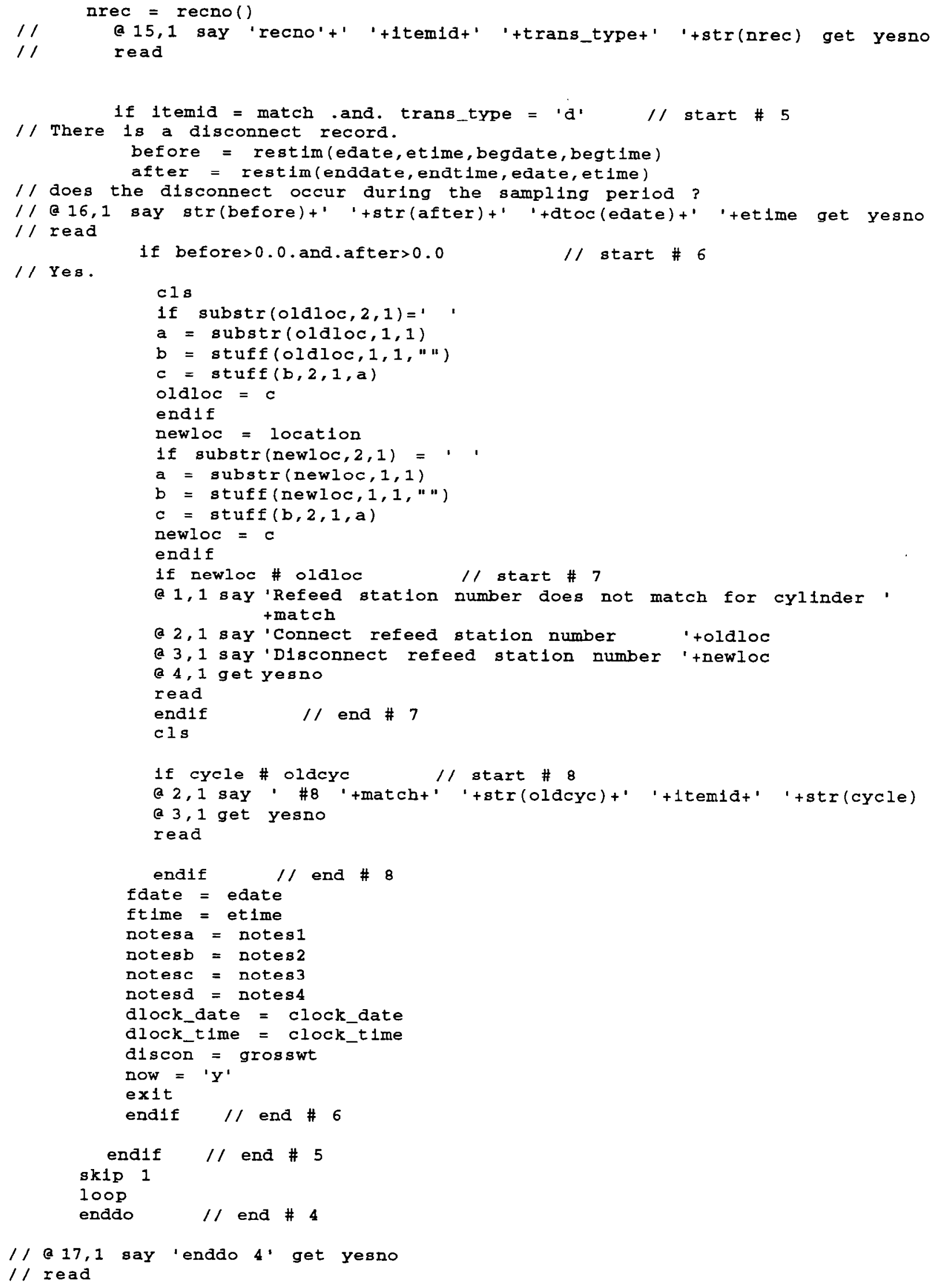




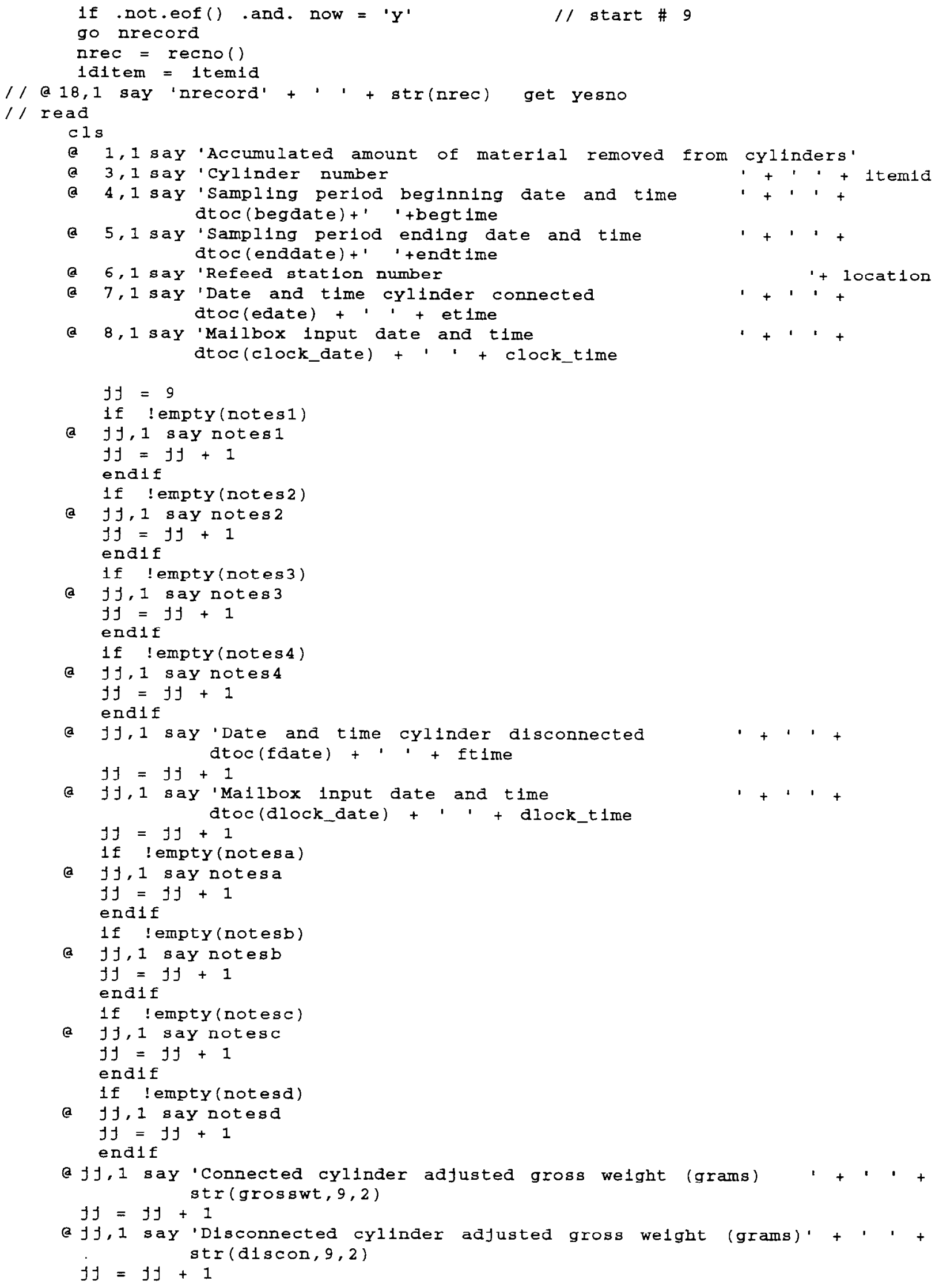




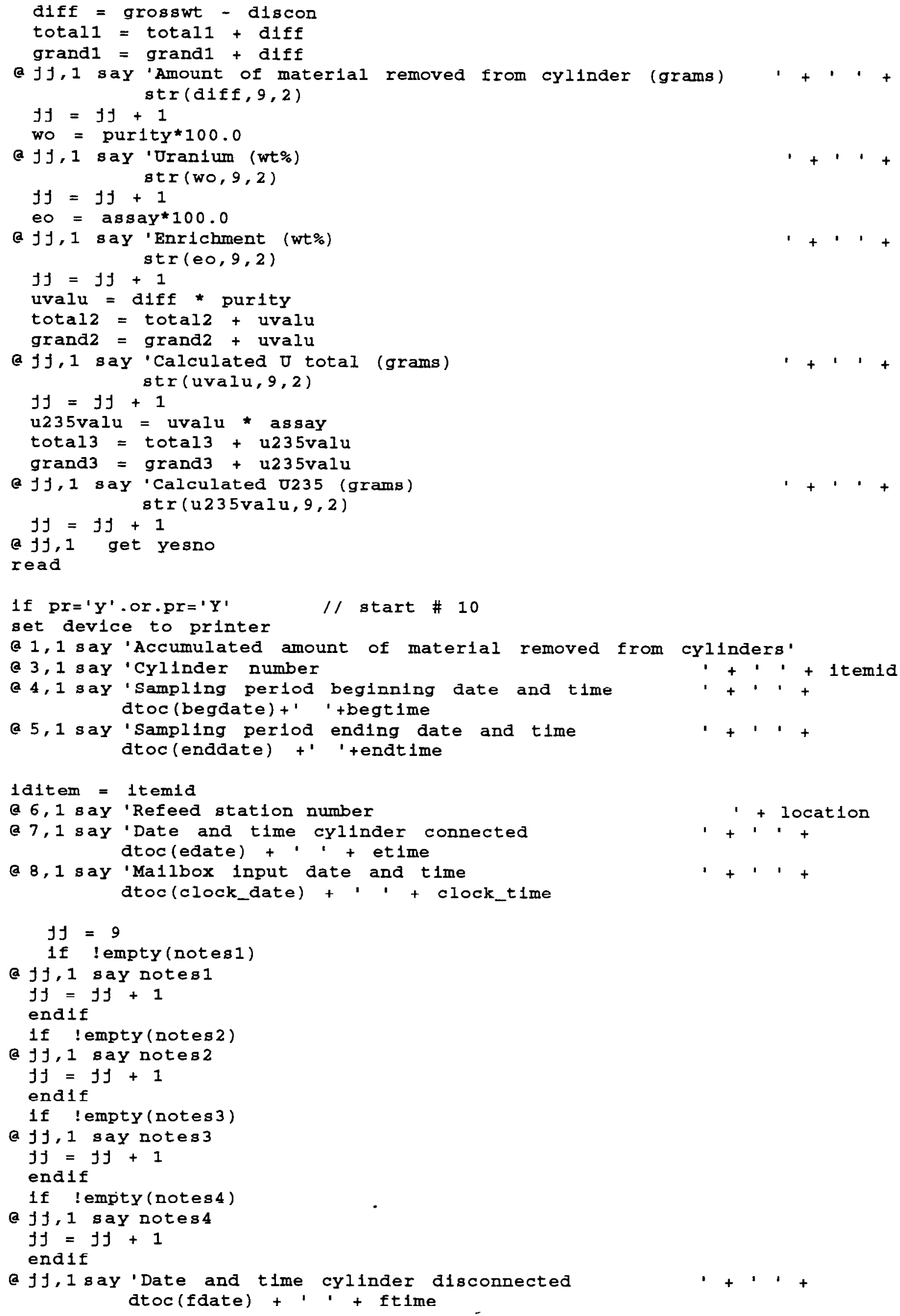




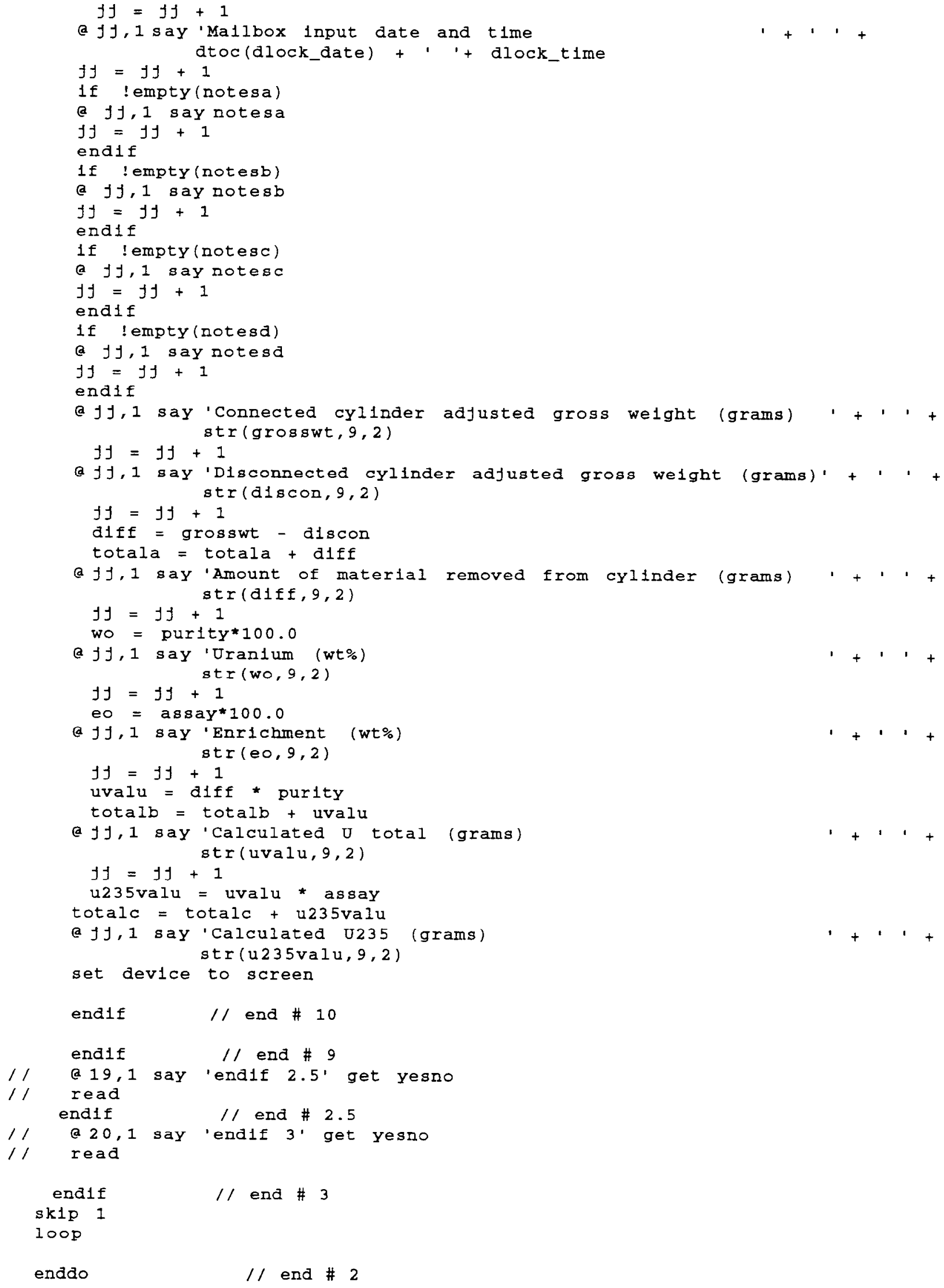




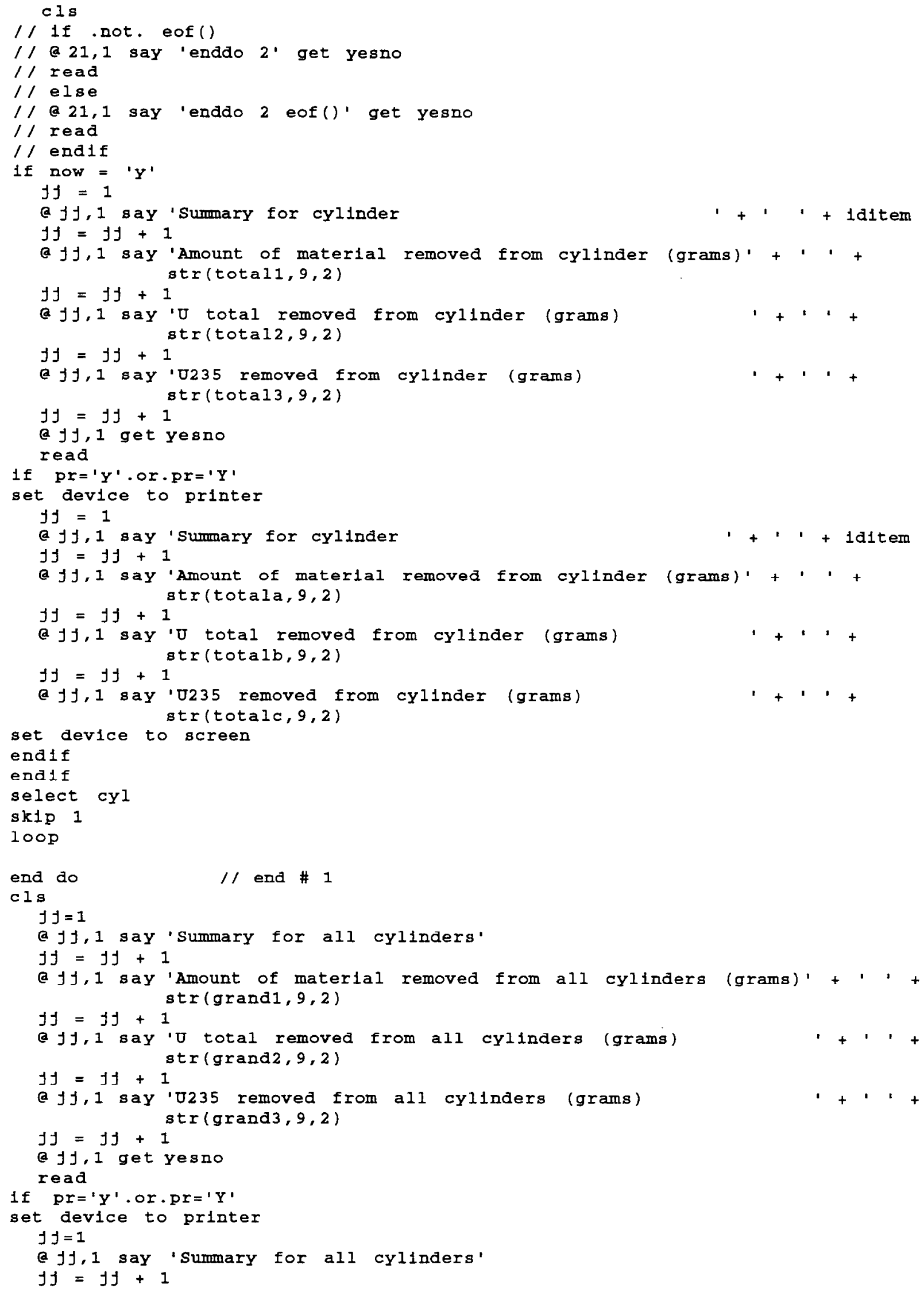




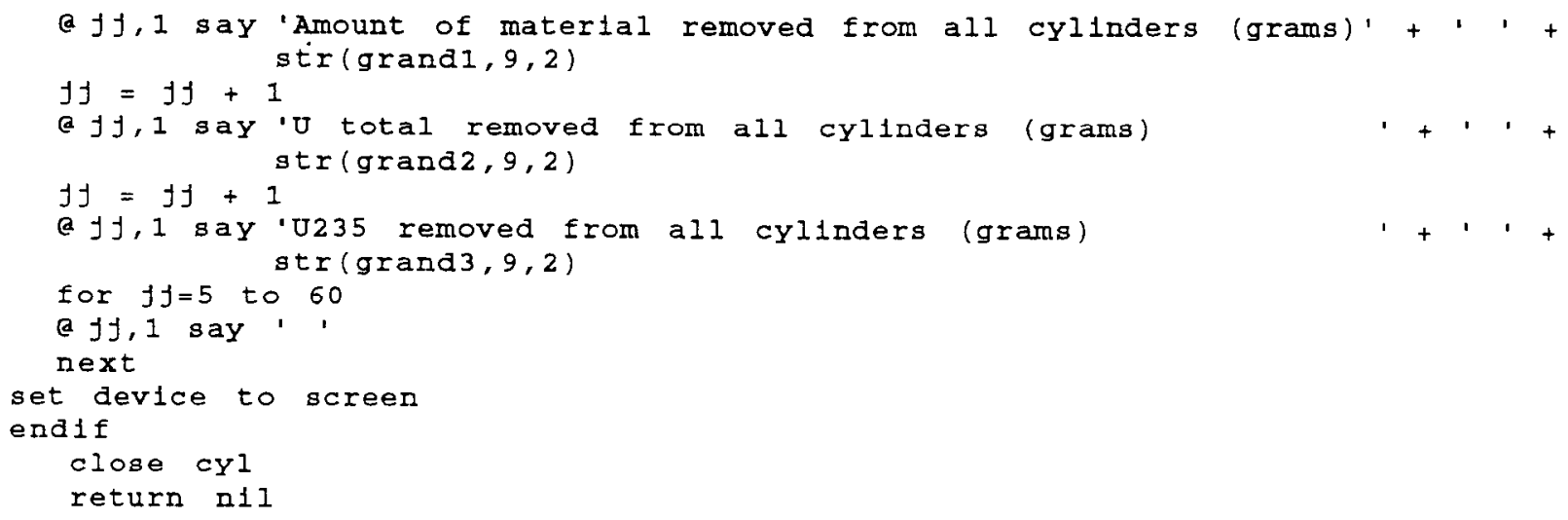




\section{Appendix Q}

5) CLIPPER5 source code for the program to generate reports of actual residence time compared with declared residence time for normal refeed

file c:lsnrilsrcliaealfour.prg

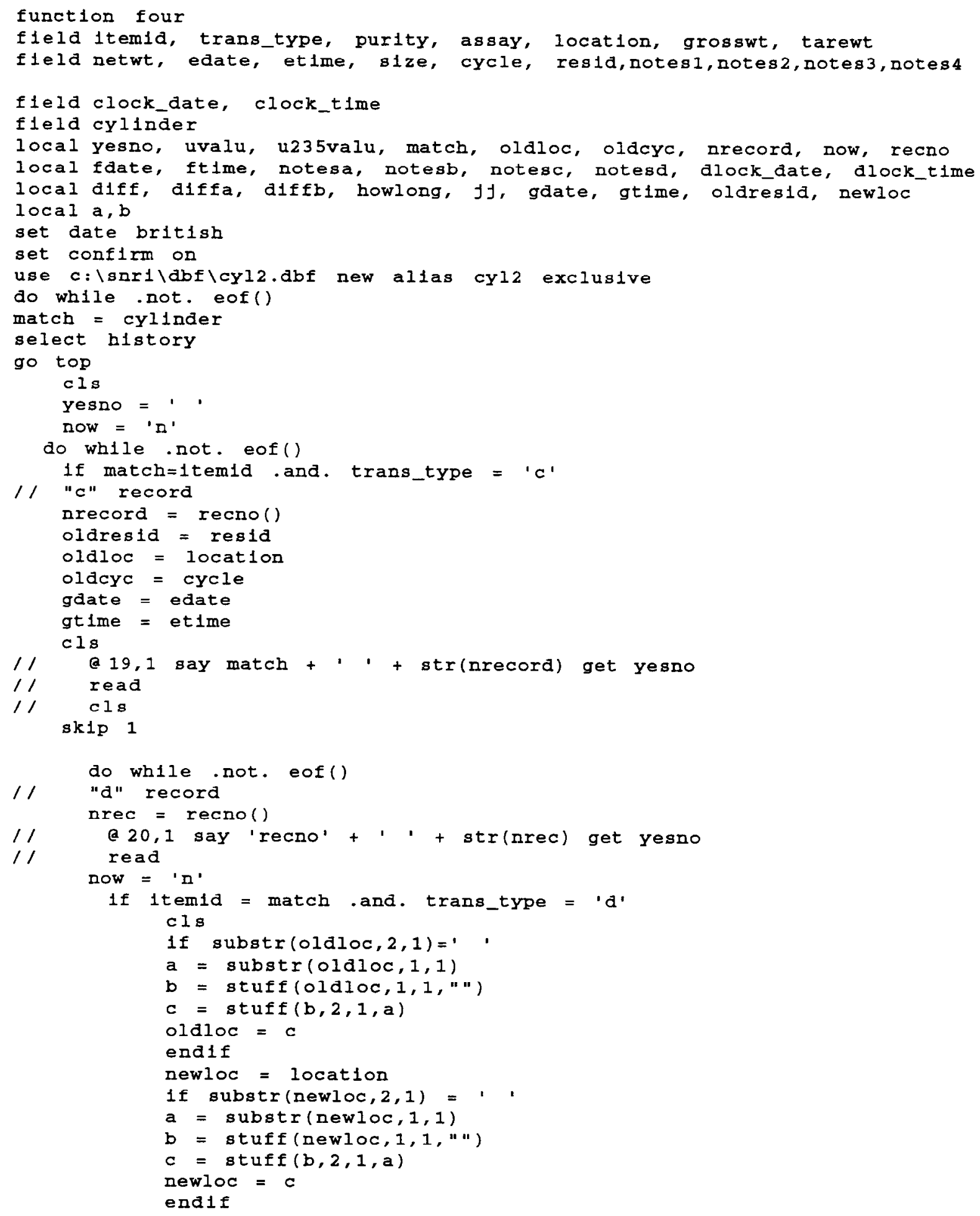




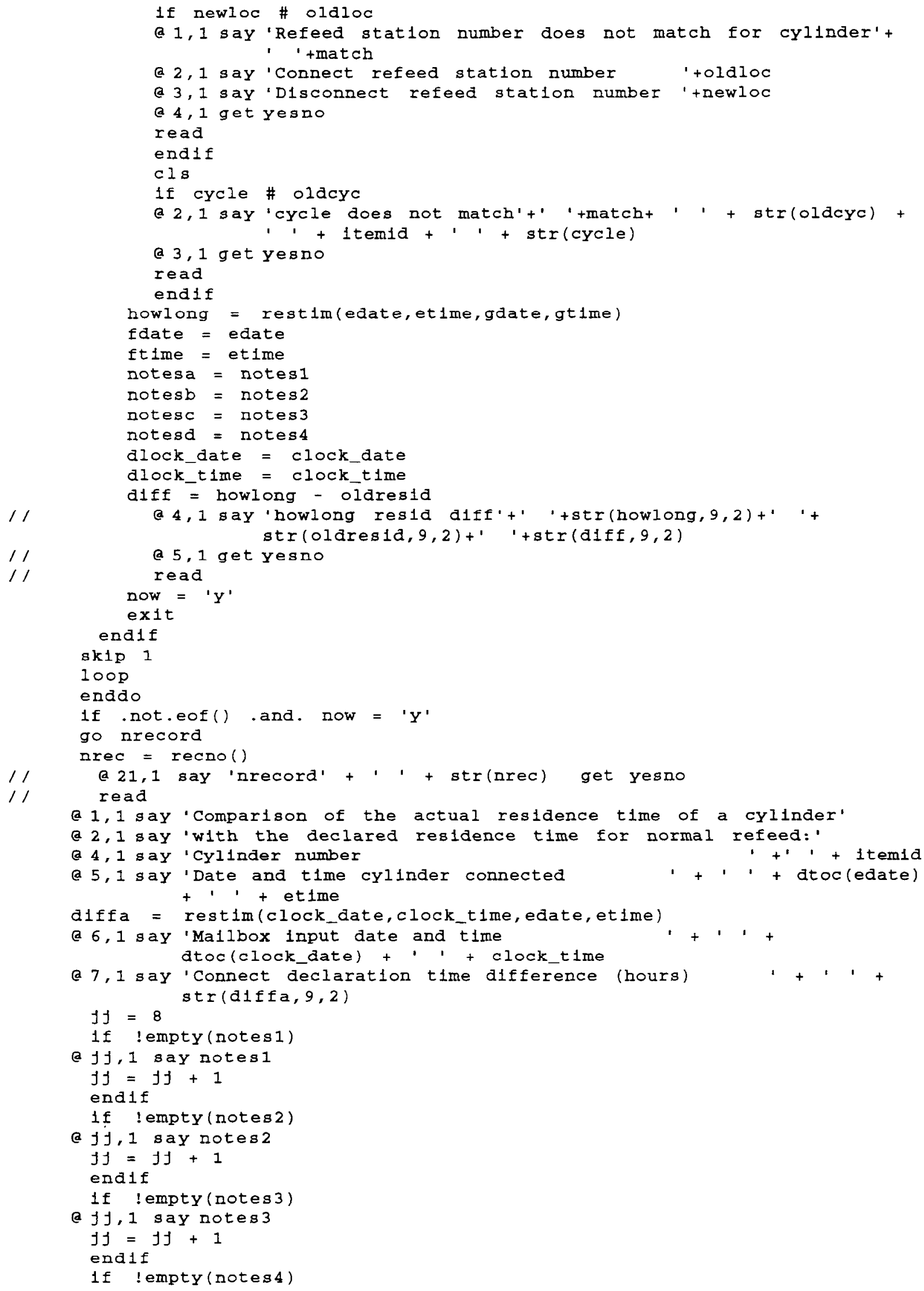




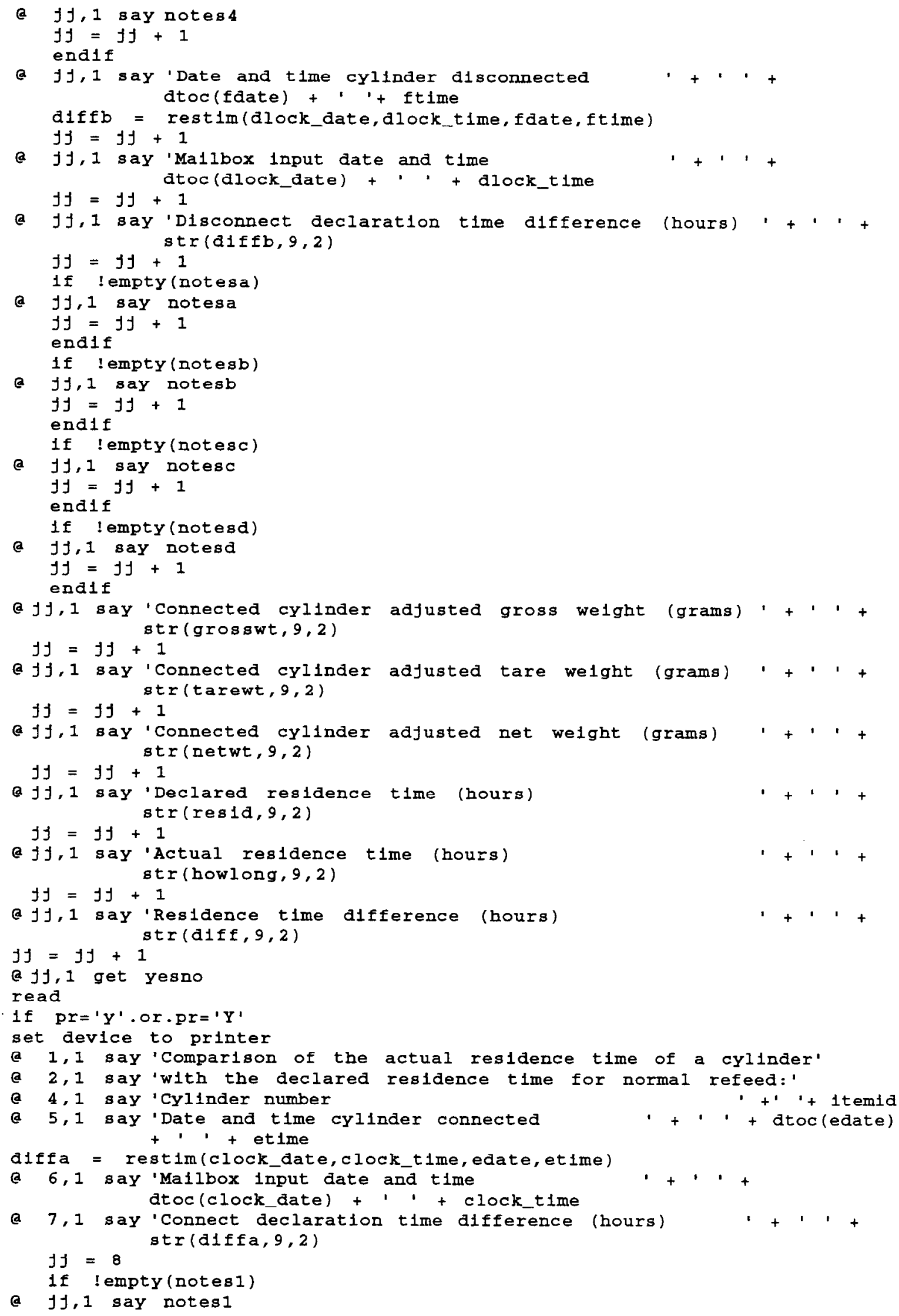




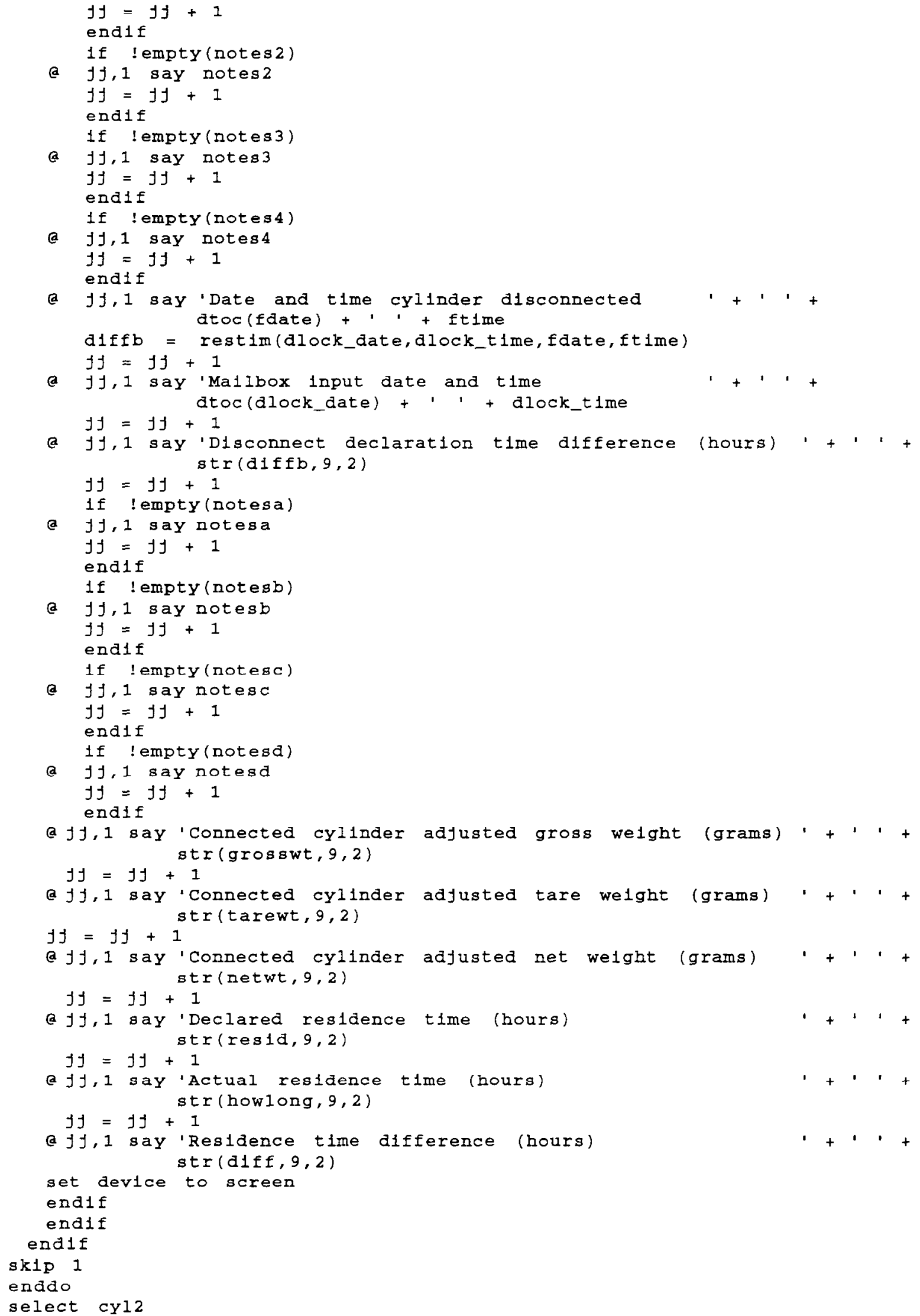


sk1p 1

$100 p$

enddo

close cyl2

return n1l 


\section{Appendix Q}

6) CLIPPER5 source code for the program to generate a compact printed table of the material removed from all cylinders over a specified period

file c: Isnrisrcliaealfive.prg

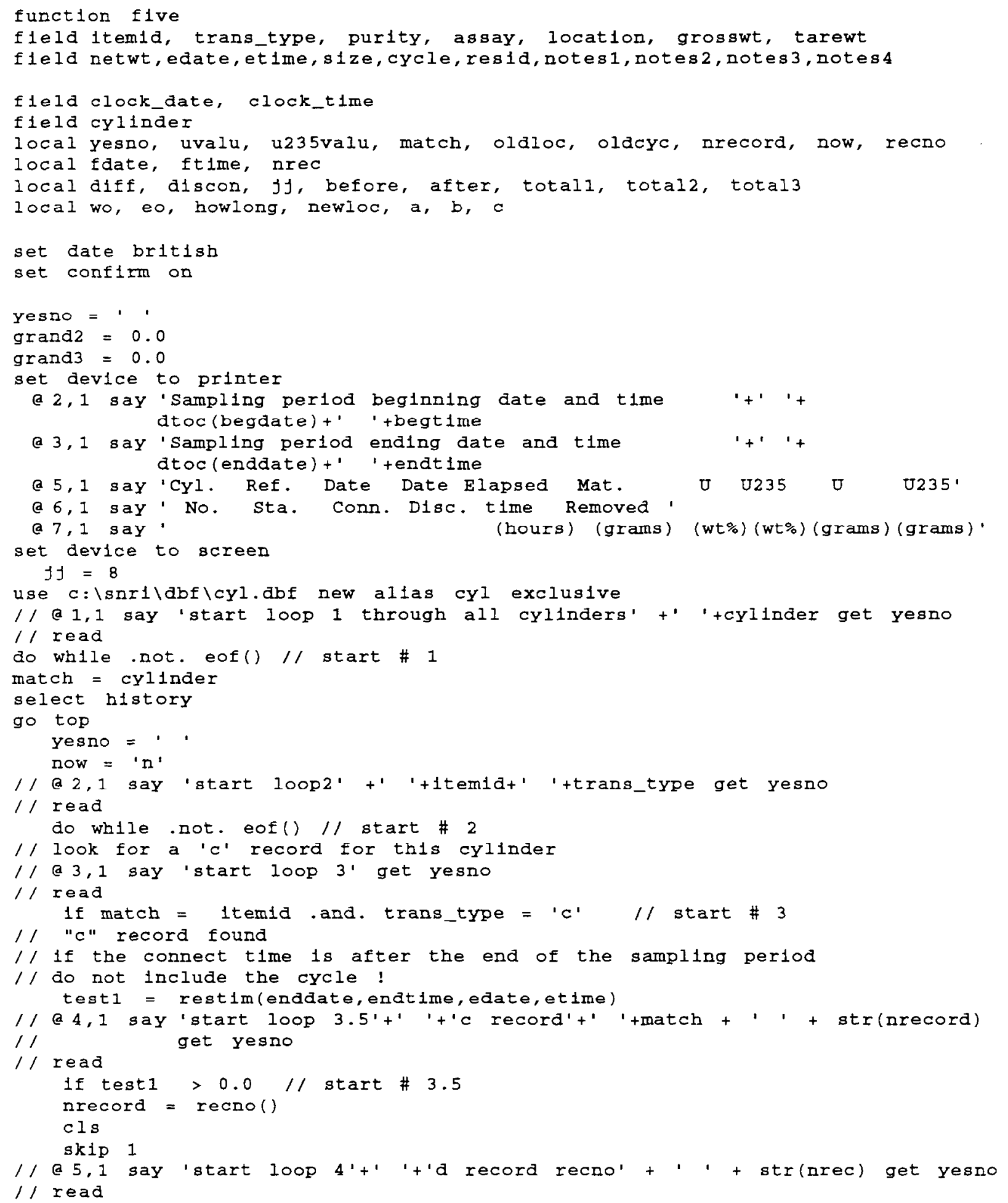




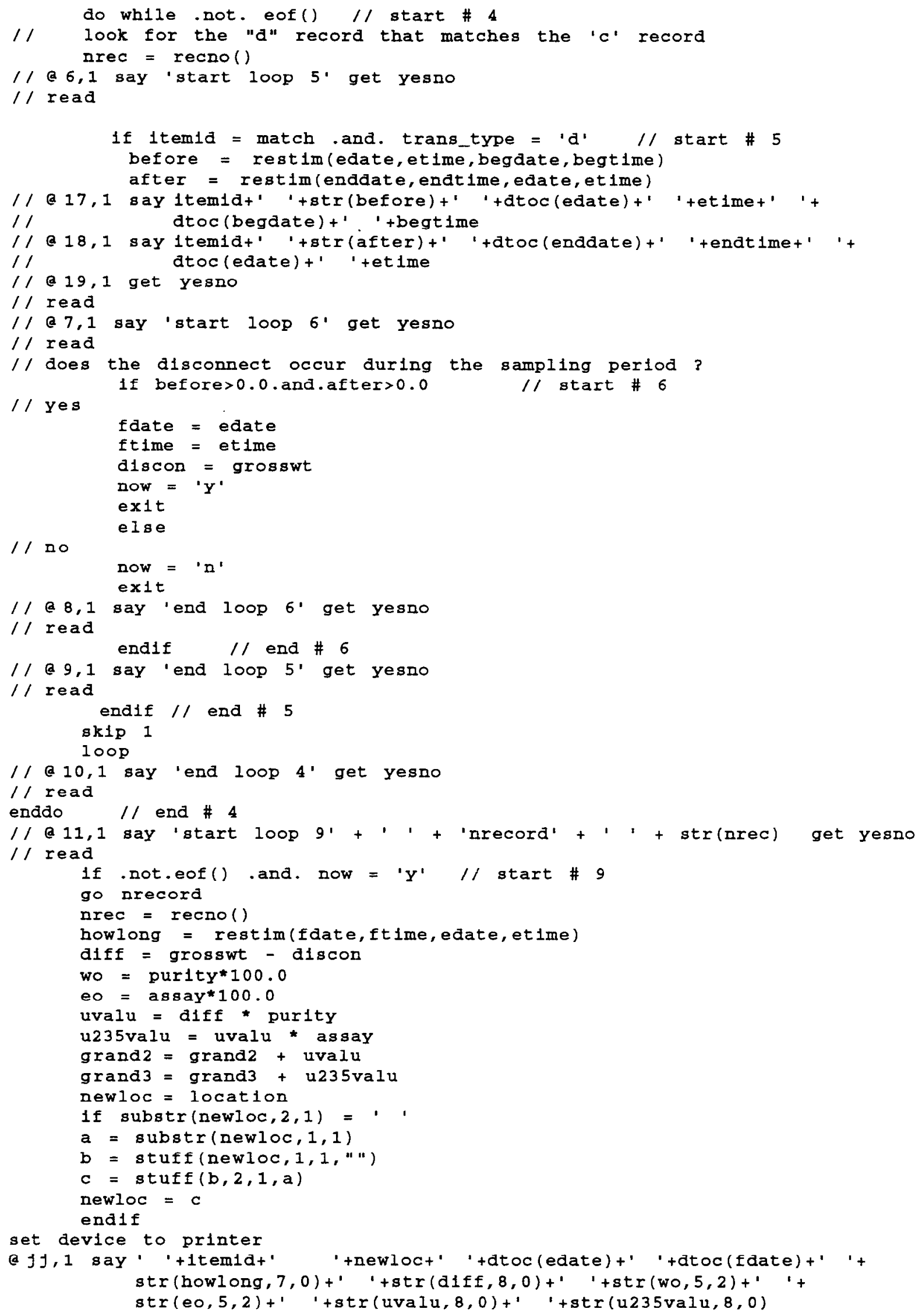




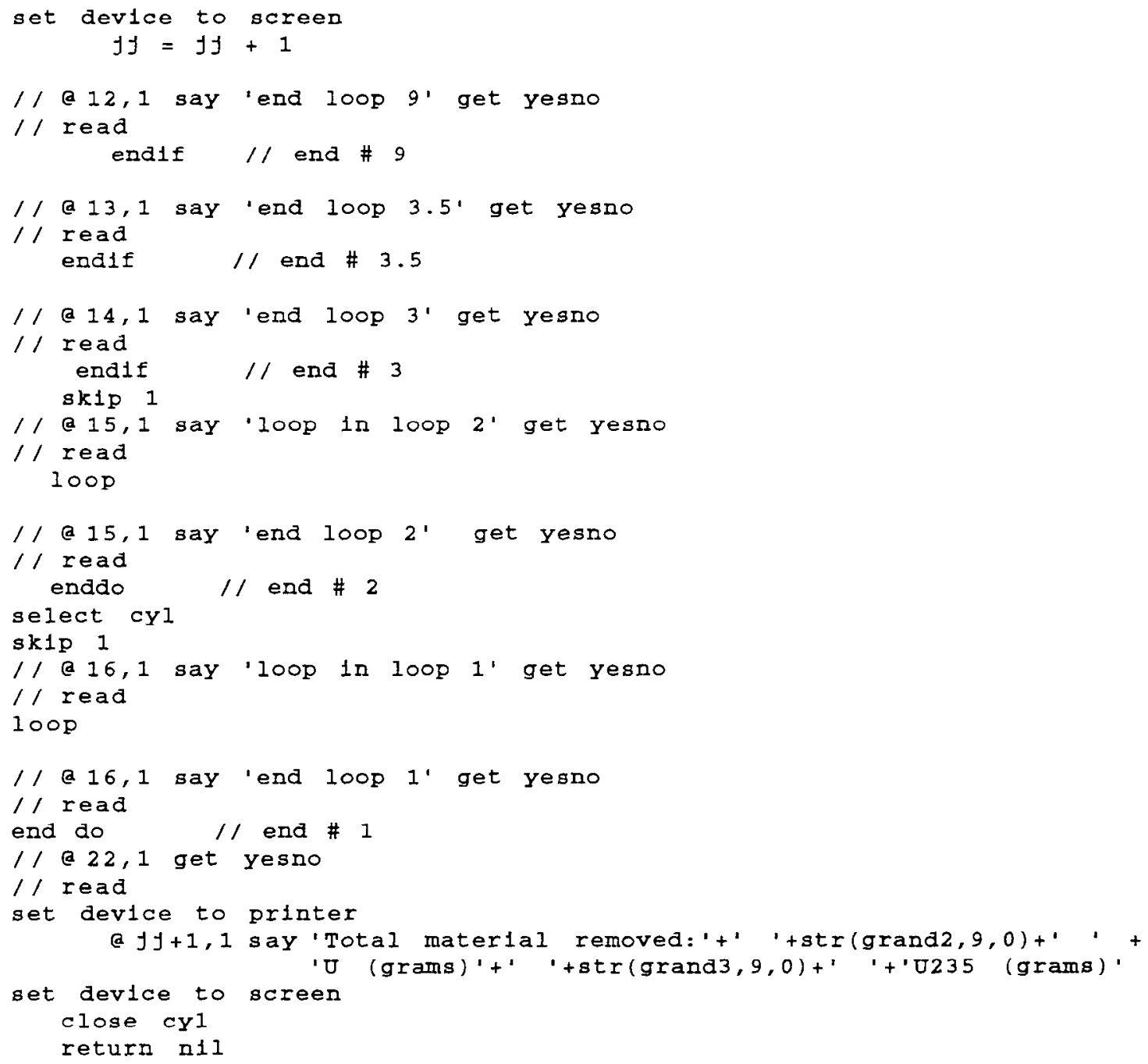




\section{Appendix Q}

7) Listing of input data to the CLIPPER RMAKE utility file c: Isnrisrcliaealiaea.rmk

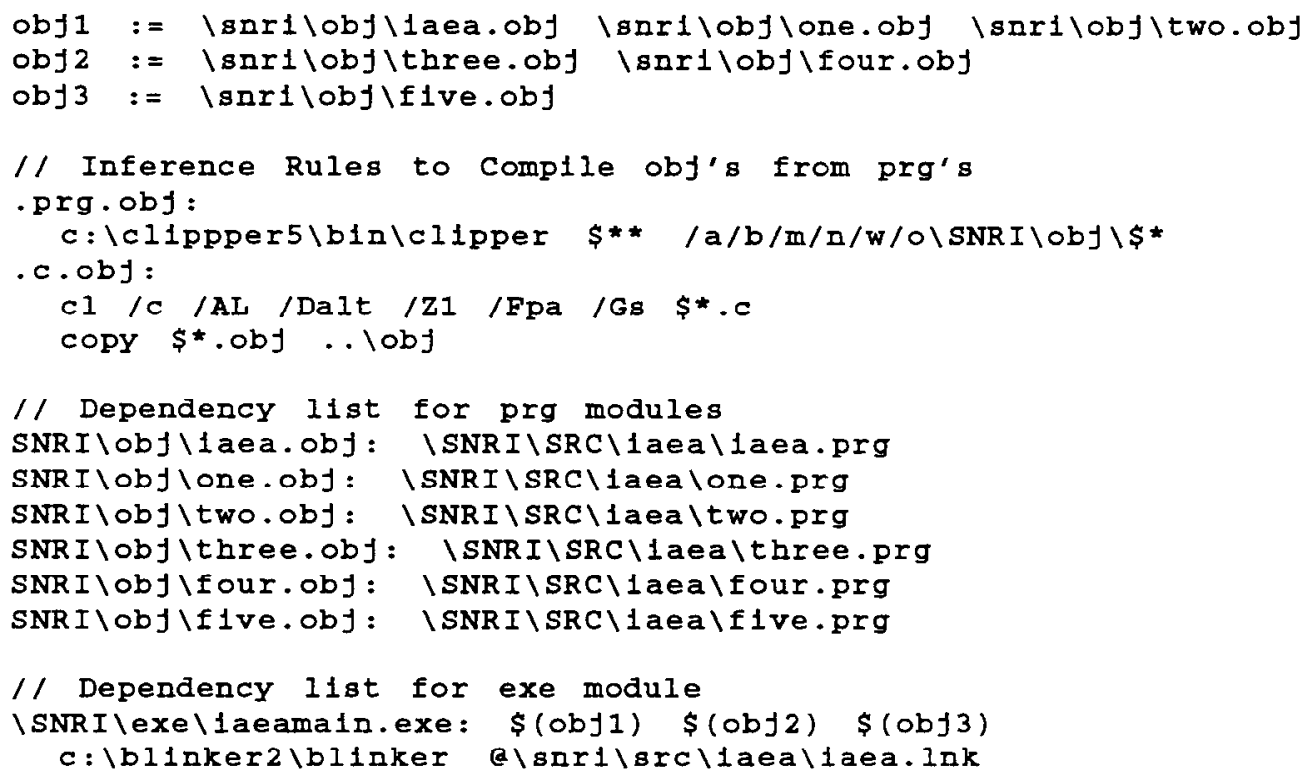

8) Listing of input to the BLINKER2 loader file c: Isnrilsrcliaealiaea.lnk

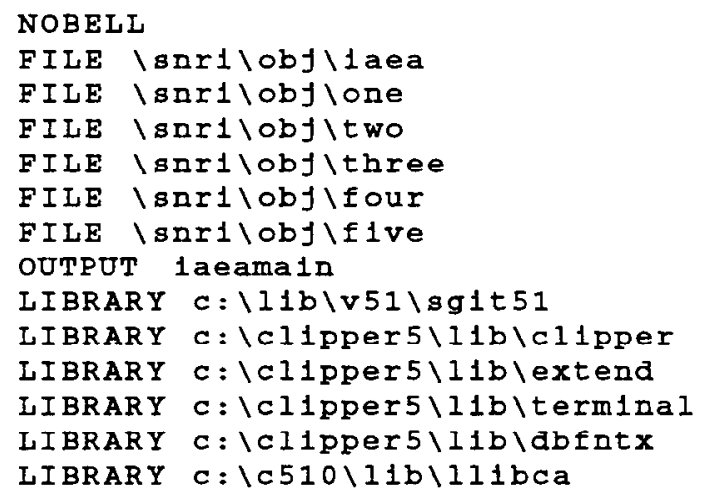

9) Batch file to execute the report generator program

file c:treports.bat

aecho off

reptmain \%1 
(THIS PAGE INTENTIONALLY LEFT BLANK)

Q-28 


\section{Appendix R}

\section{Sample Reports}

1) Sample listing of declarations for cylinder operations

2) Report of a cylinder that should be attached to a feed station because its residence time has not been exceeded

3) Report of a cylinder that should be attached to a feed station because there is no cylinder disconnection reported for it

4) Detailed report of the accumulated amount of uranium removed from cylinders over a specified period

5) Compact printed table of the uranium removed from all cylinders over a specified period

6) Report of actual residence time of a cylinder compared with its declared residence time for normal refeed operations 


\section{Appendix R}

\section{1) Sample listing of declarations for cylinder operations}

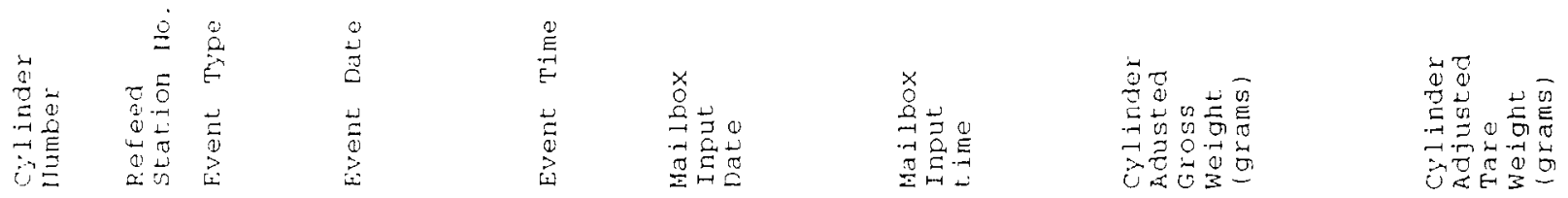

\begin{tabular}{|c|c|c|c|c|c|c|c|c|}
\hline $\operatorname{sto}+44$ & 05 & d & $01: 20 / 98$ & $09: 18: 00$ & $01 / 20 / 98$ & $11: 32: 05$ & 26120.000 & 25618.000 \\
\hline 050099 & Dó & $d$ & $01 / 20 / 98$ & $09: 19: 00$ & $01 / 20 / 98$ & $11: 32: 05$ & 28870.000 & 28331.000 \\
\hline $17540: 9$ & 05 & $c$ & $01 / 20 / 98$ & $10: 37: 00$ & $01 / 20 / 98$ & $11: 32: 05$ & 35180.000 & 28037.000 \\
\hline 051874 & 05 & c & $01 / 20 / 98$ & $10: 35: 00$ & $01 / 20 / 98$ & $11: 32: 05$ & 43890.000 & 26827.000 \\
\hline sto142 & 02 & d & $01 / 21 / 98$ & $14: 27: 00$ & $01 / 21 / 98$ & $15: 21: 14$ & 25790.000 & 25306.000 \\
\hline sto298 & 02 & $c$ & $01 / 21 / 98$ & $15: 09: 00$ & $01 / 21 / 98$ & $15: 21: 14$ & 42280.000 & 25943.000 \\
\hline sto120 & 03 & i & $01 / 22 / 98$ & $09: 36: 00$ & $01 / 22 / 98$ & $14: 14: 51$ & 25800.000 & 25475.000 \\
\hline 051938 & 08 & $d$ & $21 / 22 / 98$ & $09: 37: 00$ & $01 / 22 / 98$ & $14: 14: 51$ & 29820.000 & 28896.000 \\
\hline sto100 & 10 & a & $01 ; 22 ; 98$ & $09: 38: 00$ & $01 / 22 / 98$ & $14: 14: 51$ & 26560.000 & 26166.000 \\
\hline st0138 & 03 & $c$ & $01 / 22,98$ & $12: 32: 00$ & $01 / 22 / 98$ & $14: 14: 51$ & 36400.000 & 25686.000 \\
\hline st0273 & 08 & c & $01: 22,98$ & $12: 36: 00$ & $01 / 22 / 98$ & $14: 14: 51$ & 39100.000 & 25417.000 \\
\hline$s t 0275$ & 10 & $c$ & $01: 22 / 98$ & $12: 40: 00$ & $01 / 22 / 98$ & $14: 14: 51$ & 32650.000 & 26214.000 \\
\hline sto085 & 07 & d & $01 / 23 / 98$ & $08: 50: 00$ & $01 / 23 / 98$ & $15: 28: 45$ & 26420.000 & $256: 5.000$ \\
\hline sto355 & 00 & a & $01: 23 / 98$ & $08: 45: 00$ & $01 / 23 / 98$ & $15: 28: 45$ & 25180.000 & 25742.000 \\
\hline$s 00 ? 67$ & 07 & $c$ & $0: 123 / 98$ & $10: 05: 00$ & $01 / 23 / 98$ & $15: 28: 45$ & 26270.000 & 26038.000 \\
\hline$s=0396$ & 09 & c & $01 / 23 / 98$ & $10: 09: 00$ & $01 / 23 / 98$ & $15: 28: 45$ & 34040.000 & 25679.000 \\
\hline$n 54019$ & 05 & d & $01 / 24,98$ & $09: 00: 00$ & $01 / 24 / 98$ & $11: 41: 53$ & 28410.000 & 28037.000 \\
\hline 051871 & 06 & a & $01 / 24 / 98$ & $09: 05: 00$ & $01 / 24 / 98$ & $11: 41: 53$ & 27170.000 & 26827.000 \\
\hline st0038 & 05 & c & $01 / 24 / 98$ & $10: 20: 00$ & $01 / 24 / 98$ & $11: 41: 53$ & 41250.000 & 25256.000 \\
\hline 051528 & 06 & C & $01 / 24 / 98$ & $10: 15: 00$ & $01 / 24 / 98$ & $11: 41: 53$ & 38630.000 & 27524.000 \\
\hline$s t 0298$ & 02 & d & $0: / 25 / 98$ & $09: 15: 00$ & $0: / 25 / 98$ & $11: 28: 59$ & 26320.000 & 25943.000 \\
\hline$s 50275$ & 20 & d & $01 / 25 / 98$ & $09: 20: 00$ & $01 / 25 / 98$ & $11: 28: 59$ & 25340.000 & 26214.000 \\
\hline st0122 & 02 & c & $01 / 25 / 98$ & $10: 00: 00$ & $01 / 25 / 98$ & $11: 28: 59$ & 38260.000 & 25075.000 \\
\hline $8+0260$ & 10 & $c$ & $01 / 25 / 98$ & $10: 05: 00$ & $01 / 25 / 98$ & $1:: 28: 59$ & 36900.000 & 26395.000 \\
\hline
\end{tabular}




\section{Appendix R}

2) Report of a cylinder that should be attached to a feed station because its residence time has not been exceeded

The following cylinder should be attached to a feed station because the residence time has not been exceeded:

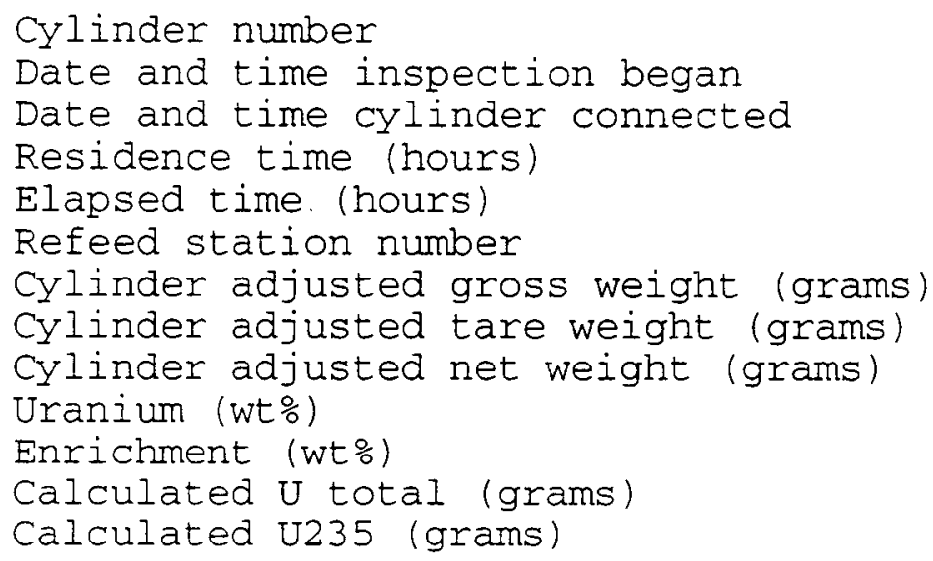

$$
\text { st } 0038
$$$$
26 / 01 / 98 \quad 13: 30: 00
$$$$
24 / 01 / 98 \quad 10: 20: 00
$$$$
66.00
$$$$
51.17
$$

41250.00

25256.00

15994.00

67.34

96.42

10770.36

10384.78 


\section{Appendix R}

3) Report of a cylinder that should be attached to a feed station because there is no cylinder disconnection reported for it

The following cylinder should be attached to a feed station because there is no disconnect recorded:

Cylinder number

Date and time inspection began

Date and time cylinder connected

Residence time (hours)

Refeed station number

Cylinder adjusted gross weight (grams)

Cylinder adjusted tare weight (grams)

st 0122

$26 / 01 / 98 \quad 13: 30: 00$

$25 / 01 / 98 \quad 10: 20: 00$

66.00

Cylinder adjusted net weight (grams)

Uranium (wt\%)

Enrichment (wt\%)

Calculated $U$ total (grams)

Calculated U235 (grams)

67.35

93.06

8880.10

8263.82 


\section{Appendix R}

\section{4) Detailed report of the accumulated amount of uranium removed from cylinders}

over a specified period

Accumulated amount of material removed from cylinders

Cylinder number

Sampling period beginning date and time

Sampling period ending date and time

Refeed station number

Date and time cylinder connected

Mailbox input date and time

Date and time cylinder disconnected

Mailbox input date and time

Connected cylinder adjusted gross weight (grams)

Disconnected cylinder adjusted gross weight (grams)

$\begin{array}{rr}\text { st0 } 0298 \\ 17 / 12 / 97 & 00: 01: 00\end{array}$

$26 / 01 / 98 \quad 13: 30: 00$

Amount of material removed from cylinder (grams)

Uranium (wt: )

Enrichment (wto)

Calculated U total (grams)

02

Calculated U235 (grams)

21/01/98 15:09:00

$21 / 01 / 98 \quad 15: 21: 14$

$25 / 01 / 98 \quad 09: 15: 00$

$25 / 01 / 98 \quad 11: 28: 59$

42280.00

26320.00

15960.00

67.30

96.61

10741.08

10376.96

Summary for cylinder

Amount of material removed from cylinder (grams)

st0298

$U$ total removed from cylinder (grams)

U235 removed from cylinder (grams)

15960.00

10741.08

10376.96

Summary for all cylindera

Amount of material removed from all cylinders (grams) $\quad 45760.00$

$\mathrm{U}$ total removed from all cylinders (grams)

U235 removed from all cylinders (grams)

30830.09

23748.64 


\section{Appendix R}

5) Compact printed table of the uranium removed from all cylinders over a specified period

Sampling period beginning date and time
Sampling pericd ending date and time

\begin{tabular}{|c|c|c|c|}
\hline Gy?. Ref. & Date & Date & Elapsed \\
\hline No. & Conn. & Disc. & $\begin{array}{l}\text { Time } \\
\text { (hours) }\end{array}$ \\
\hline 05 & $20 / 01 / 98$ & $24 / 01 / 98$ & 94 \\
\hline 06 & $20,101.98$ & $24 / 01,98$ & 95 \\
\hline 12 & $2: 101: 98$ & $25 / 02 / 98$ & 90 \\
\hline 10 & $22: 01 / 98$ & $25: 01: 98$ & 69 \\
\hline
\end{tabular}

Total mazerial rercved:

30830 U (grams)

\begin{tabular}{|c|c|c|c|c|}
\hline \multicolumn{2}{|c|}{$\begin{array}{l}27 / 12 / 97 \\
26 / 01 / 98\end{array}$} & $00: 01: 00$ & \multirow[b]{2}{*}{$U$} & \multirow[b]{2}{*}{ JU235 } \\
\hline Mat. & $\mathrm{U}$ & $\llbracket 235$ & & \\
\hline Removed & & & & \\
\hline (grams) & (wt: & (wt: $)$ & (grams) & (grams) \\
\hline 5770 & 67.33 & 92.86 & 4558 & 4233 \\
\hline 16720 & 67.47 & 45.92 & 11281 & 5180 \\
\hline$=5960$ & 67.30 & 96.61 & 10741 & 10377 \\
\hline 6310 & 67.35 & 93.15 & 4250 & 3959 \\
\hline
\end{tabular}




\section{Appendix R}

6) Report of actual residence time of a cylinder compared with its declared residence time for normal refeed operations

\begin{tabular}{|c|c|}
\hline Cylinder number & st0298 \\
\hline Date and time cylinder connected & $15: 09: 00$ \\
\hline Mailbox input date and time & $15: 21: 14$ \\
\hline Connect declaration time difference (hours) & 0.20 \\
\hline Date and time cylinder disconnected & $09: 15: 00$ \\
\hline Mailbox input date and time & $11: 28: 59$ \\
\hline Disconnect declaration time difference (hours) & 2.22 \\
\hline Connected cylinder adjusted gross weight (grams) & 42280.00 \\
\hline Connected cylinder adjusted tare weight (grams) & 25943.00 \\
\hline Connected cylinder adjusted net weight (grams) & 16337.00 \\
\hline Declared residence time (hours) & 66.00 \\
\hline Actual residence time (hours) & 90.10 \\
\hline Residence time difference (hours) & 24.10 \\
\hline
\end{tabular}


(THIS PAGE INTENTIONALLY LEFT BLANK)

R-8 